\title{
Phenotypic and genotypic characterization of lumbosacral stenosis in Labrador retrievers
}

\author{
Meenakshi Mukherjee
}

Follow this and additional works at: https://researchrepository.wvu.edu/etd

\section{Recommended Citation}

Mukherjee, Meenakshi, "Phenotypic and genotypic characterization of lumbosacral stenosis in Labrador retrievers" (2016). Graduate Theses, Dissertations, and Problem Reports. 6277.

https://researchrepository.wvu.edu/etd/6277

This Dissertation is protected by copyright and/or related rights. It has been brought to you by the The Research Repository @ WVU with permission from the rights-holder(s). You are free to use this Dissertation in any way that is permitted by the copyright and related rights legislation that applies to your use. For other uses you must obtain permission from the rights-holder(s) directly, unless additional rights are indicated by a Creative Commons license in the record and/ or on the work itself. This Dissertation has been accepted for inclusion in WVU Graduate Theses, Dissertations, and Problem Reports collection by an authorized administrator of The Research Repository @ WVU.

For more information, please contact researchrepository@mail.wvu.edu. 


\title{
PHENOTYPIC AND GENOTYPIC CHARACTERIZATION OF LUMBOSACRAL STENOSIS IN LABRADOR RETRIEVERS
}

\author{
Meenakshi Mukherjee \\ Dissertation submitted to \\ Davis College of Agriculture, Natural Resources and Design \\ West Virginia University
}

In partial fulfillment of the requirements for the degree of

Doctor of Philosophy in

Genetics and Developmental Biology

Jianbo Yao, PhD (Co-chair)

Jeryl Jones, DVM, PhD (Co-chair)

Amy Welsh, PhD

Raymond Raylman, PhD

Barbara Jean Meade, DVM, MD, PhD

Division of Plant and Soil Sciences,

\author{
Morgantown, West Virginia
}

2016

Keywords: lumbar spinal stenosis, computed tomography, genetics, genes, canine, working dogs, whole exome sequencing

Copyright 2016 Meenakshi Mukherjee 


\section{ABSTRACT \\ Phenotypic and genotypic characterization of lumbosacral stenosis in Labrador retrievers}

\section{Meenakshi Mukherjee}

Lumbosacral stenosis (LS) is a structural narrowing of the spinal canal in the canine lumbosacral spine. Large-sized working and sporting dog breeds such as Labrador retrievers are predisposed for reasons that are incompletely understood. The narrowing of spinal canal observed in LS can cause compression of underlying meningeal, neural and vascular tissues, which in turn can lead to clinical symptoms like lower back pain, incontinence and in severe cases loss of function in the lower limbs. The standard criteria for clinical diagnosis of this condition include a painful reaction to palpation of lumbosacral spine region, inability or unwillingness to raise the tail and/or reluctance to perform certain tasks that involve either the stretching of or stress on the lumbosacral joint. However, working and sporting breed dogs are bred to be highly stoic, cooperative, driven, and task focused. These behavioral traits make clinical detection of LS difficult in the early stages. Dogs with LS may continue to work, develop compensatory gaits, and experience repeated LS injury. By the time a diagnosis of LS is confirmed, oftentimes it is too late for successful therapeutic intervention and the only course of action left for improving the dog's quality of life is either retirement from active duty, or in severe cases euthanasia. Therefore early diagnosis is essential for maximizing the quality of life, and minimizing the likelihood of early retirement in working dogs. Lumbosacral stenosis is usually considered to be a condition associated with degenerative changes observed with normal aging, however presence of the disease in young and middle aged working dogs has also been reported. This leads to the probable theory that some dogs in large breeds like Labrador retrievers might be genetically pre-disposed to LS. 
Radiographic screening is common practice for agencies that purchase, train, and use working dogs. Dogs with morphologic traits such as canine hip dysplasia, canine elbow dysplasia, and transitional lumbosacral vertebrae are commonly rejected. However radiographs are insensitive for detecting LS. Advanced imaging methods such as computed tomography (CT) and magnetic resonance imaging (MRI) and the current standard diagnostic tests for detection of LS. These modalities are considered to be complimentary, with each offering different strengths for visualization of bony and soft tissue structures. For working dogs, computed tomography offers advantages of greater availability and the faster scanning times that allow the use of reversible sedation. Qualitative CT phenotyping is a standard method for clinical diagnosis of LS in dogs. However, for research purposes, a method for quantitative phenotyping of LS would also be beneficial. There is a lack of published evidence for a consensus on any such quantitative CT phenotypic traits in humans or dogs. In the first study, we developed one such quantitative trait using CT imaging in a sample of 25 Labrador retrievers - fat area ratio or FAR (ratio of the vertebral canal fat area content in a transverse slice to the vertebral body area in the same transverse slice). This measurement was found to have good agreement with the standard qualitative assessment of LS (as made by a certified veterinary radiologist); and we propose that FAR can be used to quantify LS especially in a research capacity.

Lumbar spinal stenosis (LSS) is a human condition that is often considered to be orthologous to canine LS. Genetic studies in humans have shown promise in identification of possible genetic factors that might be associated with LSS. The predominant genetic approach for research in canine LS has been pedigree analysis especially in the German shepherds; but no genetic association studies have been reported in any breed. The second study of the project was an attempt at the investigation into the genetic characteristics of LS in Labrador retrievers. To do so we analyzed the exome of 8 young Labrador retrievers -4 positive for LS and 4 negative for LS, from a pool of 40 Labrador retrievers in the US military working dog (MWD) program. The FAR measurement (from previous retrospective study in 25 dogs) was 
used for quantitative phenotyping of the 40 dogs (as well as qualitative CT phenotyping); followed by the selection of 8 dogs best representing the extremes of the phenotype - LS affected and LS unaffected. We were able to identify 3 genes - TTR (Transthyretin), FOLR2 (Folate Receptor 2) and USP9X (Ubiquitin Specific Peptidase 9, X-linked) - that could possibly be associated with canine LS. However, follow-up analysis is necessary to determine the true nature of the relationship between these genes and LS in Labrador retrievers. These 3 genes could potentially be new "candidate genes" for canine LS - not just in Labrador retrievers but also in other affected breeds. Further studies are also needed to investigate the role of these candidate genes in human LSS. The inability of LS in getting detected by simple radiographs is a major disadvantage for the agencies that procure, train and employ working dogs like the military and transportation safety authority. This necessitates the identification of genetic marker/s of LS that could then possibly be developed into simple diagnostic tests. And if certain breeds are indeed genetically predisposed, these diagnostic tests could perhaps even become standard screening protocol during the acquisition of these dogs. Labrador retrievers are loyal, kind, and intelligent breed of dogs; with greatly versatile applications beneficial to humans. Even though other breeds are used as working dogs around the world, Labrador retrievers cannot be easily replaced and the demand for this breed has been steadily increasing over the past decade. A possible genetic test that can identify genetic predisposition to LS in young Labrador retrievers that might become working dogs can significantly improve the procurement process. And if reasons behind early occurrence of LS were premature degenerative changes instead, early detection would mean preventative conditioning training protocols and better therapeutic treatments. However, it is important to note that LS is not restricted to working dogs (young and old) alone, the disease also appears in non-working dogs (more commonly in older dogs). But, early detection of LS would improve the quality of life of Labrador retrievers - both working and non-working that might be affected by LS. It would also be beneficial for the agencies that employ and have financial stakes in these dogs. 


\section{DEDICATION}

This document marks the completion of a nearly four-and-a-half-year long project towards a doctoral degree in genetics. None of this would have been possible without the love and support from the two most important people in my life - my parents. I would like to thank them both from the bottom of my heart for all the sacrifices that they have made over the years, making it possible for me to be where I am today. I share the honor of this degree with both of them. I owe who I am today - as a person and as an academic - to the values that they instilled in me. I would also like to acknowledge all the friends I have made throughout my life - you all have shown me love, loyalty and support. I am a better individual today for having known all of you and I am extremely grateful that you all chose me to be your friend. And last but not the least (even though she will be unable to read this), I would like to thank my best friend and loving loyal companion Maggie, for always being present with unconditional love and support. 


\section{ACKNOWLEDGEMENT}

I would first like to thank all my committee members for their guidance throughout this project - both with experimental design and implementation of the study. I would like to thank staff members at the Veterinary Teaching Hospital in the Virginia-Maryland College of Veterinary Medicine, Ryan Hospital in the University of Pennsylvania, and the Holland Military Dog Hospital in the Lackland Air Force Base for assistance in acquiring data for the dogs used in the study. I would also like to acknowledge the WVU Genomics Core Facility at West Virginia University for help with genetic and bioinformatic analyses. I am also grateful to Dr. Holásková for her help with the statistical analyses in the project. I also extend my gratitude to the staff members at the Animal and Nutritional Sciences Department of West Virginia University for their help with all the administrative work. I am also grateful to Clemson University, Dr. Leigh Ann Clark and the members of the canine genetics laboratory for technical guidance. I would like to thank Dr. Jeryl Jones for believing in my abilities right at the onset and giving me this opportunity to pursue my doctoral degree, but also guiding and helping me throughout this entire journey. And last but not the least I would like to thank Dr. Jianbo Yao for taking me in as a graduate student for the last year and allowing me to finish my work in West Virginia University, and agreeing to be my co-major advisor. This project was funded by the following agencies: West Virginia Agricultural and Forestry Experiment Station USDA Hatch Act Formula Grant, Davis Michael Endowment for PreVeterinary Sciences; and the US Army Research Office. 


\section{TABLE OF CONTENTS}

\begin{tabular}{|l|r|}
\hline Abstract & $\mathrm{ii}$ \\
\hline Dedication & $\mathrm{v}$ \\
\hline Acknowledgments & $\mathrm{vi}$ \\
\hline Table of Contents & $\mathrm{vii}$ \\
\hline List of Figures & $\mathrm{viii}$ \\
\hline List of Tables & $\mathrm{ix}$ \\
\hline List of Appendices & $\mathrm{x}$ \\
\hline List of Symbols, Abbreviations and Nomenclature & $\mathrm{xi}$ \\
\hline Chapter I. Introduction & 1 \\
\hline Chapter II. Review of literature & 5 \\
\hline $\begin{array}{l}\text { Chapter III. Phenotypic characterization of lumbosacral stenosis in Labrador } \\
\text { retrievers }\end{array}$ & 26 \\
\hline $\begin{array}{l}\text { Chapter IV. Genetic characterization of lumbosacral stenosis in Labrador } \\
\text { retrievers }\end{array}$ & 49 \\
\hline Chapter V. Overall Summary and Conclusions & 94 \\
\hline Chapter VI. Recommendations & 98 \\
\hline Bibliography & 101 \\
\hline Appendices & 123 \\
\hline Curriculum Vitae & 142 \\
\hline
\end{tabular}




\section{LIST OF FIGURES}

\begin{tabular}{|c|c|}
\hline $\begin{array}{l}\text { Figure III.1. Positioning of a dog for acquiring CT scan of the lumbosacral } \\
\text { spine. }\end{array}$ & 37 \\
\hline $\begin{array}{l}\text { Figure III.2. Lateral CT image depicting the six measured locations of the } \\
\text { canine lumbosacral spine }\end{array}$ & 38 \\
\hline $\begin{array}{l}\text { Figure III.3. Representative screenshots illustrating the methodology for the } \\
\text { quantitative measurements }\end{array}$ & 39 \\
\hline $\begin{array}{l}\text { Figure III.4. Mean canal area ratio comparisons between LS-positive and LS- } \\
\text { negative dogs }\end{array}$ & 40 \\
\hline $\begin{array}{l}\text { Figure III.5. Mean fat area ratio comparisons between LS-positive and LS- } \\
\text { negative dogs }\end{array}$ & 41 \\
\hline $\begin{array}{l}\text { Figure III.6. Logistic regression between quantitative measurements and } \\
\text { qualitative assessment of lumbosacral stenosis }\end{array}$ & 42 \\
\hline $\begin{array}{l}\text { Figure III.7. Predicted probabilities for being LS-positive at each of the six } \\
\text { vertebral locations. }\end{array}$ & 44 \\
\hline $\begin{array}{l}\text { Figure IV.1. Consequences of } 229 \text { variants analyzed by Ensembl Variant Effect } \\
\text { Predictor }\end{array}$ & 72 \\
\hline $\begin{array}{l}\text { Figure IV.2. Percentage breakdown of variants with coding regions based on } \\
\text { type of mutation }\end{array}$ & 73 \\
\hline Figure A.1. Mean canal area ratios (CARs) in study 1 & 121 \\
\hline Figure A.2. Mean canal area ratios (CARs) in study 2 & 122 \\
\hline Figure A.3. Mean fat area ratios (FARs) in study 1 & 123 \\
\hline Figure A.4. Mean fat area ratios (FARs) in study 2 & 124 \\
\hline Figure A.5. Mean canal areas (CAs) in study 1 & 125 \\
\hline Figure A.6. Mean canal areas (CAs) in study 2 & 126 \\
\hline Figure A.7. Mean fat areas (FAs) in study 1 & 127 \\
\hline Figure A.8. Mean fat areas (FAs) in study 2. & 128 \\
\hline Figure A.9. Logistic regression of FAR v qualitative $\mathrm{LS}$ at $\mathrm{L} 6 \mathrm{Cr}$ & 130 \\
\hline Figure A.10. Logistic regression of age $v$ qualitative $\mathrm{LS}$ at $\mathrm{L} 6 \mathrm{Cr}$ & 131 \\
\hline
\end{tabular}




\section{LIST OF TABLES}

\begin{tabular}{|l|r|}
\hline Table II.1. Major causes of lumbar spinal stenosis in humans & 25 \\
\hline Table III.1. Clinical data demography of the study samples & 46 \\
\hline $\begin{array}{l}\text { Table III.2. T-test p-values for canal area ratio and fat area ratio comparisons } \\
\text { between LS-positive and LS-negative dogs }\end{array}$ & 47 \\
\hline $\begin{array}{l}\text { Table III.3. Logistic regression p-values - quantitative measurements (CAR and } \\
\text { FAR) and qualitative CT assessment of stenosis }\end{array}$ & 48 \\
\hline Table IV.1. Clinical data demography of the study samples & 74 \\
\hline $\begin{array}{l}\text { Table IV.2.A. Maximum and minimum fat area ratio values for } 8 \text { vertebral } \\
\text { locations among the } 8 \text { dogs selected to represent the extremes of the } \\
\text { phenotype }-1^{\text {st }} \text { round of selection (samples lost) }\end{array}$ & 75 \\
\hline $\begin{array}{l}\text { Table IV.2.B. Maximum and minimum fat area ratio values for } 8 \text { vertebral } \\
\text { locations among the } 8 \text { dogs selected to represent extremes of the phenotype - } \\
2^{\text {nd }} \text { round of selection (whole exome sequenced samples) }\end{array}$ & 76 \\
\hline Table IV.3. Demographic data of the 8 dogs selected for exome sequencing & 77 \\
\hline $\begin{array}{l}\text { Table IV.4. List of single nucleotide variants present within the canine exome } \\
\text { and the genes that the exons correspond to as detected by manual curating }\end{array}$ & 78 \\
\hline $\begin{array}{l}\text { Table IV.5. List of canine genes with exonic single nucleotide variants and their } \\
\text { percentage homology with human and mouse orthologues }\end{array}$ & 81 \\
\hline $\begin{array}{l}\text { Table IV.6. Variants with moderate impact as detected by Ensembl's Variant } \\
\text { Effect Predictor (VEP) }\end{array}$ & 83 \\
\hline $\begin{array}{l}\text { Table IV.7. Biological significance and function of the } 33 \text { genes with detected } \\
\text { exonic variants }\end{array}$ & 84 \\
\hline $\begin{array}{l}\text { Table IV.8. Human LSS candidate genes and their location in the canine } \\
\text { genome }\end{array}$ & 93 \\
\hline
\end{tabular}




\section{LIST OF APPENDICES}

\begin{tabular}{|l|l|}
\hline Appendix I: Protocol used for DNA extraction from FTA cards & 123 \\
\hline $\begin{array}{l}\text { Appendix II: Description of an unexpected qualitative phenotypic trait observed } \\
\text { in this sample of Labrador retrievers, i.e. "a reverse trapezoid vertebral canal". }\end{array}$ & 126 \\
\hline $\begin{array}{l}\text { Appendix III: Logistic regression analysis of the association between FAR and } \\
\text { qualitative LS status in the } 40 \text { dogs recruited for the second study (chapter IV) }\end{array}$ & 136 \\
\hline $\begin{array}{l}\text { Appendix IV: Proposed explanations for clinical low back pain observed in } \\
\text { dogs from both studies. }\end{array}$ & 139 \\
\hline $\begin{array}{l}\text { Appendix V: Analysis of covariance and multivariate logistic regression tests } \\
\text { for effects of covariates on comparisons between FAR and LS status in dogs } \\
\text { from both studies. }\end{array}$ & 141 \\
\hline
\end{tabular}




\section{LIST OF SYMBOLS, ABBREVIATIONS AND NOMENCLATURE}

LSS - Lumbar Spinal Stenosis

LS - Lumbosacral Stenosis

CT - Computed Tomography

MRI - Magnetic Resonance Imaging

$\mathrm{Cr}$ - Cranial end of vertebrae

$\mathrm{Cd}$ - Caudal end of vertebrae

L4 $-4^{\text {th }}$ lumbar vertebrae

L5 $-5^{\text {th }}$ lumbar vertebrae

L6 $-6^{\text {th }}$ lumbar vertebrae

$\mathrm{L} 7-7^{\text {th }}$ lumbar vertebrae

$\mathrm{S} 1-1^{\text {st }}$ sacral vertebrae

LBP - Low Back Pain

CAR - Canal area ratio (transverse vertebral canal area / transverse vertebral body area)

FAR - Fat area ratio (transverse vertebral fat content area / transverse vertebral body area)

DNA - Deoxyribonucleic acid

SSA - Systemic Senile Amyloidosis

JJ - Jeryl C. Jones

MM - Meenakshi Mukherjee

IH - Ida Holásková 


\section{CHAPTER I. INTRODUCTION}

Working dogs are high-performance athletes and vital members of teams that support public service, national security and military missions in the U.S. and around the world

1 . The job titles of working dogs are varied and include, but are not limited to: guide dogs (for the disabled like the blind and the deaf); service dogs (for individuals with medical conditions that range from epilepsy to diabetes); assistance and therapy dogs (for individuals with physical disabilities and post-traumatic stress disorder as seen in war veterans); detection dogs (explosives, arson accelerants, illegal drugs, agricultural pathogens, pirated DVDs and other contraband, for the Transportation Security Administration, the police, and the military); and search and rescue dogs (natural or man-made disasters). The list of ways in which dogs are trained to perform currently (and could potentially be trained to in the future) are both varied and numerous. German shepherds, Labrador retrievers, and Belgian Malinois are the most commonly used breeds ${ }^{2}$ and; since $9 / 11$, the demand for working dogs has only increased dramatically 3

One such in-demand population of working dogs is the military working dog (MWD). Military forces worldwide recognize MWDs as "force multipliers". An American Forces Press Service release (October, 2015) estimated the US military to have around 2,300 MWDs (http://usmilitary.about.com/od/jointservices/a/militarydogs.htm). The dogs represent all branches of the military, and together with their handlers they are deployed worldwide to serve American interests. According to a 2011 US Government Pentagon memo, typical purchasing and training costs for a high quality military working dog can range anywhere from $\$ 20,000$ to $\$ 40,000$ (depending on the nature of their assignments, and whether or not the dog is trained for multiple types of tasks) (http://www.nytimes.com/2011/05/12/world/middleeast/12dog.html?_r\&_r=0). Once they are trained, the service lifetime of a typical MWD is expected to average about 10-12 years (http://todaysmilitary.com/videos/a-military-working-dog-handler). However this time is often cut short significantly by degenerative spinal disease, overuse injuries, and 
trauma ${ }^{2}$. Premature loss of active duty capability in a trained MWD causes not only a major financial loss to the US Military, but also a functional loss for the productivity of the team that depends on the particular dog. Team readiness remains reduced until they can purchase and train a new dog. As the worldwide competition for high quality dogs increases; so does the cost of breeding, raising and subsequent training of the dogs, as a result of which, the availability of new dogs also decreases. Therefore, ideally teams need to have dogs that can maintain functionality for as long as possible.

Lumbosacral stenosis (LS) is the most common pathological condition affecting the canine lumbosacral spine ${ }^{4} 5{ }^{5}$. Lumbosacral stenosis is defined as an abnormal narrowing of the lumbosacral canal, vertebral canal, and/or the intervertebral foramina between the L5-S3 vertebral segments leads to the compression of the underlying neural and vascular tissues ${ }^{78}$. This structural "narrowing" can lead to clinical conditions like cauda equina syndrome (CES). Degenerative LS is the most commonly reported etiology that is believed to be associated with aging; similar to the orthologous human condition known as lumbar spinal stenosis (LSS). However, some studies suggest LS might have a genetic predisposition that can manifest itself at an early age 91011 . This predisposition has been predominantly accounted for by the congenital anomaly of lumbosacral transitional vertebra (LTV) - an abnormally formed vertebra usually between the last lumbar and first sacral vertebra ${ }^{12}{ }^{13}$. The presence of LTV often leads to abnormally narrow spinal canal (lumbosacral stenosis); which in turn can lead to clinical conditions like CES. Congenital version of LS is rare, but the causes can be either developmental (achondroplasia related) or idiopathic (reasons unknown).

The larger sized breeds like German shepherds, Labrador retrievers and Golden retrievers that are the popular choice for working dogs also happen to have a higher than normal incidence of LS. Scientific research of canine LS has leaned heavily on the German shepherds breed, both due to high number of reported cases as well as their popularity as working dogs. However in recent years the popularity of the Labrador retrievers breed has been increasing steadily in the working dog community especially 
due to their excellent scent detection skills, high drive, eager-to-please attitude and ease of trainability ${ }^{14} 3$. Labrador retrievers are also the most popular household pet breed in the United States, and have been so for the past twenty-five years in a row ${ }^{15}$. Unfortunately the very characteristics that make this breed such great working dogs; also make it difficult to detect LS. Working Labrador retrievers are excellent at masking their pain and discomfort to continue pleasing their people/handlers/owners. The degenerative/progressive nature of the disease can be extremely harmful if detection/management is delayed. Currently CT/MRI imaging methods are the only way of detecting the structural abnormality of stenosis or "narrowing". However, unless a dog presents with some clinical signs of pain or discomfort, expensive imaging studies are not performed in "suspicion" of an underlying condition like lumbosacral stenosis; and the condition can go undetected longer often exacerbating the condition. Therapeutic interventions are more effective in young dogs with mild stage clinical conditions, with relatively successful return to active life, thus the need for early detection ${ }^{16}$. The procurement, training and ultimately the deployment of the working dogs to their theater of duty is an extensive process that involves significant investment of time, money and other valuable resources. An improved understanding of the genetic mechanisms underlying LS would be highly beneficial - not only for better therapeutics but also for better diagnostics.

Findings from canine LS studies in Labrador retrievers could also be applicable to other dog breeds (and possibly humans too due to the pathophysiological similarity between canine LS and human LSS). Lumbar spinal stenosis is defined as "any type of narrowing of the spinal canal, nerve root canals or intervertebral foramina" that leads to neurogenic claudication ${ }^{17}$. Degenerative LSS is the most commonly reported type of human LSS affecting individuals older than $65{ }^{18}{ }^{19}$. However aging is not the sole contributing factor for this structural abnormality, even though rare LSS has also been observed in younger individuals. The most common type of congenital LSS is usually associated with dwarfism related genetic disorders (supporting the theory that LSS is a genetic disorder, albeit a complex one). Some studies have tried to identify and 
understand the underlying genetic mechanism of LSS. They have been able to identify some genetic polymorphisms that appear to be associated with the presentation of LSS 2021 . In the United States alone, there is an estimated 400,000 individuals affected with LSS ${ }^{22}$. Decompressive surgery to correct LSS has become the most common spinal surgical procedure in recent times ${ }^{23}$. Similar to the canine version, LSS is not life threatening but it does significantly diminish the quality of life due to substantial disability, limiting the ability to perform routine daily life activities. Currently there is no cure for LSS in humans or LS in dogs, only ways of managing the symptoms to improve the quality of life 242522 . The genetic similarities between the two species - human and canine, could allow findings in one to benefit the other. 


\section{CHAPTER II. LITERATURE REVIEW}

\section{Lumbar Spinal Stenosis}

\section{Anatomy of the normal lumbar spine}

The spinal canal is delineated by the vertebrae, discs and the posterior longitudinal ligament anteriorly; pedicles, the ligamentum flavum and the neuro-foraminae laterally; and laminae, facet joints and the ligamentum flavum posteriorly. The normal shape of the human lumbar spinal canal can be circular, elliptical/oval or trefoil (rounded triangle) 2627 . There is a gradual change from a more circular to a more triangular shape (narrowing trend) as the spine transitions from thoracic to sacral region. The trefoil shape of the spinal canal usually appears in the fifth lumbar vertebrae. The anteroposterior (AP) diameter of the lumbar spinal canal usually decreases from L1 to L3 and increases from L3 to L5, so it is at its narrowest at the third lumbar vertebrae 282930 . There is a small increase in the transverse diameter from L1 to L3, after which (L3 to L5) there is a simultaneous increase corresponding to the increase in AP diameter. Cross-sectional areas decrease from $L 1$ to $L 2$, remains somewhat constant in $L 2$ to $L 4$, followed by an increase at L5. The consistent increase in the cross-sectional area of the lower spine from all angles seems to be present to accommodate the neural tissue of the cauda equina. Cauda equina, which literally translates to "horse's tail", is the bundle of all the spinal nerves and nerve roots that originate throughout the spine $\left(2^{\text {nd }}\right.$ to $5^{\text {th }}$ lumbar, $1^{\text {st }}$ to $5^{\text {th }}$ sacral and the single coccygeal) but emerge only from the conus medullaris (termination point of the spinal cord).

\section{Etiology and pathogenesis}

The amount of space available to the nervous tissue inside the spinal canal is decided by a combination of two factors: morphogenesis and development of the spine during gestation and the early developmental years; and the degenerative changes that occur to the spine over the course of time. The lumbar vertebrae begin to form after the seventh week of gestation when two chondrification centers, one in each vertebral arch, 
begin to develop ${ }^{31}$. These arches then start to ossify and meet at the centrum - the union being the first defining event to decide the dimensions of the neural canal (even though the canal does not finish forming until several years after birth) ${ }^{32}$. Any kind of error during this stage can result in a narrowed spinal canal, which can remain clinically asymptomatic until other confounding factors give rise to a clinical condition. The stenotic canal usually presents with a narrower inter-pediculate diameter ${ }^{33}$. Both the pedicles and lamina appear to be shorter and thicker ${ }^{34}$. The facets also become enlarged and bulbous, nearly coming in contact with the spinous processes. This abnormal narrowing of the spinal canal, nerve root canals and/or intervertebral foramen leading to compression of the inner neural tissue is defined as spinal stenosis ${ }^{17}$.

Arnoldi classified lumbar spinal stenosis into three types based on anatomy - central canal stenosis (bordered by vertebral bodies, discs, and articular processes); lateral recess stenosis (sub-articular canal extending from the thecal sac to the pedicle); and foraminal stenosis (intervertebral foramen or nerve root canal present under the pedicle) 17. The causes that result in the different forms of stenosis are as follows: 1) central canal stenosis from hypertrophy of the interlaminar portion of the ligamentum flavum, or disc protrusion/herniation; 2) lateral recess stenosis from degeneration of the ligaments and/or facets, disc herniations, posterolateral disc protrusion, or superior articular process hypertrophy; and; 3) foraminal stenosis from bone "spur" formations (osteophytes), facet joint hypertrophy (osteoarthrosis), or tissue hypertrophy due to spondylolisthesis.

Arnoldi (1976) classified lumbar stenosis into three types based on etiology congenital, acquired, or a combination of both. First reported in children by Sarpyener (1945) ${ }^{35}$, the congenital form can be further divided into two categories - idiopathic and achondroplastic. The idiopathic form is extremely rare and only a few cases have been reported to date. The achondroplastic form is slightly more common and is associated with dwarfism related disorders ${ }^{36}$. However, recent studies have reported congenital cervical canal stenosis ${ }^{37}$ and lumbar spinal stenosis ${ }^{38}$ in adults younger than 51 , with 
cervical form being more common in younger individuals than the lumbar form ${ }^{39}$. Verbiest (1954) was the first to observe acquired stenosis in adults. This form of stenosis has proved to be the most prevalent type and is usually known to present itself in individuals older than $65^{18}$. This delayed appearance of stenosis is believed to be due to the association of spinal stenosis with aging. It may often take up to the fifth decade of life for the degenerative effects of aging to accumulate and manifest itself with initial clinical signs. Commonly observed degenerative changes associated with LSS are disc degeneration, facet joint osteoarthritis, ligament hypertrophy, spondylosis, spondylolisthesis, and/or osteophytes ${ }^{40}$. Acquired stenosis can also be a result of surgical ${ }^{41}$ or traumatic conditions ${ }^{42}$, like - diffuse idiopathic skeletal hyperostosis ${ }^{43}$, Paget's disease ${ }^{44}$, ankylosing spondylitis ${ }^{45}{ }^{46}$, or rheumatoid arthritis ${ }^{47}$. Metabolic diseases like acromegaly ${ }^{48} 49$, hypoparathyroidism ${ }^{50}$, pseudohypoparathyroidism ${ }^{51}$, or X-linked hypophosphatemic osteomalacia ${ }^{52}$ can also cause lumbar spinal stenosis. Ciricillo and Weinstein (1993) have listed the known causes of spinal stenosis in their review paper (Table II.1) ${ }^{53}$.

\section{Clinical presentation}

The first ever mention of lumbar spinal stenosis related symptoms was in Greek mythology - the God Hephaestus was achondroplastic, and after a trauma to the narrow spinal canal developed a limp, which in turn led him to being mocked by the Olympians ${ }^{54}$. Mythological references aside, the French physician Antoine Portal was the first to correlate low back pain (LBP) with narrowing of the spinal canal ${ }^{55}$. However until the 1950's, the primary cause for LBP was believed to be solely disc-related ${ }^{56}$ and spinal stenosis as a cause for LBP went mostly uninvestigated. Dutch neurosurgeon Hank Verbiest was the first to coin the term "spinal stenosis" in his landmark 1954 publication ${ }^{57}$. Even though LBP is the symptom most commonly associated with spinal stenosis, it is not the defining symptom for diagnosis of the disorder - clinical symptoms can be highly variable. The current standard clinical symptom for a confirmed diagnosis of LSS is neurogenic claudication - described as the presence of weakness, tiredness, burning pain, cramps, and/or discomfort in the legs on walking short distances that 
usually go away on resting $\begin{array}{llll}58 & 59 & 17 & 60\end{array}$. However, there exists a lack of consensus regarding the true constitution of the clinical symptoms that arise due to LSS, making diagnosis difficult ${ }^{61}$. However, there exists a lack of consensus regarding the true constitution of the clinical symptoms that arise due to LSS, making diagnosis difficult ${ }^{61}$.

The physiological explanation of the symptom of intermittent neurogenic claudication is made up of the combination of two theories - neurogenic compression theory and vascular compression theory ${ }^{626063}$. The neurological dysfunction can be explained by the neurogenic compression theory. As seen in animal models, if there is mechanical stimulation after prolonged compression of neural tissue, an abnormal electrical discharge happens that presents itself as pain. Compression of neural tissue actually means decreased supply of cerebrospinal fluid and other nutritional substances to the nervous tissue, which in turn causes edema, build-up of noxious substances and fibrosis due to microvascular changes. The intermittent aspect of the functional dysfunction can be explained by vascular compression theory. According to this theory, the increased pressure inside the spinal canal is not only on the neural tissue but also on the blood vessels that supply the neural tissue. When active or in motion, the compressed blood supply is not sufficient for proper functioning of the neural tissue, causing pain. When in rest, the canal widens, blood supply becomes sufficient enough and the pain goes away. But both the theories cannot explain how some patients with severe stenosis can still remain asymptomatic. Other symptoms include mechanical low-back pain that worsens during activity, atypical non-radicular leg pain, pain in the buttocks and on rare cases cauda equina syndrome ${ }^{56} 64$. Cauda equina syndrome may include associated symptoms of urinary and bowel incontinence.

With regards to the localization of symptoms, the pain is bilateral and poorly localized in central canal stenosis, while in lateral canal stenosis the pain is more localized to one or few nerve roots ${ }^{53}$. Multi-level neural tissue compression has also been associated with neurogenic claudication in cauda equina syndrome ${ }^{656260}$. However, it should be noted that the number of vertebral levels affected by stenosis has shown no direct correlation 
with the severity of clinical symptoms displayed. Some studies suggest that males are affected by LSS more than females ${ }^{66} 6753$; however contradictory reports have also been published where any one sex has not proved to be more affected by LSS than the other ${ }^{19}$.

\section{Clinical diagnosis and diagnostic imaging}

Congenital forms of stenosis, though rare, are easily diagnosable by radiographs ${ }^{68}$. The acquired form of stenosis is slightly more deceptive. Even though a chronic condition, the symptoms of LSS can often develop insidiously with sudden onset. Clinical examination can also be misleading, but once detected, like similar spinal disorders, a thorough neurological examination is mandatory protocol ${ }^{69}$. The non-specific symptoms include limited lumbar extension, sensory deficit, muscle weakness, straight-leg raising, and missing knee and ankle reflexes. The intermittent as well as the sometimesasymptomatic nature of the symptoms like neurogenic claudication can often lead to delayed diagnosis. Thus, the only way to confirm a positive diagnosis of LSS is through diagnostic imaging studies ${ }^{70} 71$. Each confirmed case of LSS by imaging can be further graded as mild, moderate or severe; but this grading is subjective and can be another cause of misdiagnosis.

The two most common diagnostic tests for LSS in human and LS in dogs are computed tomography (CT) and magnetic resonance imaging (MRI). These methods are often considered to be complementary to each other. The most striking difference between the CT and MRI is that denser tissue appears brighter and whiter in CT, while denser tissues appear darker and blacker in MRI. Computed tomography works on the principle of electromagnetic energy attenuation - x-ray photons penetrate the body and based on the density of the target tissue, some of the energy gets absorbed and the rest exits the body slightly attenuated. The residual energy that escapes the body gets registered on a photon detector which when developed, reflects the difference in tissue densities depicted in shades of grey. MRI is also an emission-based technology that takes advantage of the water content in living tissues. Protons present in water molecules 
emit radiofrequency signals in the presence of opposing magnetic fields and start resonating. This resonance is detected and recorded in the form of grey-scale images.

Computed tomography uses a hollow x-ray tube that rotates around a stationary patient table, emitting $\mathrm{x}$-rays that pass through and get captured as a series of $\mathrm{X}$-ray projections on detector films, producing cross-sectional anatomical images that distinguish between tissues based on density differences ${ }^{72}$. Computed tomography can capture images from multiple panes, and give a detailed and precise three-dimensional visual for the bone and soft tissue structures inside the body (after multiplanar reconstruction) ${ }^{74} 75$. The ability of CT lies to capture images in the trans-axial plane makes it the preferred imaging method for the detection of LSS ${ }^{76}$. Computed tomography also allows evaluation of the shape of the canal, and making accurate measurements of the bony spinal canal dimensions directly from the images. Computed tomography has good contrast resolution (differentiating between bony and soft tissue) and can directly view the effects of disk pathology, facet hypertrophy, and thickened ligamentum flavum on the cross-sectional area of the canal ${ }^{77}$. However, the soft tissue resolution of CT is not as great as that of MRI - making it difficult to detect nerve root compression and other soft tissue pathologies. It is possible to overcome this disadvantage of poor soft tissue resolution by detecting changes in adjoining tissues (dural sac and epidural fat) for diagnosis of LSS ${ }^{78}$. Therefore, CT is the considered to be an optimum imaging technique for the overall diagnosis of LSS -balanced detection capability of changes in both bony and soft tissue. Spinal canal area measurements made by CT often do not agree with measurements made by MRI often in the same samples, theorized to be due to the superior delineation of the ligamentum flavum by $\mathrm{CT}^{79}$. Computed tomography is also better at visualizing zygapophyseal joints ${ }^{80}$ and differentiating between hard versus soft disc pathology ${ }^{81}$.

\section{Qualitative and quantitative computed tomography characteristics}

The application of CT to spinal imaging began in the 1970s and has since then provided great insights into the various factors that can lead to LSS (narrowing of the spinal canal 
and compression of the emerging nerve root) 82838471 . McAfee and Ullich (1982) described the normal anatomy of the lumbar spine, using the $5^{\text {th }}$ lumbar vertebra as an example, as observed in 3 successive trans-axial CT images (increments of $1.5 \mathrm{~mm}$ ): First slice: nerve roots lie in an unresolved bunch within the lateral recesses of the vertebra at the lower edge of the pedicles, and epidural fat remains distributed around the thecal sac in a symmetrical manner. Second slice: nerve roots exit through the upper portion of the neural foramina that lies immediately beneath the lower margin of the pedicles, the ligamentum flavum appears as a V-shaped soft tissue behind the thecal sac, the anterior extensions of which join the medial portions of the facet joint capsules. Third slice: nerve roots become part of the paraspinal structures after its exit from the neural foramina and the posterior longitudinal ligament remains indistinguishably adjacent to the annulus fibrosis.

A stenotic canal appears distinctly different from the normal canal in a CT image ${ }^{70} 83$. Qualitative characteristics of LSS visible in CT images include: bulging discs, osteophytes along the vertebral margin, spondylolisthesis, thickened pedicles, spinous and transverse processes, thickened ligamentum flavum, facet joint capsule hypertrophy and subluxation, and/or degeneration of the discs ${ }^{71}$. These bony and soft tissue abnormalities can be both causes of LSS, as well as symptoms and side effects of LSS. This in turn leads to difficulty in identification of the actual cause of stenosis in an individual once the symptoms start progressing. Since the visible structural abnormalities usually present themselves in combinations of each other, separating one from the rest can be difficult ${ }^{77} 7585$.

Even though LSS is defined as "narrowing", there are very few evidence-based reports where the "stenotic" vertebral canal dimensions have been defined, or compared with "normal" canal dimensions ${ }^{86}$. Radiological measurements for a stenotic canal were the first to be proposed ${ }^{87}$ but their accuracy was questionable due to two reasons: (i) they were static measurements and did not account for the dynamic nature of the condition; and, (ii) they were estimates and not exact values. Computed tomography is the better 
choice as it allows for exact measurements of the spinal canal while also taking into account that LSS is a dynamic and multi-level condition ${ }^{62}{ }^{65}$. This is possible because CT also allows for images to be collected from symmetric axial sections perpendicular to the anterior bony wall of the vertebral canal ${ }^{88}{ }^{89}$. McAfee and Ullrich (1982) described their quantitative criteria for diagnosing LSS using 3 numerical measurements: (1) antero-posterior (AP) diameter; (2) inter-pediculate distance; and (3) cross-sectional area; and a canal was assigned LSS positive if either the anteroposterior diameter was less than $11.5 \mathrm{~mm}$, and/or inter-pediculate distance was less than $16 \mathrm{~mm}$, and/or cross-sectional area was less than $1.45 \mathrm{~cm}^{275}$. Schonstrom (1985) defined the threshold for a "stenotic" canal as a cross-sectional area of $0.85 \mathrm{~cm}^{283}$; and Zheng (2006) assigned a cross-sectional area threshold value of $1.4 \mathrm{~cm}^{2} 90$. Verbiest (1954) defined a canal as "stenotic" when the sagittal diameter was less than $10 \mathrm{~mm}$. Of the three measurements described by Ullrich (1982): AP diameter, inter-pediculate distance and cross-sectional area - the cross-sectional area measurement is considered to be the most sensitive for diagnosis of central canal stenosis since it integrates the entire bony ring that forms the canal and is more likely to detect asymmetrical canal narrowing or lateral canal narrowing 7785839192 .

\section{Genetic characteristics}

The congenital form of stenosis is typically associated with achondroplastic disorders, which are genetic disorders by nature ${ }^{36} 93$. So it has long been suspected that other types of LSS might also be influenced by genetic factors. Some early familial studies of LSS in siblings have also pointed towards a genetic connection ${ }^{94} 9596$.

Ossification of posterior longitudinal ligament (OPLL) is a pathology that can often lead to LSS and has a higher than normal incidence in the Japanese population ${ }^{97}$. This genetic predisposition in a geographically distinct population also supports the theory that LSS is influenced by genetic factors. Both Postacchini (1985) and Yoshida (1992) have discussed the importance of collagen fibers in the disease process of LSS ${ }^{98} 99$. Maeda et.al (2001) identified a linkage between OPLL and a region of chromosome $6 p$ 
that also contains the gene $\operatorname{COL} 11 \mathrm{~A} 2{ }^{100}$. Lumbar disc disease (LDD) is another pathology that is believed to be a leading cause of LSS. Tryptophan alleles in COL9A2 (Trp 2) ${ }^{101}$ and COL9A3 (Trp 3) ${ }^{102}$ have shown an association with LDD in the Finnish population. A study done in mice to study age-related spine degeneration, identified a heterozygous mutation that causes haplo-insufficiency of the aggrecan gene (AGC1) and results in intervertebral disc herniation and degeneration ${ }^{103}$. This finding in mice was later repeated in humans along with identification of an association between a VNTR in AGC1 and LDD in humans ${ }^{104}$. Lumbar disc degeneration has also been associated with polymorphisms in vitamin D receptor gene (VDR) 10510681 and matrix metalloproteinase-3 gene MMP-3 ${ }^{107}$. All these polymorphisms found in OPLL and LDD (diseases closely related and presenting simultaneously with LSS), support the theory that LSS could also be influenced by genetic factors ${ }^{20}$.

Noponen-Hietala et.al were the first to investigate candidate genes of LSS based on genes identified in related diseases. The study subjects comprised of 29 probands (LSS positive) and 56 controls (LSS negative) from the Finnish population. The phenotype was established using both $\mathrm{CT}$ and MRI. The following 9 candidate genes were selected - COL1A1, COL1A2, COL2A1, COL9A1, COL9A2, COL9A3, COL11A1, COL11A2 and AGC1. The study also included 2 SNPs in VDR gene and one SNP in MMP-3 gene promoter. The study was able to identify two variants in COL9A2 gene -

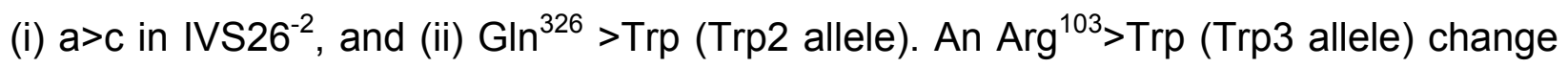
in COL9A3 was also found. The previously reported a>t polymorphism in IVS6 ${ }^{-4}$ of COL11A2 (from OPLL studies in Japanese populations) did not show any significant association between LSS and Finnish population. The authors justified this result by stating the fact that OPLL is not prevalent among Finnish population, and that the previously identified COL11A2 polymorphism is related to OPLL alone and not LSS in general. However, the frequency of the $t$ allele was significantly higher in probands $(93.1 \%)$ than the control group $(72.3 \%)$. Further analysis showed that while the frequency of t/a and a/a genotypes was not significantly varying between the probands and controls, the $\mathrm{t} / \mathrm{t}$ genotype had a much higher frequency in probands and had a 
dominant effect. They estimated that $20 \%$ of the affected subjects in the population could attribute their diseased state to the high-risk $t / t$ genotype. Analysis of the other previously reported polymorphisms in AGC1, VDR and MMP-3 genes showed no significant differences in allele frequencies between the proband and control groups ${ }^{20}$. Hyon et.al (2011) based their study on the findings of the Noponen-Hietala et.al. study (2203). The authors studied COL9A2 gene as a candidate gene for LSS in the Korean population ${ }^{21}$. Using MRI to establish phenotype, the study had 205 proband and 101 control subjects. The study identified 42 COL9A2 polymorphisms along with the previously reported $\operatorname{Trp} 2$ allele found in Finnish population study ${ }^{20}$. Out of the 43 SNPs identified, further analysis was done on the six that were present in the exons (and had a minor allele frequency of at least $20 \%$ ), but none were statistically significant that could signal possible causal nature. This led the investigators to search for hidden susceptibility alleles in COL9A2 for LSS by studying the haplotype structure of the gene. The authors were able to identify the HAP2 haplotype (GCAGCG) overexpressed in probands $(p=0.023$ and odds ratio=1.86) and HAP4 haplotype (TCAGCG) overexpressed in controls $(p=0.042$ and odds ratio $=0.52$ ). The authors concluded that COL9A2 does indeed play a role in lumbar spinal stenosis but the mechanism behind this involvement remains unknown. The authors suggest a possible reason for this observation - mutations in COL9A2 promoter region can affect the level of collagen IX protein in relevant tissues by down-regulating expression ${ }^{21}$.

\section{Treatment}

There is no cure for LSS. Management of the symptoms, either by surgery or conservative means, is the only effective course of action ${ }^{25}$. The common perception is that LSS is a progressive disease and conservative treatments are ineffective, only surgery is effective and has long-term effectiveness ${ }^{108} 109$. Non-surgical treatments of LSS have also shown some success for mild and moderate cases of LSS. However, there are no standardized protocols for conservative management of LSS to guide physicians. Medications are used to control the symptoms of pain and discomfort. This includes analgesics, non-steroidal anti-inflammatory drugs (NSAIDs), muscle relaxants 
and opioids. Dosage is based on individual cases and the discretion of the physician. Physical therapy is an essential aspect of treatment of this disease. Exercise is believed to condition the body against the deleterious effects that might be the result of inactivity due to pain and discomfort. However there are several contradictory scientific reports that either support or discredit this belief. Epidural injections are another form of pain management. But the most commonly preferred form of treatment of LSS is neural decompression surgery. This procedure usually involves the removal of thickened connective tissue and/or osteophyte formations relieving the pressure on the nerve tissue inside the spinal canal. In fact most studies on LSS focus on the before and after aspect of neural decompression surgery. The success rate of surgery ranges from $26 \%$ to $100 \%{ }^{110}$. 


\section{Lumbosacral stenosis}

\section{Anatomy of the normal canine lumbosacral spine}

The anatomy of the spine in dogs is very similar to the anatomy of the spine in humans. The arrangement and layout of the musculoskeletal elements follow a similar pattern. However there is one distinct difference - the canine lumbar and sacral vertebral segments are not separate entities as in humans, but are often considered to be one single unit called the "lumbosacral" segment. The lumbosacral vertebral canal is considered to be one continuous element comprising of the $5^{\text {th }}$ to $7^{\text {th }}$ lumbar (L5 to L7) and the $1^{\text {st }}$ to $3^{\text {rd }}$ sacral (S1 to S3) in that order. Another difference from human anatomy is the fusion of the three sacral vertebrae to form the sacrum. The vertebral laminae, articular processes, pedicles and bodies of each of the L5-S3 vertebrae make up the canal boundary. The space in between the caudal aspect of one vertebrae and the cranial aspect of the adjacent vertebrae is the intervertebral foramen. The shape of the vertebral canal in transverse profile is usually round or oval with the transverse diameter tending to be greater than the dorso-ventral diameter ${ }^{111}$. The shape of the lumbosacral canal becomes progressively semi-circular or crescent shaped as it transitions from the cranial to the caudal end of the canal ${ }^{112}$. The cross-sectional area of the canal is at its greatest at mid-lumbar level and gets progressively narrower both cranially and caudally to that.

The spinal canal and the vertebral column start developing in the embryo together at the same rate, but later on the vertebral column overtakes the spinal cord in the development rate. This results in the vertebral column extending beyond the conus medullaris (termination point of the spinal cord), so the nerves and nerve roots of vertebrae towards the end of the spinal cord have to travel longer to exit caudally to their corresponding vertebra. This forms a bundle of neural tissue called the "cauda equina" residing in the empty space inside the vertebral canal caudal to the cord. The dorsal and ventral roots of each spinal nerve have separate origins but unite to form a single spinal nerve that passes through the intervertebral foramina and immediately divides into dorsal and ventral branches. The ventral branches of the L4-S3 (L4, L5, L6, 
L7, S1, S2 and S3) nerve roots contribute to the lumbosacral plexus, which controls the hips, hind limbs, tail, urinary bladder, rectum, anus, and external genitalia. The ligamentum flavum or interarcuate ligament (dorsally and dorso-laterally), intervertebral discs and the dorsal longitudinal ligament (ventrally) form the soft tissue boundary of the lumbosacral vertebral canal. The caudal ligament anchors the cord caudally. The ligamentum flavum is a loose, elastic sheet that bridges the arches of adjacent vertebrae in the dorsal vertebral canal. Laterally, it is continuous with the joint capsules surrounding the articular processes. The intervertebral disc that sits between the individual vertebrae consists of a central nucleus pulposus, and an outer annulus fibrosus. The dorsal longitudinal ligament lies on the dorsal surfaces of the vertebral bodies, in the ventral portion of the vertebral canal. It is narrow at the middle of the vertebral body and wide over the intervertebral disc. The caudal ligament is a continuation of the dura mater and attaches to the periosteum of the $5^{\text {th }}$ or $6^{\text {th }}$ caudal lumbar vertebra.

The spinal branches of the lumbar arteries, which arise from the abdominal aorta, supply arterial blood to the caudal spinal cord. The venous drainage for the spinal cord is primarily through the internal vertebral venous plexus. The plexus consists of paired interconnected vessels extending from the skull to the caudal end of the vertebral column. These paired vessels lie inside the ventral side of the canal nestled among the epidural fat. The spinal veins originate from the venous plexus following the same path as the nerve roots, entering and exiting through the intervertebral foramina.

The caudal spinal cord and the cauda equina nerve roots are cushioned by three layers of meninges, that together form the thecal sac. The meningeal layers consist of the dura mater, arachnoid membrane, and the pia mater. The outer dura mater consists of longitudinal collagen bundles that cover the cord and nerve roots as they exit the canal, becoming continuous with the epineurium and perineurium of the spinal nerves. The dura is separated from the periosteum of the vertebral canal by a wide epidural space filled with fat. It is attached caudally to a point in the middle of the tail by the filum 
terminale and the caudal ligament. The middle layer or arachnoid membrane is separated from the inner pia mater by the subarachnoid cavity. This space is filled with cerebrospinal fluid. The arachnoid membrane is joined to the underlying pia by trabeculae. The pia mater is affixed tightly to the surface of the cord, and is usually one cell layer. It is thickened laterally to form denticulate ligaments that attach the cord to the dura. The thecal sac is more round than oval like the vertebral canal and the diameters are at their greatest at the L4-L5 level, narrower cranial to L4 and wider caudal to L5.

\section{Etiology and pathogenesis}

Lumbosacral stenosis (LS) is a multifactorial neuro-orthopedic disorder similar in nature to human LSS ${ }^{7}$. The classical definition of LS in dogs is - an abnormal narrowing of the lumbosacral canal, vertebral canal, and/or the intervertebral foramina between the L5S3 segments that can lead to the compression of the neural and vascular tissues inside the canal ${ }^{7} 8$. Cauda equina syndrome (CES) ${ }^{113}$ is often a direct result of said compression, so most of the clinical symptoms of LS often overlap with those of CES 114. Canine LS also has multiple etiologies (similar to human LSS) -congenital (developmental or idiopathic), or acquired (degenerative or post-traumatic) ${ }^{7} 1155116$. Also similar to humans, acquired or degenerative LS is the most commonly observed type of LS. However there is a theory that instead of any one distinct type of etiology, canine LS might be a combination of two etiologies - both congenital and degenerative $117{ }^{4}$. This theory is supported by the fact that most dogs start showing symptoms of LS at a young age, well before degenerative changes should theoretically present themselves. Another similarity with human LSS is that canine LS can also affect the vertebral column across multiple vertebral levels, and affects not just the neural tissue but also the vascular tissue - thereby also explaining the pathology behind intermittent neurogenic claudication 118626511960 .

Some studies in humans have documented that individuals who get clinical signs of LSS at a later age usually have pre-existing, subclinical bone malformations like transitional vertebrae ${ }^{120}$. Lumbosacral transitional vertebrae (or LTV) is a common find 
in dogs positive for spinal conditions like congenital LS $\begin{array}{llll}13 & 121 & 9 & 122\end{array}$. The more common degenerative form of LS usually results from a combination of several degenerative changes including hypertrophied interarcuate ligament (ligamentum flavum), epidural fibrosis, osteophytes, disc herniation or hypertrophy, spondylolisthesis and/or spondylosis 1155116114 .

\section{Clinical presentation}

The most commonly observed neurological symptom of LS is intermittent lameness and weakness in motor functions of the hindlmbs, which can progress to atrophy of the hindlimb muscles and paresthesia (physically inexplicable sensation of tingling/tickling/pricking/burning of the skin). Paresthesia can in turn lead to selfmutilation of the hindlimbs, tail, perineum, anal area and genitalia that is unrelated to any other dermatological condition. Other symptoms include vocalizing during exercise; difficulty in standing up, sitting or lying down; low carriage of the tail; kyphosis (abnormally excessive convex curvature of the spine); stiff or unnatural gait; dragging of paws; hypotonia of the tail; and last but not the least urinary and fecal incontinence ${ }^{123}$ 124125 . Most of these symptoms usually overlap with other neuro-orthopedic and/or musculoskeletal disorders like cauda equina syndrome ${ }^{116}$, osteoarthritis ${ }^{126},{ }^{127}$, and intervertebral disc degeneration ${ }^{128}$.

Even though Tarvin (1980) was the first to report LS in dogs, his study comprised of mostly small breeds ${ }^{7}$; since then a trend has been identified - LS usually affects largersized dog breeds ${ }^{16} 129130$. German shepherds are the breed that is most represented 123124 125; but other high risk breeds include Labrador retrievers, Rottweilers, Bernese Mountain dogs, Boxers, Dalmatians, Irish setters, and Doberman pinschers ${ }^{130}$. Lumbosacral stenosis also appears to affect males more than females (again similar to

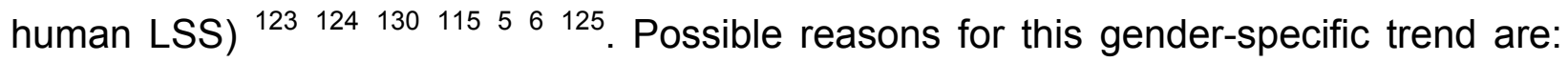
male dogs are usually heavier in size, faster in their growth rate and are selected more often for strenuous physical activity ${ }^{123}$. The average age of onset for LSS is around 7 years 56123124125 . 


\section{Clinical diagnosis and diagnostic imaging}

The primary symptom presented by majority of dogs with degenerative LS is reduced physical activity and pain sensitivity in the lumbosacral region (on external manual palpation) ${ }^{114}$. However, positive diagnosis of degenerative LS can be complicated by the subtle nature of the clinical signs: (i) symptoms might not appear until the dog undergoes hard physical exertion; (ii) symptoms can mimic those of other spinal diseases like intervertebral disc degeneration (IVDD) diseases ${ }^{131}$, degenerative sacroiliac joint disease (DSJD) ${ }^{132}$, foraminal stenosis ${ }^{133}$, Schmorl's nodes ${ }^{134}$; and (iii) dogs being unable to vocalize pain, masking signs of pain especially the high-drive breeds, and/or dogs asymptomatic at the time of examination. Another concern of diagnosing LS in dogs based on clinical symptoms is the unreliable nature of how a dog responds to pain or discomfort.

Diagnosis of LS is most commonly performed using CT and/or MRI because conventional radiographs are usually unable to capture the spinal canal in the transaxial plane - where most of the signals for lumbosacral stenosis are present. Computed tomography is a well-established non-invasive diagnostic imaging technique used for evaluating the lumbosacral spine in dogs ${ }^{135} 111,115136112$, and has been used to study lumbar spinal diseases like spina bifida ${ }^{137}$, IVDD ${ }^{138}$ and vacuum phenomenon of the spine ${ }^{73}$. The advantages of using CT over MRI in veterinary practices include: (i) greater availability; (ii) lower cost; and (iii) shorter duration allowing for reversible sedation instead of general anesthesia. Tarvin (1980) identified L6-L7 and L7-S1 transitional locations as the most at-risk vertebral segments for LS.

\section{Qualitative and quantitative computed tomography characteristics}

Fingeroth (1989) was the first to use CT for the clinical diagnosis of a spinal disease in an English bulldog ${ }^{137}$. Since then CT has become a commonly used imaging technique in dogs especially for spinal diseases. Jones et.al (1996) studied the CT anatomy of the 
lumbosacral spine of 9 large breed dogs clinically diagnosed with LS, and then confirmed the said imaging anatomy with surgical evaluation ${ }^{139}$. The commonly observed CT abnormalities in these dogs (with surgically confirmed LS) were: loss of epidural fat, increased soft tissue opacity, bulging in the intervertebral disc margin, spondylosis, displacement of the thecal sac, narrowed intervertebral foramina, narrowed vertebral canal, thickened articular processes, subluxation of the articular processes, bone spurs in the articular processes, and telescoped sacral lamina. The authors acknowledged the possibility that all these traits might not be true clinical signs of LS since some of the traits were also detected in dogs with no signs of LS. However, the study was able to identify 2 possible qualitative traits of LS - loss of epidural fat and loss of soft tissue transparency that was observed in all of the 9 dogs positive for LS. Other observed traits with a high frequency included disc bulging, spondylosis, and thecal sac displacement (findings also supported by studies of human LSS). Epidural fibrosis was another trait observed only in surgery but not directly in the CT images. An ill-defined region of soft tissue opacity and loss of nerve root/thecal sac visualization were the only observable characteristics of fibrosis in the epidural region in CT images cause and significance of which is not well understood in dogs ${ }^{116} 115$. Human studies have suggested that epidural fibrosis might be a post-surgical complication rather than a spontaneous phenomenon ${ }^{13582,83}$. Some of the qualitative traits observed were not at the exact site of neural compression but in adjoining vertebral segments, thus also hinting at a possible multi-level etiology of canine LS ${ }^{7}$. The clinical symptom of neurological claudication has been attributed to this multi-level phenomenon in human LSS $^{62} 60$.

Feeney et.al (1996) published a morphometric study to quantify the normal canine lumbosacral spine ${ }^{140}$. The subjects in this study were three Beagles and three mixedbreeds. The canal and foramen diameters as well the thecal sac diameters were measured manually in transverse CT images. The average intervertebral foramen diameter range was $0.20 \mathrm{~cm}-0.30 \mathrm{~cm}$. Epidural fat was found to be present on all aspects of the thecal sac in all vertebral levels and no correlation was found between 
epidural fat and body weight of the dog. To compensate for the difference in body size of the different dogs, all the measurements were standardized based on the measurement of the least variable L6 vertebral mid-body. Despite the standardization, significant variation was observed among the six dogs. The vertebral canal was oval but the thecal sac was more circular in profile, and the space within the canal that was not occupied by the thecal sac was filled up by epidural fat. The authors proposed cautious interpretation of the loss of epidural fat in the vertebral canal as a symptom of stenosis ${ }^{139}$, since it could just be normal anatomical adjustment instead of a clinical symptom. However this study did not state any absolute values to define a normal lumbosacral spine and only recorded for any significant differences among the dimensions measured in the six dogs of the study. The morphometric study of the lumbosacral spine by Jones et.al had a larger sample size of 42 large breed dogs (21 cases and 21 controls) and included dogs from multiple breeds ${ }^{112}$.

\section{Genetic characteristics}

The modern day dogs we observe today have become an essential part of the human way of life ${ }^{141}$. Dogs (Canis lupus familiaris) are in fact the domesticated sub-species of the grey wolf (Canis lupus) ${ }^{142}$. The oldest dog domestication records found date back to approximately 15,000 years, but some studies argue that the first canine domestication event could have happened up to 100,000 years ago in Eastern Asia ${ }^{143} 142144$. Humans and dogs have evolved in parallel with each other over time ${ }^{145}$, sharing living space and food sources based on a mutually beneficial relationship - thus making the comparative analysis of the human genome possible due to the shared environment which in turn led to shared evolution ${ }^{146}$. This unique shared history among humans and dogs makes the canine species a perfect model to explore the genetic basis of diseases, variation in morphology and behavioral traits - with respect to not only how it affects the canine species but also how similar disease processes might affect humans.

After the initial phase of domestication, dogs underwent extensive artificial selection due to their intentional breeding by humans focused on fixing specific traits - resulting in the creation of the breed structure seen in dogs today ${ }^{147}{ }^{148}$. While there are a wide variety 
of canine breeds, population structure within each breed is relatively homogenous and is comparable to the population structure observed in geographically isolated human populations ${ }^{148,149} 150151147152153$. And similar to human populations, certain dog breeds have a higher prevalence for certain diseases than other breeds ${ }^{154}$. This further enhances the desirability of the canine model for human biological research - diseases with unknown etiology in humans are often first studied in smaller geographically isolated population in which the disease has a higher than normal incidence, before the findings can be translated to a larger population. Another factor that makes dogs such good models is that most canine diseases also have a version that affects humans often with similar clinical manifestations ${ }^{155}$. Other key factors that make dogs good models for human disease studies include: 1 ) dogs usually enjoy high quality of medical care alongside humans for similar medical conditions; 2) both being mammals, dogs and humans are comparable to each other both anatomically and physiologically; 3) dogs generally cohabit with humans thus negating the effects of differing environmental exposures; 4) many human diseases occur naturally in dogs thus there is no need for chemical or mechanistic techniques to artificially induce the disease state; and 5) dogs have shorter life span, allowing for longitudinal studies to observe the progression of diseases over time ${ }^{156}$. This unique relationship between dogs and humans, and the success of the canine model for human disorders, would allow bidirectional beneficial flow of information - findings in canine studies would not just benefit humans, but finding in human studies could also be applicable in dogs ${ }^{151}$. Genetic analysis of a diverse array of traits in dogs has provided further proof supporting this theory. The canine genome has been completely sequenced by the Broad Institute in $2003^{149}$. More than 650 million base pairs (more than 25\%) of the dog sequence align uniquely to the human genome including orthologs for 18,473 of the 24,567 annotated human genes ${ }^{157}$. For certain traits the dog genome is more similar to humans that the common rodent models ${ }^{158}$.

Some genetic factors (especially those dealing with collagen genes) have been implied to be playing a role in LSS in some geographically isolated human populations in 
previous studies ${ }^{20} 21$. No such genetic studies have been conducted in dogs except a pedigree association study of LS in German shepherds ${ }^{11}$. However to the best of our knowledge, no genetic association study has been reported that focuses on LS in Labrador retrievers. The canine model has found success in study of several human musculoskeletal diseases that include intervertebral disc disease (IVDD) ${ }^{159}$; Duchenne Muscular Dystrophy (DMD) ${ }^{160}$; and osteoarthritis (OA) ${ }^{161}$. Quantitative diagnostic imaging has been used to study other human diseases in canine models in diseases like ischemic renal disease ${ }^{162}$. Experimental bone regeneration has also found some success in the canine model in recent years ${ }^{163} 164$. Delamarter et.al introduced an experimental canine model for LSS in $1990{ }^{165}$. However, larger sized breeds like the German shepherds and Labrador retrievers would make them better models for LSS, since the disease process of LS in these breeds is more organic and natural.

\section{Treatment}

Tarvin (1980) was the first to report treatment plan for LS in 15 dogs $^{7}$. The dogs were treated conservatively with anti-inflammatory drugs and Elizabethan collars (or Ecollars) to prevent the dogs from self-mutilating themselves. Similar to LSS in humans, the most popular treatment approach is surgical - decompression by deep dorsal laminectomy in combination with lateral foraminotomy of the affected vertebrae ${ }^{7} 166$. Laminectomy and foraminotomy both involve the removal of hypertrophied tissue to an extent that the neural tissue inside the vertebral column is no longer compressed thereby also relieving the pressure on the vascular tissue. The treatment strategies have not changed much over the last 30 or so years ${ }^{167}$. Non-surgical therapy still involves oral analgesics or anti-inflammatory drugs to provide symptomatic pain relief (again similar to the approach used in majority of human subjects that present with LBP). 
Table II.1. Major causes of lumbar spinal stenosis in humans

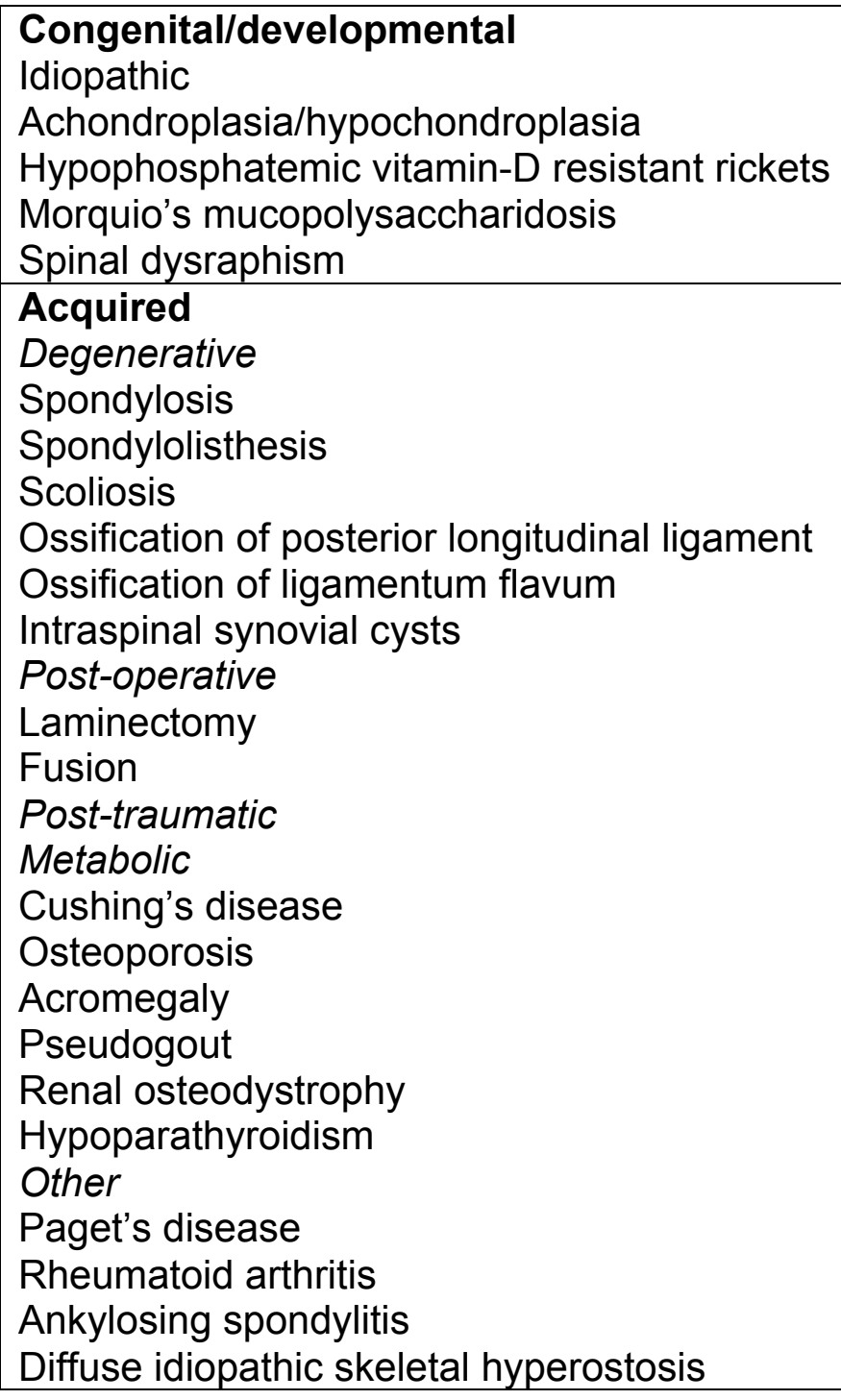




\section{CHAPTER III. PHENOTYPIC CHARACTERIZATION OF LUMBOSACRAL STENOSIS IN LABRADOR RETRIEVERS}

\section{III.1: Introduction}

The definition of lumbar spinal stenosis (LSS) is the structural narrowing of the lumbar spinal canal, nerve root canal and/or intervertebral foramina ${ }^{168}{ }^{17}$. Clinical symptoms may arise when this narrowing results in compression or entrapment of the underlying nerve tissue, meninges and/or blood vessels inside the vertebral canal ${ }^{168}{ }^{66}$. Lumbar spinal stenosis can be confined to a single vertebra or spread across multiple vertebral levels 16917017171172173174 . Lateral canal or foraminal stenosis is a specific type of LSS that involves the lateral portions of the vertebral canal or intervertebral foramina. Based on the time of onset, LSS can also be classified as either primary stenosis (narrowing due to congenital or developmental malformation) or acquired stenosis (narrowing due to encroaching proliferative tissues and/or vertebral malalignment). Acquired or degenerative causes of stenosis include facet joint arthrosis or hypertrophy, thickening and bulging of the intervertebral disc, hypertrophy of the ligamentum flavum and/or spondylolisthesis. Some studies have also implicated genetics as a factor in the pathogenesis of human LSS 2021 .

The canine version of LSS is known as lumbosacral stenosis (LS) ${ }^{7}$. The larger sized working/sporting breeds of dogs are predisposed to LS 8123161751291155624112139 . Labrador retrievers are the most popular household pet dog breed in the United States 15 and also one of the most common breeds used worldwide as working dogs 123163 ${ }^{176}$. This breed is also considered to be at high-risk for LS $^{130}$.

X-ray computed tomography (CT) is an accepted non-invasive method for deep phenotyping of LSS in humans 17717889179777544180831811829171183184 185; as well as

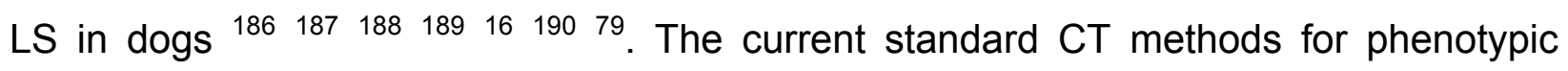
characterization of LS in dogs are based on qualitative observations made in dogs with 
surgically confirmed presence of LS $\begin{array}{lllll}139 & 191 & 129 & 16 & 190\end{array}$. These criteria include loss of epidural fat, increased soft tissue opacity, bulging of intervertebral disc, spondylosis, thecal sac displacement, narrowed intervertebral foramen, narrowed vertebral canal, narrowed articular processes, articular process subluxation and articular process osteophytosis ${ }^{139}$. For research purposes, quantitative criteria for phenotyping LS would be desirable because they would allow for use of more powerful parametric statistical tests.

Quantitative CT measures of human LSS have been extensively described, however traits measured and values used for defining stenosis have varied between reports ${ }^{178} 76$ 86751929119330194 . Cross-sectional vertebral canal area, antero-posterior diameter and inter-pedicular diameter measurements of the spinal canal are the most commonly described quantitative traits in humans ${ }^{75} 1798692192837819590196$. Other measurements reported include the following: mid-sagittal vertebral canal diameter, lateral recess sagittal diameter, transverse thecal sac area, inter-facet ligamentous diameter and thecal sac diameter. Cross-sectional area measurements offer an advantage over diameter measurements because they are more likely to detect asymmetrical canal narrowing or lateral canal narrowing 8675919290 . However, despite the established definition of stenosis being "narrowing", there are very few evidence-based reports where the "stenotic" vertebral canal area range has been defined, or compared with "normal" area measurements ${ }^{86}$, or the threshold value agreed upon. The contradictory threshold values for a stenotic canal range anywhere from $0.85 \mathrm{~cm}^{2} 83$ to $1.45 \mathrm{~cm}^{2} 75$. Another study assigned $1.4 \mathrm{~cm}^{2}$ as the stenosis threshold ${ }^{90}$. No such studies exist in dogs that focus on quantitatively differentiating between "stenotic" and "non-stenotic" canals. There is one previous canine study that did a morphometric comparison between quantitative CT characteristics of the lumbosacral vertebral canal in dogs with versus without symptoms of cauda equina dysfunction ${ }^{112}$, but not LS. Vertebral canal diameter and area values were found to correlate with adjacent vertebral body dimensions in asymptomatic dogs, therefore ratios of vertebral canal and vertebral body measurements were used to correct for variations in dog body size in subsequent 
comparisons. Differences between groups were found for ratios of vertebral canal transverse area to vertebral body transverse area at caudal L5 (0.42 LS, 0.46 control) and caudal L6 (0.36 LS versus 0.44 control). However, this study included dogs from multiple breeds and the study was able to quantify only bony canal stenosis (soft tissue stenosis was not quantified). Also, at the time of the previous study, availability of advanced CT image analysis softwares that allow for both manual and automated measurements of selected structures of interest were limited. To the authors' knowledge no published reports have compared CT quantitative measures to qualitative assessments of LS.

The aims of this current study were to develop a CT quantitative method for characterizing the morphologic phenotype of LS in Labrador retrievers and to compare findings from this method with findings from current standard qualitative CT methods. The hypotheses of this study were: 1) ratios of CT vertebral canal transverse area to vertebral body transverse area, and novel ratios of vertebral canal transverse epidural fat content area to vertebral body transverse area can be used to quantify LS in Labrador retrievers; and 2) the assessment of LS made using these quantitative measurements will yield results comparable to the current standard qualitative assessment of LS. 


\section{III.2: Materials and Methods}

\section{Study samples}

This cross-sectional retrospective study was based on CT scans and medical records of Labrador retrievers obtained from three sources: the Holland Military Working Dog Hospital at the Lackland Air Force Base, Virginia-Maryland Regional College of Veterinary Medicine Veterinary Teaching Hospital and the University of Pennsylvania Ryan Veterinary Hospital/Working Dog Center. A board certified veterinary radiologist (JJ) reviewed the scans to ensure they met inclusion criteria. The scans had to contain the lumbosacral region and evidence of no previous lumbosacral surgery, neoplasia, fractures or infection in order to be included in the study.

\section{Computed Tomography}

All included scans were analyzed using CT image analysis freeware (OsiriX DICOM Viewer, Version 4.2) and image analysis workstations (Mac Pro and MacBook Pro Apple Inc. Cupertino, CA). Under the supervision of a board-certified veterinary radiologist (JJ), a single observer (MM) independently measured and recorded quantitative values while unaware of qualitative CT findings and medical history. After a delay period, the veterinary radiologist then recorded a qualitative diagnosis of presence or absence of LS at each of the vertebral locations using standard criteria. At the time of interpretation, the radiologist was unaware of quantitative or medical record findings. After quantitative CT measurements were completed, the same observer (MM) then made note of the age, sex, body weight, low back pain (LBP) status and working status; as entered into the medical records at the time of the original CT scan.

Slice thickness for each study was standardized at $5 \mathrm{~mm}$ using the software's "thick slab mean mode" tool in order to maximize contrast resolution for soft tissues and minimize sources of partial volume averaging variability between studies 197135 . The following quantitative CT phenotypic variables were measured in triplicate at each of six vertebral locations previously established as the lumbosacral region primarily affected by LS 
(caudal L5, cranial L6, caudal L6, cranial L7, caudal L7 and cranial S1) ${ }^{7139}$ (Figure III.1): vertebral canal area, vertebral body area and vertebral canal fat area. Vertebral canal area at each vertebral location was measured using a bone window setting (WL 300, WW 1500) tracing the canal boundary with a pencil tool ensuring the surrounding bone did not get included inside the tracing (Figure III.2A). Using the same pencil tool and window setting, the vertebral body area was traced ensuring that no surrounding soft tissue was included. The vertebral canal fat area at each vertebral location was measured in a soft tissue or "abdomen" window (WL 40, WW 350), using segmentation tools to set the lower and upper threshold at -200 and 0 Hounsfield units (HU) respectively (Figure III.2B). A region of interest (ROI) was generated automatically by clicking the cursor over all locations within the canal where fatty tissue appeared to be present (visibly darker color grey than other soft tissue). All area values were measured in $\mathrm{cm}^{2}$. The means of all triplicate measurements were calculated. Vertebral canal/vertebral body area ratio (CAR) ${ }^{112}$ and canal fat area/vertebral body area ratio (FAR) (novel methodology) were then calculated from the means at each location for each dog.

Canal stenosis was qualitatively assessed and recorded as present or absent for each dog at each of the six vertebral locations. The assessment was done twice in two separate reading sessions by the same veterinary radiologist $(\mathrm{JJ})$. To minimize read bias, scans were interpreted in random order and the second reading session was done three days later, at a different time of day and in a re-randomized order. In cases where there was a discrepancy between the first and second readings, the radiologist made a third assessment that was deemed to be the final decision. For purposes of this study, qualitative stenosis at a vertebral location was considered to be present if the radiologist detected at least two of the following CT lesions: thickened pedicle(s), thickened lamina(e), loss of epidural fat on opposing sides of neural tissue, proliferative bone or soft tissue in the canal and/or a subjectively narrowed canal ${ }^{7} 175{ }^{198}$. Stenosis was considered to be absent if one or no lesions were detected. 


\section{Statistical analyses}

A single statistician $(\mathrm{IH})$ selected and performed statistical tests using commercial software (JMP ${ }^{\circledR}$, Version Pro 11, SAS Institute Inc., Cary, NC, Copyright@ 2013). Dogs were grouped under the following clinical data categories for analyses: sex - M (male) or F (female); LBP status - absent or present; and working status - working or nonworking. Age and weight were treated as continuous variables. Significance criterion alpha for all tests was set at $0.05(5 \%)$. Initially, continuous variables such as canal area ratios (CAR) and fat area ratios (FAR) for each of the 6 vertebral locations in all dogs were screened for normal distribution using the Shapiro-Wilk $W$ test ${ }^{199}$. Lack of normality was detected in CAR for L5Cd, L6Cd and L7Cd. Negative inverse $(-1 / x)$ transformation was applied to $\mathrm{L} 5 \mathrm{Cd}$, while $\mathrm{L6Cd}$ and $\mathrm{L7Cd}$ were natural $\log \ln (x)$ transformed. Variance equality in CAR and FAR between LS positive and LS negative dogs (assigned based on CT image analysis) were inspected using Levene's test ${ }^{200}$. Ttests were used to test the null hypotheses: both quantitative measurements (CAR and FAR, independently) are not different in LS positive from LS negative dogs (based on the qualitative CT assessment). Secondary analysis included logistic regression with dichotomous response ${ }^{201}$ - LS positive or LS negative based on qualitative CT assessment, where CAR and FAR were applied as explanatory continuous variables to predict the presence or absence of LS, done individually for the 6 different vertebral locations in the lumbosacral spine. Logistic regression analysis allowed the examination of the variables (CAR or FAR), as to which quantitative measurement would be the better predictor for the probability of being LS positive based on the CAR (or FAR) measurements at a specific vertebral location. The predicted probability curves of LS based on logistic regression were generated for each location. Untransformed data were used for plot constructions. Significance was defined as $p<0.05$ after BenjaminiHochberg correction with a false discovery rate (FDR) of $20 \%{ }^{202}$. 


\section{III.3: Results}

\section{Study samples}

This analytical cross-sectional retrospective study comprised of CT scans collected between the period of 1997 and 2013, and included scans from a total of 25 Labrador retrievers that met the inclusion criteria. The scan of one of the 25 dogs in the study, included only four of the six vertebral locations (L6 caudal, L7 cranial and caudal, and $\mathrm{S} 1$ cranial). For the two missing locations ( $5^{\text {th }}$ caudal and $6^{\text {th }}$ cranial lumbar vertebra), analyses were performed on 24 dogs. The study involved 17 males and 8 females. The ages of the subjects ranged from 11 months to 14 years (mean $6.46 \pm 0.84$ years). Dog weights ranged from $23.6 \mathrm{~kg}$ to $44 \mathrm{~kg}$ (mean $32.3 \pm 1.13 \mathrm{~kg}$ ). 9 dogs showed signs

of lower back pain at the time of CT examination. Six of these 9 dogs were older than 5 years of age. The remaining 16 dogs had no signs of lumbosacral pain. Eight dogs were classified as working dogs and the other 17 as non-working dogs. No significant correlation between age and LBP was found. The study sample population is described in Table III.1.

\section{Computed Tomography scans}

Twelve dogs were scanned with single slice CT scanners (IQXtra or PQ5000, Picker International, Cleveland, Ohio) and 13 dogs were scanned with multi-slice CT scanners (Aquilion, Toshiba, Tustin, CA; LightSpeed VCT or BrightSpeed, GE Medical Systems, Pewaukee, WI). All single slice scans were acquired in axial mode and all multi-slice scans were acquired in helical mode. The scan matrix for all dogs was $512 \times 512$. Volume scans were acquired at $0.625 \mathrm{~mm}$ slice thickness for 7 dogs, $1 \mathrm{~mm}$ slice thickness for 2 dogs, and $2 \mathrm{~mm}$ slice thickness for 1 dog. Contiguous scans were acquired at $5 \mathrm{~mm}$ slice thickness for 2 dogs and $0.5 \mathrm{~mm}$ slice thickness for 1 dog. Scans with a $1 \mathrm{~mm}$ overlap were acquired at $2 \mathrm{~mm}$ slice thickness for 2 dogs, $5 \mathrm{~mm}$ slice thickness for 9 dogs, and $4 \mathrm{~mm}$ slice thickness for 1 dog. A standard scan filter was used for 18 dogs, detail/bone filter for 6 dogs, and body filter for 1 dog. Technique 
settings were $13-400 \mathrm{~mA}$ and $120-140 \mathrm{kVp}$. All the CT scans were acquired from dogs positioned in dorsal recumbency.

\section{Statistical analyses}

Based on the performed t-tests, the mean CAR values at the cranial end of the L7 vertebra in LS positive dogs was significantly smaller than the mean CAR of LS negative dogs $(p$-value $=0.0409$ ). There was no statistically significant difference in CARs between the LS positive and LS negative dogs at any of the other 5 locations (Table III.2) (Figure 3). The t-tests for mean fat area ratios (FARs) indicated that FARs for LS positive dogs were significantly smaller than FARs for LS negative dogs across all 6 vertebral locations (Table III.2) (Figure 4). Logistic regression analysis between quantitative CAR measurements and qualitative CT diagnoses of LS (standard test) showed no statistical significance at any of the six vertebral locations (Table III.3) (data not shown). Logistic regression between quantitative FAR measurements and the same qualitative CT diagnoses showed statistically significant associations at each of the six vertebral locations (Table III.3) (Figure 5). Predicted probabilities for LS positive dogs (y axis) against FAR measurements (x axis) for all six locations were plotted based on our

model and are represented in Figure 6 . All of the predicted probability curves had high $R^{2}$ values $(L 5 C d=0.999 ; L 6 C r=0.997 ; L 6 C d=0.998 ; L 7 C r=0.998 ; L 7 C d=0.991$; and $\mathrm{S} 1 \mathrm{Cr}=0.997)$ and displayed a pattern of increase in the probability of being LS positive with decreasing FAR values. 


\section{III.4: Discussion}

The purpose of this study was solely to develop a quantitative CT method for structural phenotyping of LS (that could be comparable with traditional qualitative detection methods) in Labrador retrievers - facilitating research related statistical analysis, and not diagnosis of LS for clinical applications. Clinical detection of lower back pain can be unreliable as an outward indicator of LS in dogs, especially in stoic and high-drive dogs such as Labrador retrievers. Hence the need for deep phenotyping using advanced imaging modalities like CT and MRI. While qualitative assessment of scanned images is the standard for clinical applications with regards to LS in dogs, statistical analyses are strengthened with quantifiable variables.

Our first hypothesis was that quantitative CT measurements could quantify LS in Labrador retrievers. We started with two measurements: canal area ratio (CAR) and fat area ratio (FAR), however the most significant results were achieved by the novel measurement (FAR) in quantification of LS. Stenosis has been defined as narrowing of the spinal canal, CAR was assumed (and has been used in previous studies ${ }^{112}$ ) to be a vital numerical measurement that could signal stenosis. Transverse canal area ratios were used instead of absolute values to compensate for difference in body sizes of the dogs (bigger dogs have bigger vertebral canals and vertebral bodies; and vice versa). Loss of epidural fat at the location of stenosis has also been reported as one of the most frequently observed CT lesions for surgically confirmed stenosis in dogs ${ }^{139}$. To compensate for the difference in body sizes of the dogs and be comparable to CAR (the other measurement), we chose to use FAR (fat-content transverse area with vertebral body transverse area) instead of the absolute values.

Our second hypothesis was that the assessment of LS made by CT quantitative measurements would yield results comparable to current standard qualitative CT assessment of LS in Labrador retrievers. Findings supported one part of our hypothesis but not the other. The previously reported quantitative measurement (CAR) did not 
show statistically significant agreement with the qualitative assessment made by the board certified veterinary radiologist. However, the novel quantitative measurement (FAR) had significant agreement with the standard qualitative assessment of LS. Canal area ratio was found to differ at some vertebral locations in dogs with versus without signs of cauda equine nerve dysfunction ${ }^{112}$, however to our knowledge, no previous papers have compared quantitative and qualitative CT characteristics of stenosis in dogs. There are no reported threshold values for any quantitative traits that measure LS in dogs. The predicted probability curves (based on logistic regression between LS and FAR measurements) supported our study hypothesis in that a decrease in the FAR at a vertebral canal location ( $\mathrm{L} 5 \mathrm{Cd}, \mathrm{L} 6 \mathrm{Cr}$, L6Cd, L7Cr, L7Cd and $\mathrm{S} 1 \mathrm{Cr}$ ) increased the probability of the vertebral location being classified as LS positive by an expert reader. These probability plots provide preliminary evidence that FAR threshold values may be used for determining LS positive or negative status at individual vertebral locations in Labrador retrievers. Further investigations in larger samples of Labrador retrievers are needed to establish the FAR threshold values for LS status in this breed, at each of the vertebral locations of the lumbosacral spine. The process could also be repeated in other breeds of dogs to develop breed-specific FAR threshold values.

This study had the following limitations: small sample size, manual tracing measurements of vertebral canal area and vertebral body area, use of only one radiologist for qualitative assessment and only one observer for the quantitative measurements, and different CT technique settings used at the time the scans were acquired. Our choice to focus on Labrador retrievers limited our sample size, but helped minimize outside variability due to breed differences that could have interfered with our analyses. We attempted to maximize the sample size by seeking cases from 3 different hospitals. We also included a dog whose scan covered only four of the six locations, to maximize the sample size for the available four locations.

The study had roughly equal number of LS positive and LS negative dogs (11 LS negative and 14 LS positive). Dogs older than 5 were overrepresented in the LS positive 
group (average age $=8.07 \pm 0.99$ ). Males were affected more than females in the LS positive group (in agreement with previous reports). Low back pain status did not have good agreement with LS status (also consistent with previous reports). Only 6 of the 14 LS positive dogs were also LBP positive, and 5 out of these 6 dogs were older than 5 years of age. Findings subjectively supported the theory that younger LS positive dogs may not initially present with clinical signs of LBP and that the likelihood of lower back pain detection may increase with age, however no statistically significant association could be demonstrated due to small sample size. Small sample size also inhibited the testing of associations between qualitative LS assessments and any of the other demographic data - none were significant.

Making triplicate measures and using an average of these measures for analyses minimized observer effects in manual measurements. Using only one observer for the measures and one radiologist, another external source of variability was minimized. However this prevented us from performing inter-observer repeatability tests for the methodology. Being a retrospective study, the study had no control over the technical CT settings used at the time of the scan - another possible source of external variability. But this could also be an advantage since the results can be applicable to a wide range of $\mathrm{CT}$ settings. Attempts were made to reduce variability due to different technical settings by standardizing the settings in the image analysis freeware (Osirix) while making measurements. So, findings from the current study indicate that CT FAR measurements yield comparable results to qualitative CT assessment of LS by an expert reader for Labrador retrievers. Further studies are needed to verify the efficacy of FAR as a research tool for quantitative phenotyping of LS in Labrador retrievers as well as in other breeds of dogs. 
Figure III.1.

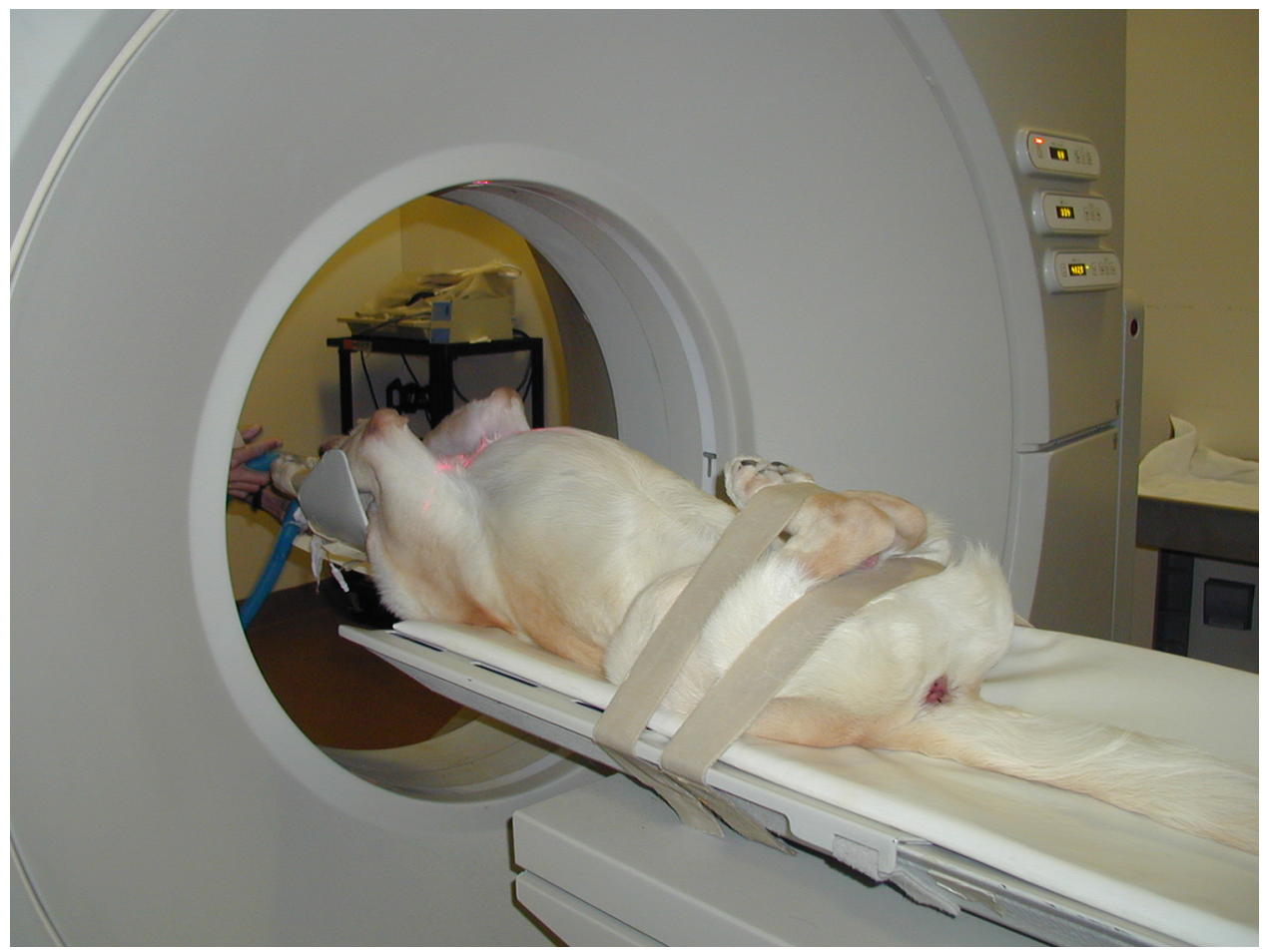

Figure III.1. Positioning of a dog for acquiring CT scan of the lumbosacral spine.

Photograph of a Labrador retriever positioned for CT scanning of the lumbosacral spine. The dog is under general anesthesia and positioned in dorsal recumbency on the CT table with the hind limbs flexed in order to flatten the lumbosacral angle.

Credit: Veterinary Teaching Hospital, Virginia-Maryland College of Veterinary Medicine 
Figure III.2.

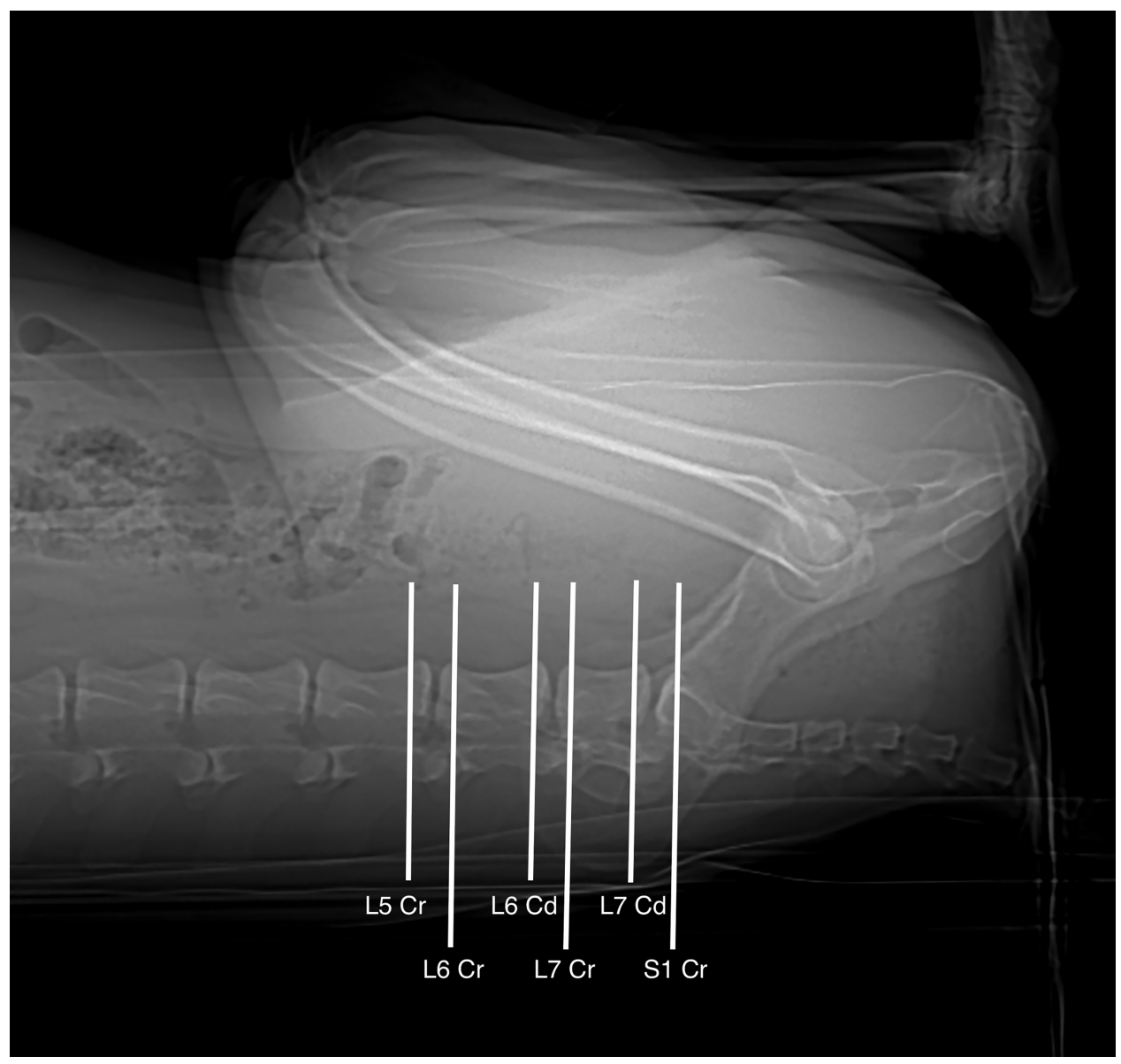

Figure III.2. Lateral CT image depicting the six measured locations of the canine lumbosacral spine

Lateral localizer CT image of the lumbosacral region illustrating the locations where canal and fat area measurements were acquired. $\mathrm{L} 5 \mathrm{Cd}=$ caudal portion of the $5^{\text {th }}$ lumbar vertebra, L6 $\mathrm{Cr}=$ cranial portion of the $6^{\text {th }}$ lumbar vertebra, L6 Cd = caudal portion of the $6^{\text {th }}$ lumbar vertebra, $L 7 \mathrm{Cr}=$ cranial portion of the $7^{\text {th }}$ lumbar vertebra, L7 $\mathrm{Cd}=$ caudal portion of the $7^{\text {th }}$ lumbar vertebra and $\mathrm{S} 1 \mathrm{Cr}=$ cranial portion of the $1^{\text {st }}$ sacral vertebra. 
Figure III.3.

A

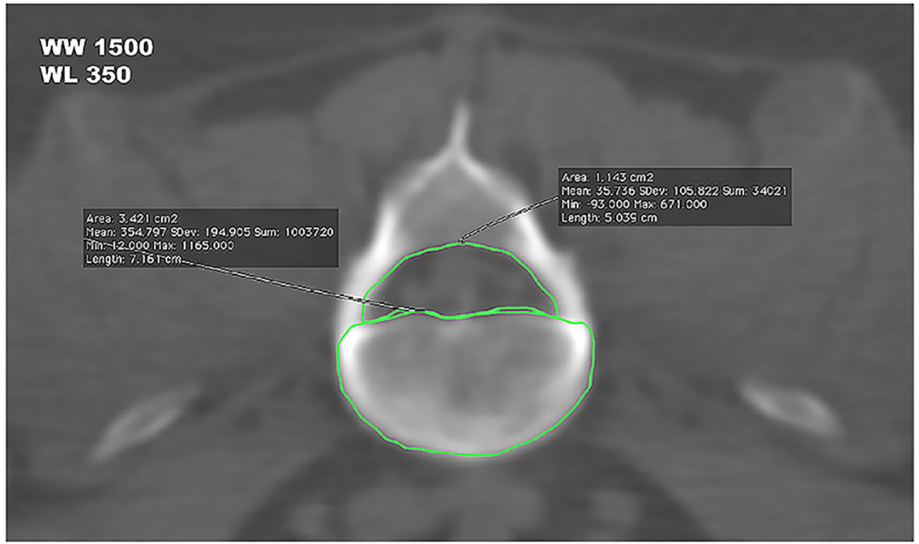

B

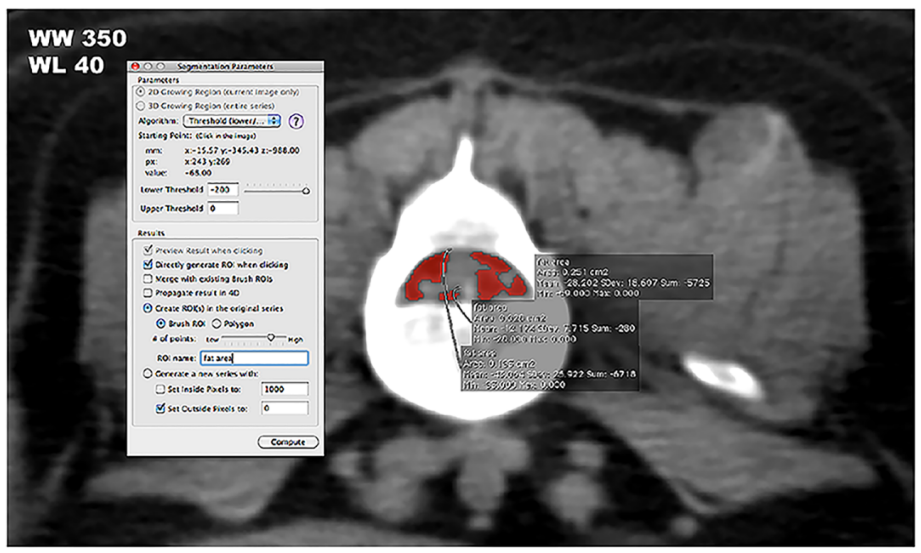

Figure III.3. Representative screenshots illustrating the methodology for the quantitative measurements

(A) Transverse bone window CT image of the lumbosacral spine at L6 caudal location illustrating the regions of interest $(\mathrm{ROI})$ that were hand-drawn for vertebral canal area and vertebral body area measurements (B) Transverse soft tissue window CT image of the lumbosacral spine at the same location in the same dog illustrating the automated ROls that were generated for vertebral canal fat area measurements. 
Figure III.4.

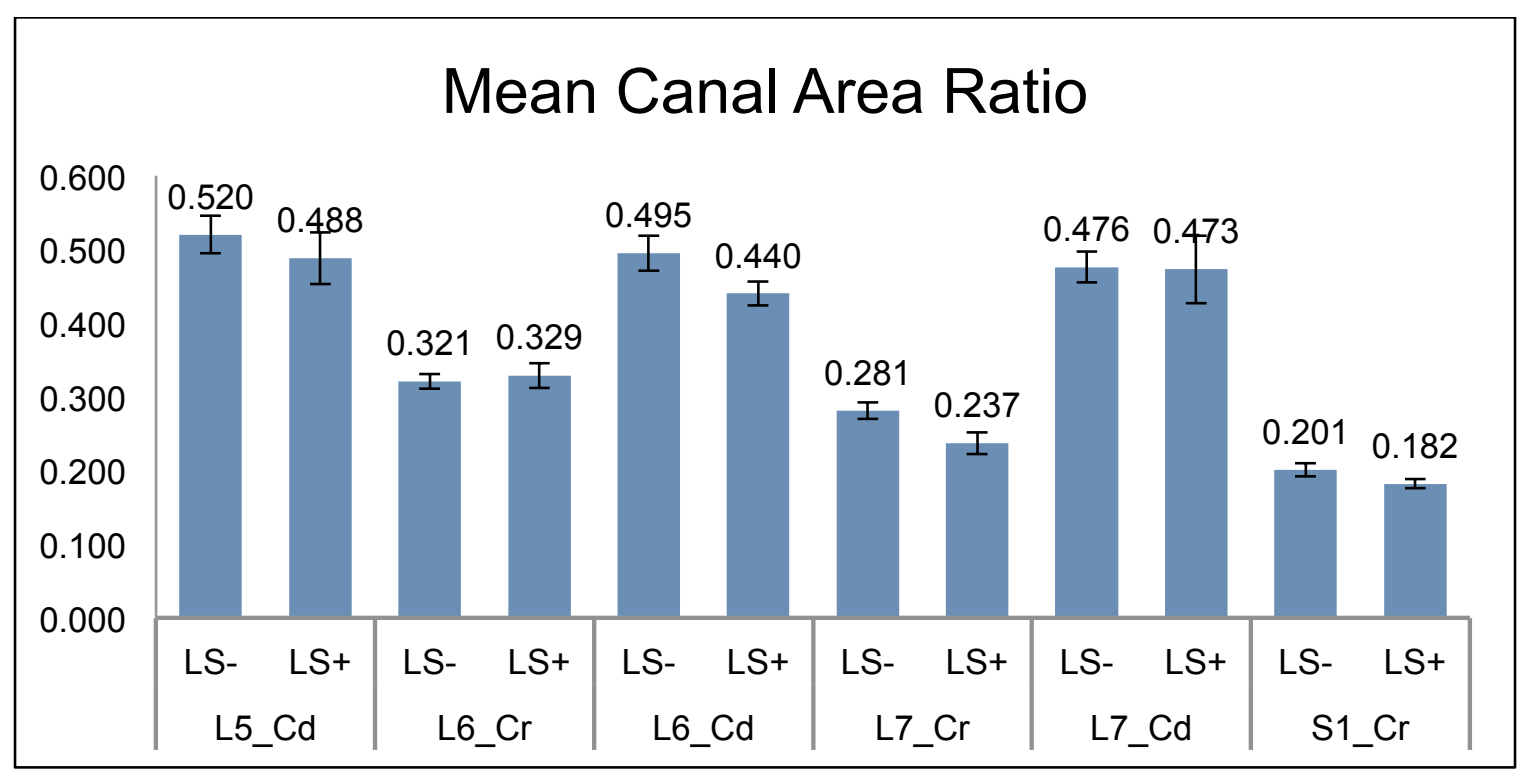

Figure III.4. Mean canal area ratio comparisons between LS-positive and LS-negative dogs. Significant difference $(p \leq 0.05)$ is denoted by $\left({ }^{*}\right) . N=25$ except at $5^{\text {th }}$ caudal and $6^{\text {th }}$ cranial lumbar vertebra $(n=24)\left({ }^{\Psi}\right)$. 
Figure III.5.

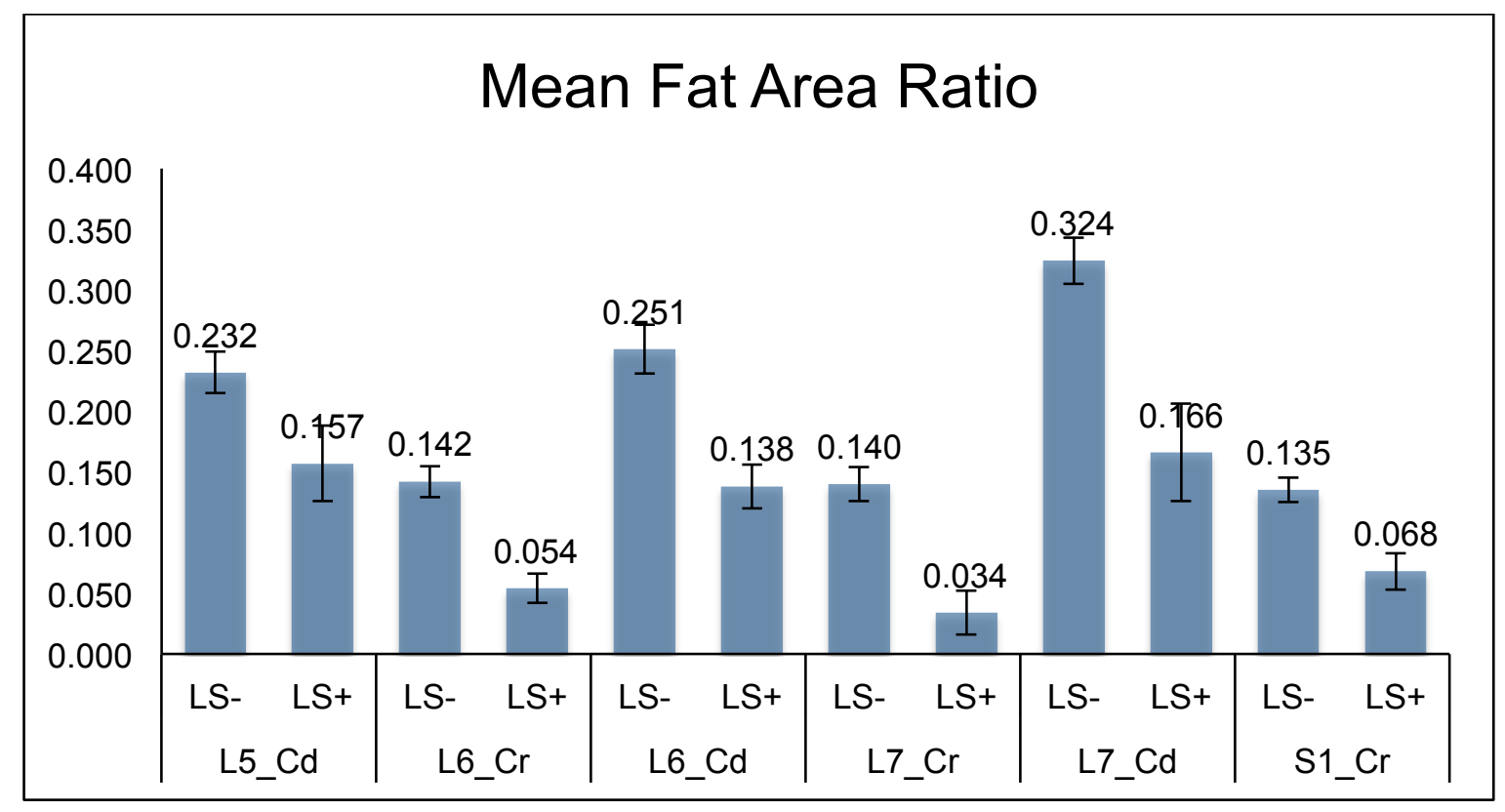

Figure III.5. Mean fat area ratio comparisons between LS-positive and LS-negative dogs. Significant difference $(p \leq 0.05)$ is denoted by $\left(^{*}\right) . N=25$ except at $5^{\text {th }}$ caudal and $6^{\text {th }}$ cranial lumbar vertebra $(n=24)\left({ }^{\psi}\right)$. 
Figure III.6.
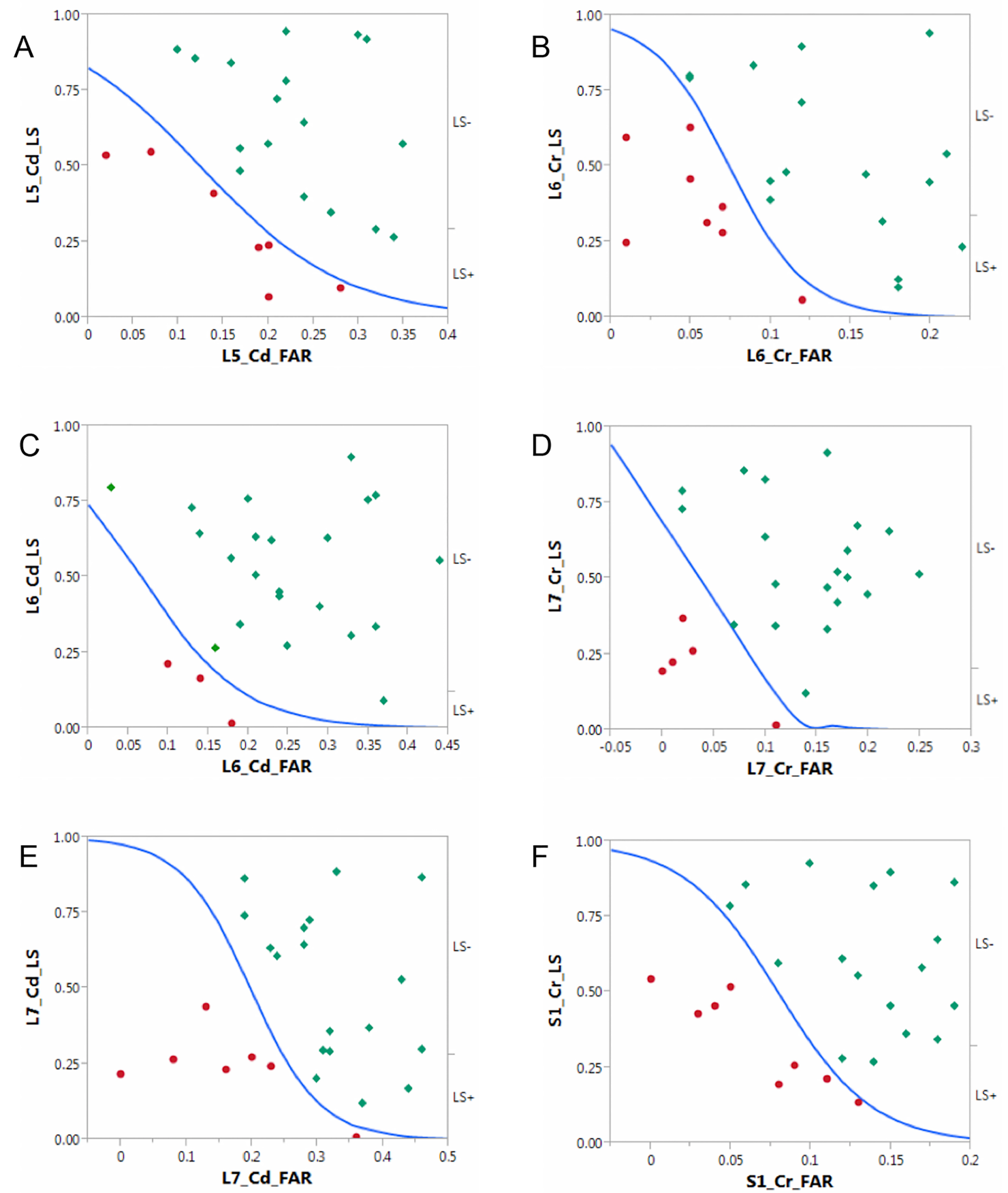
Figure III.6. Logistic regression between quantitative measurements and qualitative assessment of lumbosacral stenosis

Logistic regression between the quantitative fat area ratio measurements and the qualitative CT diagnoses of lumbosacral stenosis for each of the six vertebral locations (A) L5Cd: caudal end of $5^{\text {th }}$ lumbar vertebra; (B) L6Cr: cranial end of $6^{\text {th }}$ lumbar vertebra; (C) L6Cd: caudal end of $6^{\text {th }}$ lumbar vertebra; (D) L7Cr: cranial end of $7^{\text {th }}$ lumbar vertebra; (E) L7Cd: caudal end of the $7^{\text {th }}$ lumbar vertebra; $(F)$ S1Cr: cranial end of the $1^{\text {st }}$ sacral vertebra 
Figure III.7.
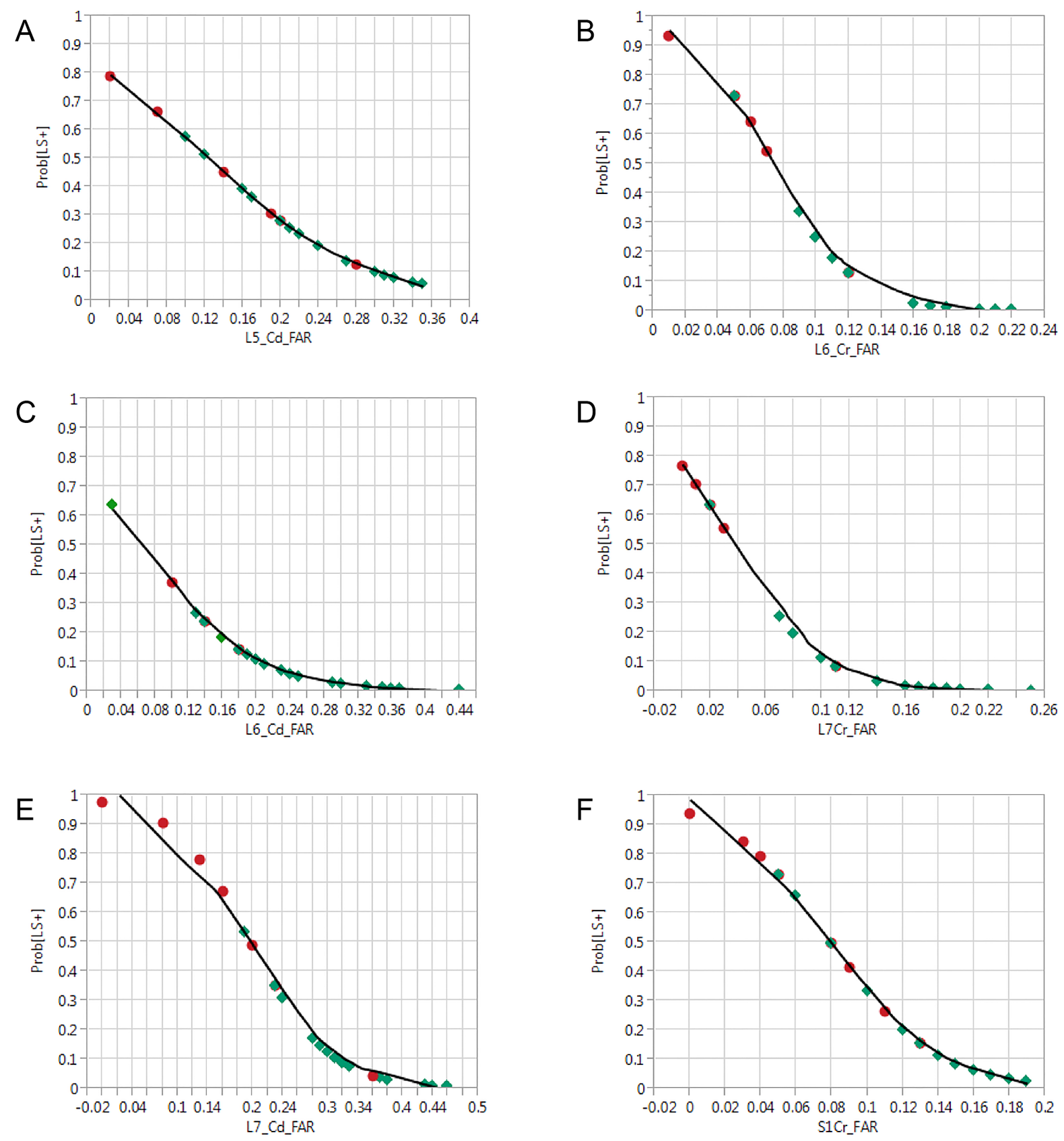
Figure III.7. Predicted probabilities for being LS-positive at each of the six vertebral locations

Probability of being LS-positive has been predicted based on the logistic regression analysis between the novel quantitative measurement of stenosis (fat area ratio or FAR) and the standard qualitative CT diagnosis of being LS-positive for each vertebral location (A) L5Cd: caudal end of $5^{\text {th }}$ lumbar vertebra; (B) L6Cr: cranial end of $6^{\text {th }}$ lumbar vertebra; (C) L6Cd: caudal end of $6^{\text {th }}$ lumbar vertebra; (D) L7Cr: cranial end of $7^{\text {th }}$ lumbar vertebra; (E) L7Cd: caudal end of the $7^{\text {th }}$ lumbar vertebra; (F) S1Cr: cranial end of the $1^{\text {st }}$ sacral vertebra. 
Table III.1. Clinical data demography of the study samples

\begin{tabular}{|l|l|l|}
\hline Group & CT LS negative & CT LS positive \\
\hline Number & 11 & 14 \\
\hline Average Age & $4.45( \pm 1.08)$ & $8.07( \pm 0.99)$ \\
\hline Age Range & $1-11$ & $1-14$ \\
\hline Sex & $8 \mathrm{M}, 3 \mathrm{~F}$ & $9 \mathrm{M}, 5 \mathrm{~F}$ \\
\hline Average Weight & $31.35( \pm 1.22)$ & $33.07( \pm 1.69)$ \\
\hline Weight Range & $25.7-40.4$ & $23.6-44.0$ \\
\hline Working status & $6 \mathrm{~W}, 5 \mathrm{NW}$ & $2 \mathrm{~W}, 12 \mathrm{NW}$ \\
\hline Low back pain (LBP) status & 3 positive, 8 negative & 6 positive, 8 negative \\
\hline
\end{tabular}

Legend:

\begin{tabular}{|l|l|}
\hline CT - computed tomography & LS - lumbosacral stenosis \\
\hline M - male & F - female \\
\hline W - working & NW - non-working \\
\hline
\end{tabular}


Table III.2. T-test $p$-values for canal area ratio and fat area ratio comparisons between LS-positive and LS-negative dogs

\begin{tabular}{|l|l|l|}
\hline \multirow{2}{*}{ Vertebral location } & T-test p-values \\
\cline { 2 - 3 } & Canal area ratio (CAR) & Fat area ratio (FAR) \\
\hline 5th Lumbar caudal (L5_Cd) & $0.2201^{\Psi}$ & $0.0391^{*}{ }^{\Psi}$ \\
\hline 6th Lumbar cranial (L6_Cr) & $0.6205^{\Psi}$ & $<0.0001^{*} \Psi$ \\
\hline 6th Lumbar caudal (L6_Cd) & 0.0723 & $0.0054^{*}$ \\
\hline 7th Lumbar cranial (L7_Cr) & 0.0409 & $0.0010^{*}$ \\
\hline 7th Lumbar caudal (L7_Cd) & 0.4287 & $0.0049^{*}$ \\
\hline 1st Sacrum cranial (S1_CR) & 0.1037 & $0.0005^{*}$ \\
\hline
\end{tabular}

$\mathrm{N}=25$ dogs except where denoted by ${ }^{\Psi}$ ( $\mathrm{n}=24$ dogs)

Difference was defined as significant $\left(^{*}\right)$ when $p<0.05$ after Benjamini-Hochberg correction. 
Table III.3. Logistic regression p-values - quantitative measurements (CAR and FAR) and qualitative CT assessment of stenosis

\begin{tabular}{|l|l|l|}
\hline \multirow{2}{*}{ Vertebral location } & \multicolumn{2}{|l|}{ Logistic regression p-values } \\
\cline { 2 - 3 } & Canal area ratio (CAR) & Fat area ratio (FAR) \\
\hline 5th Lumbar caudal (L5_Cd) & $0.4564^{\psi}$ & $0.0390^{*}$ \\
\hline 6th Lumbar cranial (L6_Cr) & $0.7251^{\psi}$ & $0.0003^{*}$ \\
\hline 6th Lumbar caudal (L6_Cd) & 0.3467 & $0.0449^{*}$ \\
\hline 7th Lumbar cranial (L7_Cr) & 0.0685 & $0.0011^{*}$ \\
\hline 7th Lumbar caudal (L7_Cd) & 0.9307 & $0.0008^{*}$ \\
\hline 1st Sacrum cranial (S1_CR) & 0.1799 & $0.0011^{*}$ \\
\hline
\end{tabular}

$\mathrm{N}=25$ dogs except where denoted by ${ }^{\psi}$ ( $\mathrm{n}=24$ dogs)

Significance is denoted by $\left(^{*}\right)$ when $p \leq 0.05$ after Benjamini-Hochberg correction. 


\section{CHAPTER IV. GENETIC CHARACTERIZATION OF LUMBOSACRAL STENOSIS IN LABRADOR RETRIEVERS}

\section{IV.1: Introduction}

Working dogs are high-performance athletes and vital members of teams that support public service, national security and military missions in the U.S. and around the world 1 . Working dogs perform a variety of tasks such as sentry-and-patrol duty; search and rescue; mobility support for disabled persons; and detection of explosives, arson accelerants, illegal drugs. Labrador retrievers are one of the most popular choices for use as detection dogs ${ }^{3,14}$. The demands for detection dogs have been increasing over recent years ${ }^{3}$. In particular, military forces worldwide recognize military working dogs (MWDs) as "force multipliers". An American Forces Press Service release (October, 2015) estimated the US military to have around 2,300 MWDs (http://usmilitary.about.com/od/jointservices/a/militarydogs.htm). The dogs represent all branches of the military, and together with their handlers they are deployed worldwide to serve American interests. All branches of the U.S. military consider MWDs to be vital for accomplishment of their missions and invest major financial and personnel resources each year to procure, train and maintain these working dogs. According to a 2011 US Government Pentagon memo, typical purchasing and training costs for a high quality MWD can range anywhere in between $\$ 20,000$ to $\$ 40,000$ US dollars (depending on the nature of MWD's assignments, and whether the dog is trained for multiple types of tasks) (http://www.nytimes.com/2011/05/12/world/middleeast/12dog.html?_r\&_r=0). The demand for high quality dogs working dogs is increasing; along with the cost of breeding, raising and subsequent training of the dogs. This has resulted in a decrease in the availability of new dogs. Therefore, ideally the military needs to have dogs that can maintain functionality for as long as possible. Once they are trained, the service lifetime of a typical MWD is expected to average about $10-12$ years of age (http://todaysmilitary.com/videos/a-military-working-dog-handler). Early retirement of a 
trained MWD would mean not just a financial loss for the US Military, but also a functional loss for the productivity of the team that depends on the particular dog.

Spinal diseases are one of the leading causes for early retirement in MWDs 2. Lumbosacral stenosis (LS) is the most common pathological condition that affects the canine lumbosacral spine, especially the large breed dogs like German shepherds

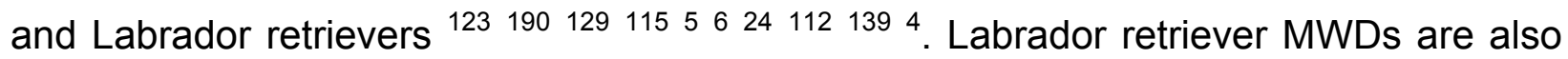
affected by LS ${ }^{16}$. Lumbosacral stenosis in dogs is defined as an abnormal narrowing of the lumbosacral canal, vertebral canal, and/or the intervertebral foramina ${ }^{7}$. This morphologic problem is a risk factor for disability due to compression of the underlying neural and/or vascular tissues. This compression can in turn be a risk factor for clinical conditions such as cauda equina syndrome (CES) ${ }^{8}$. Low back pain (LBP) on palpation of the lumbosacral spine is the primary clinical sign of LS in the majority of dogs ${ }^{114}$. However, disadvantages of diagnosing LS based on LBP status alone include the following: (i) symptoms can be intermittent with appearance only after hard physical exertion; (ii) symptoms can mimic those of other spinal diseases like intervertebral disc degeneration (IVDD) diseases ${ }^{131}$, degenerative sacroiliac joint disease (DSJD) ${ }^{132}$, foraminal stenosis ${ }^{133}$, and Schmorl's nodes ${ }^{134}$; (iii) stoic dogs may not consistently vocalize pain; and (iv) Labrador retrievers are specifically bred to be stoic and have high-drive - qualities desirable for the MWD job description but can also cause a delay in detection of sub-clinical conditions like LS. A dog can be structurally LS positive, but clinical signs can be absent until the condition worsens to such an extent that therapeutic and surgical options are no longer viable, and the only course of action for the military is retirement (and in severe cases euthanasia). Therefore improved methods for early detection of LS are critical for minimizing the risk of early retirement in these valuable canine athletes.

Computed tomography (CT) is a well-established non-invasive diagnostic imaging technique used for clinically diagnosing LS in dogs ${ }^{136} 188$. The commonly observed CT abnormalities in dogs with surgically confirmed cases of LS include: loss of epidural fat, 
increased soft tissue opacity, bulging in the intervertebral disc margin, spondylosis, displacement of the thecal sac, narrowed intervertebral foramina, narrowed vertebral canal, thickened articular processes, subluxation of the articular processes, bone spurs in the articular processes, and telescoped sacral lamina ${ }^{139}$. Quantitative phenotyping of LS using canal area measurements in large dogs of multiple breeds have also been previously reported and correlated with clinical cauda equina syndrome ${ }^{112}$. However, unless a dog presents with clinical signs of pain or discomfort, expensive imaging studies such as CT are not routinely performed and the condition can go undetected until the damage is irreversible. Therapeutic interventions are more effective in younger military working dogs with LS and mild clinical signs, and more likely to achieve a successful return to active duty status ${ }^{16,187}$. In humans, CT is an established technique for qualitative and quantitative "deep phenotyping" of structural abnormalities before they cause clinical disease. Examples include valvular calcification and aortic stenosis in heart valve disease ${ }^{203}$, airway obstruction and parenchymal destruction in chronic obstructive pulmonary disease or COPD ${ }^{113}$, emphysema 204205 and bone density abnormalities in cystic fibrosis ${ }^{206}$. Computed tomography has also been used for qualitative phenotyping and making in vivo measurements of bones in experimental mouse models ${ }^{207}$.

An improved understanding of the genetic mechanisms underlying LS would also be highly beneficial for reducing the risks of early retirement in working dogs. Similar to the orthologous human condition of lumbar spinal stenosis (LSS), canine LS has two distinct etiologies: either congenital (idiopathic and developmental) or the more common acquired (degenerative and post-traumatic) ${ }^{17}$. Studies have reported association between genetic polymorphisms in collagen genes (COL9A2 and COL11A2) and degenerative LSS in humans ${ }^{20}$. Developmental human LSS is usually observed in individuals affected by achondroplasia ${ }^{93}$, and has known genetic causes ${ }^{208}$. Canine LS studies have also suggested that LS might have genetic influences that can manifest itself at an early age ${ }^{9}{ }^{11}$. This genetic predisposition has been predominantly accounted for by the congenital anomaly of lumbosacral transitional vertebra (LTV) - an 
abnormally formed vertebra usually between the last lumbar and first sacral vertebra ${ }^{12}$ ${ }^{13}$. Presence of LTV can often cause CES due to abnormally narrow spinal canal (LS) ${ }^{10}$. However no genomic exploration studies investigating the genetics of LS in Labrador retrievers could be found at the time of manuscript preparation.

Genetic variation is the most common factor underlying most disorders - for both Mendelian and non-Mendelian (complex) disorders ${ }^{209}$. In fact, of all known Mendelian disorders that have been studied and the causes identified (around 2,600), approximately $85 \%$ are due to mutations in the coding region or the "exome" 210 . Genome wide association studies (or GWAS) have been the most widely used approach to study the complex disorders ${ }^{211}$. However, most GWAS, even the large scale ones, have been unable to explain the entire contribution of genes to most diseases ${ }^{212}$, and often the most significant variant detected is not always the actual causative locus ${ }^{213}$. The underlying reason for this limitation is that even though GWAS can detect multiple genes in most complex diseases, it cannot account for the interaction of the multiple genes with each other and with the environment ${ }^{214}$. Furthermore, each of the identified risk alleles in most complex disorders usually has small effects ${ }^{215216}$, suggesting the presence of other rare variants with relatively larger effects ${ }^{217} 218$. Theoretically, including the full sequence data and increasing the sample size should overcome this limitation, but the process would be computationally and statistically complicated ${ }^{213}$. Another disadvantage of GWAS is the requirement of large sample sizes, a factor that can be a disadvantage in exploratory studies - both due to cost and logistics. Whole exome sequencing (WES) is a better alternative approach for exploring the underlying genetic mechanisms of both Mendelian disorders and complex multi-factorial diseases 219220216 . Since coding regions constitute approximately $1 \%$ of the whole genome, WES is an efficient, cost-effective and sensitive method for exploring the genetics of a complex disorder. Another factor to consider when designing a study, the analysis of variations in the non-coding region of the genome is mostly beyond the grasp of current genetic tools available to researchers. Some of the diseases in which WES has become a common approach include cancer ${ }^{221}$; autism ${ }^{222}$ 
223; hereditary myopathy in respiratory failure ${ }^{224}$; osteogenesis imperfecta and Marfan's syndrome ${ }^{225}$. The ready availability of relatively inexpensive (compared to whole genome sequencing) off-the-shelf human exome-capture platforms also aids the entire process in exploratory studies. Due to homology between the human and other mammalian genomes (mouse, rat, dogs, cows to name a few), the human kits can also be used to study the exomes of other species as well.

In this prospective exploratory study, our objective was to explore the canine exome to identify possible variants that might be associated with LS in a sample cross-sectional population of MWD Labrador retrievers. Computed tomography imaging was used to phenotype LS, and genotyping of LS was done by whole exome sequencing using a commercially available platform (Nextera Rapid Exome Capture kit, Illumina, San Diego, CA). Additionally, candidate genes from human LSS studies were also investigated to test whether humans and dogs any of the candidate genes in common with each other. 


\section{IV.2: Materials and Methods}

\section{Subjects}

Forty Labrador retriever military working dogs (MWDs) were prospectively selected from the MWD population housed at the US Air Force Base in Lackland AFB San Antonio, TX. Presence during the time of data collection (from July 8, 2013 to July 13, 2013) was one of the selection criteria. The other criterion for inclusion in the study, besides the breed and physical presence, was the age of the dog - the dog had to be between 1 and 5 years of age. Attempts were made to ensure an approximately equal number of males and females, as well as an approximately equal number of yellow and black colored dogs. The dogs had to be available for CT scanning and physical examination. The study had necessary IACUC approval from both the Behavioral Medicine and MWD Studies Department of US Armed Forces Research Office (Department of Defense Military Working Dog Veterinary Services or DODMWDVS) and the West Virginia University Research Office.

\section{Data recorded}

All data were collected by a single individual $(\mathrm{JJ})$ with the help of personnel at the Holland Military Working Dog Hospital (Lackland AFB, San Antonio, TX). The demographic data collected included dog name and ID number, age, gender, breeder/vendor (if available) and dog duty status.

After selection for the study, each dog was brought to the military working dog hospital (within the premises of the Lackland AFB) by the handler to be examined by an experienced veterinarian for ruling out any medical concerns with sedation. The veterinarian performed a complete physical examination for each dog and recorded dog coat color and presence or absence of each of the following clinical signs: reaction to palpation of the LS junction, reaction to elevation of the tail, or reaction to extension of the hip joints. The veterinarian interviewed the dog's handler and other technical staff to record approximate times the dog spent performing tasks such as jumping up onto or climbing over obstacles, or assuming an upright stance. Presence or absence of a 
history of reluctance to perform working tasks was also recorded. When available, the dog's pedigree was also recorded.

Using a 3cc syringe and either a 22 or 20 -gauge needle, blood was drawn from the cephalic vein of each dog and collected on commercially available sample collection cards (Whatman ${ }^{\mathrm{TM}}$ FTA $^{\mathrm{TM}}$ cards, GE Healthcare UK Limited, Buckinghamshire, UK). Care was taken to ensure that the card was not saturated with blood to reduce the loss of efficiency during downstream DNA extraction process, also to decrease the time necessary for complete drying of the blood sample in the initial collection phase. After the cards were completely dry (approximately one hour as per the manufacturer's instructions), they were inserted in specially designed and labeled protective pouches for uncontaminated (both bacterial and fungal) transport of the samples. Care was also taken to avoid cross contamination between cards. The FTA ${ }^{\mathrm{TM}}$ cards were then stored in airtight boxes at room temperature, in a dry location, and out of direct sunlight to prevent mold growth and degradation of the genetic material.

Dogs were sedated using the hospital's standard sedation protocols and the CT scanner (Lightspeed, GE Medical Systems, Pewaukee, WI) present within the hospital premises was used to collect trans-axial scans of the lumbar and lumbosacral spine (L4 caudal - S1 cranial vertebrae). The following technical settings were used: axial mode, $0.625 \mathrm{~mm}$ slice thickness, $120 \mathrm{kVp}, 100 \mathrm{~mA}$, body filter, and bone convolution kernel. For each scan, dogs were positioned in dorsal recumbency. Scans were acquired with the rear limbs first placed in a maximally extended position and then repeated with the rear limbs placed in a maximally flexed position. The hospital's CT technologist under the supervision of a licensed veterinarian completed all positioning and scanning procedures. A standardized protocol for positioning was provided to the technologist to use as a reference. 


\section{Phenotyping}

Qualitative CT phenotyping was done for all 40 dogs in 8 vertebral locations, encompassing the cranial and caudal ends of 4 lumbar (L4, L5, L6 and L7) and 1 sacral (S1) vertebra - L4 caudal, L5 cranial, L5 caudal, L6 cranial, L6 caudal, L7 cranial, L7 caudal, and S1 cranial. Using standard criteria for CT radiological diagnosis of LS in dogs, a single licensed veterinary radiologist $(\mathrm{JJ})$ assigned all 40 dogs to one of two groups - LS negative or control (no structural stenosis found at any of the 8 locations); and LS positive or affected (structural stenosis observed in at least in one of the 8 locations). In the previous phenotyping study (chapter III), we found a strong association between presence of qualitative structural LS and cross-sectional canal FAR (fat area ratio) values for the 6 vertebral locations analyzed (L5 caudal, L6 cranial, L6 caudal, L7 cranial, L7 caudal, and S1 cranial). So the FAR values were also calculated in this current study for the quantitative CT phenotyping of LS in these 40 dogs (technique described in chapter III), but for 8 vertebral locations instead of the original six. Fat area ratio values for all 40 dogs were then listed in a descending order. The top ten dogs (highest FAR values $=$ LS negative/control) and the bottom ten dogs (lowest FAR value = LS positive/affected) were selected for each of the 8 locations. The 4 dogs that appeared the most number of times (high frequency) in the top ten list across all 8 locations, had the highest FAR values, and were qualitatively LS negative were selected to represent LS negative (control) dogs in the follow-up genetic analysis. Similarly, the 4 dogs with the highest frequency in the bottom ten list across all 8 locations, lowest FAR values, and qualitatively LS positive were selected to represent LS positive (affected) dogs in the genetic study.

\section{Genotyping}

Three separate attempts were made to extract genomic DNA from the peripheral blood collected on commercially available sample collection cards (FTA ${ }^{\mathrm{TM}}$, GE Healthcare UK Limited, Buckinghamshire, UK) and analyzed with 3 different commercially available DNA extraction kits (using standard manufacturer recommended protocols). First: Whatman ${ }^{\mathrm{TM}}$ FTA $^{\mathrm{TM}}$ Purification Reagent (GE Healthcare UK Limited, Buckinghamshire, UK). Second: Promega Wizard SV Genomic DNA extraction kit (Promega, Madison, 
WI). Third: GenSolve DNA Recovery Kit - GVR-110 (GenTegra LLC., Pleasanton, CA). The GenSolve protocol was the most successful and included an additional blood contamination purification step (QIAamp Blood DNA Mini Kit, QIAGEN, Hilden, Germany). The purified genomic DNA samples were then transported to the Core Genomics Facility at West Virginia University (Morgantown, WV) for sequencing and bioinformatic analyses.

\section{Exome sequencing and Bioinformatics}

A commercially available exome capture kit (Illumina Nextera Rapid Exome Capture kit, Illumina Inc., San Diego, CA) was used for exome enrichment and capture, followed by rapid exome sequencing in the commercially available bench-top sequencer (MiSeq System, Illumina Inc., San Diego, CA). The personnel at the WVU Genomics Core Facility (West Virginia University, Morgantown WV) carried out all sequencing reactions including the library preparations, using manufacturer recommended protocols without any modifications. Though the kit is designed to capture human exomes there is enough sequence homology between humans and dogs (Illumina application note http://www.illumina.com/products/nextera-rapid-capture-exome-kits.ilmn) to ensure a successful canine exome capture with a large coverage area. The white paper published by Illumina claims a success rate of $85 \%$ for canine exons with $>80 \%$ homology with human exons, while canine exons with $<80 \%$ homology had a capture success rate of $18 \%$. The MiSeq sequence data were not recorded (since the workstation is programmed to automatically map to the human reference genome) instead the raw files were selected for bioinformatic analysis.

The Genomic Core Facility of West Virginia University also carried out part of the bioinformatic analysis in this study. The quality of the raw exome reads was analyzed using FastQC ${ }^{226}$; and Trimmomatic ${ }^{227}$ was used to filter out bad reads. The retention criteria were: leading bases with quality higher than 25 , trailing not less than 20 , four base sliding window cutoff of 25 and reads over 50 bases long. Each sample exome was then mapped to the reference dog genome CanFam3.1 (Broad CanFam3.1/canFam3 Assembly, September 2011) using Bowtie2 ${ }^{228}$ (with default 
parameters); followed by variant calling using SAMtools ${ }^{229}$ and BCFtools ${ }^{230}$, respectively. SnpEff ${ }^{231}$ was used to annotate each called variant, generating a variant call file (VCF). Another round of annotation was carried out to remove variants not called in all 8 samples, creating a second VCF file. The genomics core facility provided this second VCF file to the authors for further analysis (MM). A commercially available sequence annotation software package (Golden Helix SNP and Variation Suite, Golden Helix Inc., Bozeman, MT) was used to differentiate between the 4 LS negative dogs and the 4 LS positive dogs. The VCF file was filtered using the column selection by sample genotype tool of the software. Two separate selection settings were used to identify variants between the 2 groups - 4 LS negative or control dogs and 4 LS positive or affected dogs (with "a" control or reference allele; "b" is the affected or alternate allele; "a/a" and "b/b" = homozygous for reference and alternate alleles respectively; and "a/b" is heterozygous). The $1^{\text {st }}$ setting was: control = "a/a", and affected $=$ "b/b". And the $2^{\text {nd }}$ setting was: control = "a/a", and affected $=$ "a/b" or "b/b". The $2^{\text {nd }}$ setting was designed to account for dogs being carriers of the condition (LS) in the heterozygous state. Exonic variants were identified by aligning the variant list with the canine reference genome ${ }^{146}$ CanFam3.1 (September, 2011 assembly release) ${ }^{232}$ with the University of California Santa Cruz (UCSC) genome browser ${ }^{233} 234$ (http://genome.ucsc.edu/cgibin/hgGateway?hgsid=491971977_8JlhYf9FMf1aywMqaevxvSn9eGbg\&clade=mammal \&org $=D o g \& d b=0)$. The list of variants was annotated using a variant effect predictor web interface (VEP, Ensembl Gene annotation v83, December 2015) ${ }^{235}$. Since not all canine genes have been characterized, predicted genes were recorded (based on Ensembl predicted gene sets). The National Center for Biotechnology Information (NCBI) Basic Local Alignment Search Tool (BLAST) ${ }^{236}$ was used to calculate percentage homology for the predicted canine gene sequences with the human and mouse reference gene sequences. The biological significance (i.e. association with clinical disorders) of the identified genes reported in either $\mathrm{NCBI}{ }^{237}$ or Ensembl ${ }^{238}$ databases were also recorded. 
A separate analysis was done to call on any variants previously reported as human LSS candidate genes - genes associated with other closely related musculoskeletal diseases like osteoarthritis (OA), Paget's disease, degenerative disc disease (DDD), ossification of posterior longitudinal ligament (OPLL), osteogenesis imperfecta (OI) and Ehlers Danlos syndrome (EDS). The parameters in this second analysis were the same as the previous analysis - the 4 control dogs were either "a/a" or "a/b"; and the 4 affected dogs were either "a/b" or "b/b". 


\section{IV.3: Results}

\section{Subjects}

The 40 Labrador retrievers selected for this study comprised of 20 males and 20 females. Even though we set out to get equal number of black and yellow dogs, the study ended up with 24 black and 14 yellow dogs, and 1 chocolate colored Labrador retriever; the remaining single dog's coat color record was unavailable. The average body weight of the study population was 28.48 kilograms (range $22.00-38.56$ pounds). Based on qualitative phenotyping (CT assessment) by the board-certified radiologist (JJ), 33 dogs showed signs of structural stenosis in at least one of the eight vertebral locations and the remaining 7 dogs were free from stenosis in all 8 locations. Sixteen of the 40 dogs were negative for signs of LBP (in the lumbosacral region) on physical examination during data collection (CT scanning and blood collection). The remaining 24 dogs did displayed equivocal signs of pain during physical examination. The study subject demographics are described in Table IV.1.

The 8 dogs selected from aforementioned 40 dogs for whole exome sequencing (WES) had individuals representing the entire age range of the study i.e. 1 to 5 years. The 4 most LS negative dogs were all females and aged between 1 and 3 years. Three of the LS negative dogs were related to each other - one dam and two offsprings. The 4 most LS positive dogs were all males and aged between 3 and 5 . There was poor agreement between LBP status and qualitative assessment of stenosis. Only one out of the 4 LS negative dogs was negative for signs of LBP, while only two of the 4 LS positive dogs showed signs of LBP. The demographic data of the 8 dogs selected for WES are described in Table IV.3.

\section{Phenotyping}

The 8 dogs were selected for exome sequencing based on both fat area ratio (FAR) values as well as qualitative criteria for LS. The maximum and minimum FAR values at each of the 8 vertebral locations for each of the two groups of 4 (i.e. 4 LS negative and 
4 LS positive dogs) selected to depict the extremes of the phenotype of LS after first round of selection (but genetic samples lost) are presented in Table IV.2.A. The maximum and minimum FAR values at each of the 8 vertebral locations for the 8 dogs selected for exome sequencing to represent the extremes of phenotype after second round of selection are shown in Table IV.2.B. In the 8 dogs selected in first round, the smallest FAR values for the LS negative dogs was larger than the highest FAR values of LS positive dogs at 7 of the 8 vertebral locations. In the 8 dogs from the second round of selection (whole exome sequencing samples), the lowest FAR values in the LS negative dogs was also larger than the highest FAR values of the LS positive dogs, but in 5 of the 8 locations (instead of the 7 in $1^{\text {st }}$ round of selected dogs). Dogs selected in both rounds as either LS negative or LS positive had agreement with the qualitative CT diagnosis of LS.

\section{Genotyping}

The Nextera Rapid Exome Capture kit requires a minimum concentration of $5-\mathrm{ng} / \mathrm{\mu l}$ DNA in a final volume of $10-\mu \mathrm{l}$ (50 $\mathrm{ng}$ total). The first method of extracting genomic DNA from blood on $\mathrm{FTA}^{\mathrm{TM}}$ cards using $\mathrm{FTA}^{\mathrm{TM}}$ purification reagent was mostly unsuccessful in yielding any usable DNA. The second method using Promega Wizard SV Genomic DNA extraction kit (using standard manufacturer recommended protocol) did yield some DNA, but the quality was compromised by blood contamination and insufficient quantity for high resolution downstream sequencing reactions. An unfortunate outcome from this second method attempt was the loss of samples from the 8 dogs that best met the selection criteria. A second round of phenotyping selection was done to get the next best 8 dogs (4 LS negative and 4 LS positive) that also met the selection criteria. The third method using GenSolve DNA Recovery kit had the best performance of the 3 methods at yielding DNA of sufficient quality and quantity needed for sequencing reactions. The genomic DNA yield from this method (for all 8 samples) ranged between 11.9 and $13.2 \mathrm{ng} / \mu \mathrm{l}$ suspended in a final solution volume of $100 \mu \mathrm{l} A E$ buffer (QIAGEN, Hilden, Germany) - thus more than meeting the minimum requirements of the exome capture kit used (Illumina's Nextera Rapid Exome Capture kit). 


\section{Exome Sequencing and Bioinformatics}

The sequencing runs for all 8 dogs (4 LS negative and 4 LS positive) resulted in fairly even representation among samples. After eliminating poor-quality raw exome reads, alignment with the reference canine genome (Broad CanFam3.1/canFam3 Assembly, September 2011) gave a good alignment value $(95+\%)$. The VCF file provided by the Genomics Core Facility included 110, 980 variants (variants called in all 8 samples). Out of these 110,980 variants, 439 had to be excluded because they could not be assigned to any known canine chromosome number. Golden Helix SVS was used to analyze the remaining 110,541 variants. No exonic variants matching the $1^{\text {st }}$ sample genotype setting i.e. LS negative ("a/a") vs. LS positive ("b/b"). The $2^{\text {nd }}$ sample genotype setting detected 252 variants, i.e. LS negative dogs ("a/a") vs. LS positive ("a/b" or "b/b").

Manual curation identified 82 exonic variants (out of 252). These 82 exonic variants encompassed a total of 33 genes (both annotated and predicted) and the data are represented in Table IV.4. The predicted genes along with their percentage homology with the orthologous human and mouse genes are reported in Table IV.5. The list of 252 variants was also annotated using VEP tool of Ensembl. Twenty-three of the 252 variants did not parse by VEP so could not be analyzed. Out of the 229 variants analyzed, 165 (72.1\%) were novel. All possible consequences of the 229 analyzed variants are summarized in Figure IV.1. Out of all the variants detected that were present in coding regions, majority $(80 \%)$ were synonymous mutations, and the remaining $20 \%$ were missense mutations as depicted in Figure IV.2. VEP was unable to identify any high impact variants (disruptive like protein truncation, loss-of-function or triggering nonsense mediated protein decay); but it was able to identify some moderate impact variants (non-disruptive that might change protein effectiveness) encompassing 10 genes (both annotated and predicted). The variants detected by VEP and assigned as having moderate impact are listed in Table IV.6.. Since not all canine genes have been annotated yet, there are some genes in the list with no known gene symbol, however the genome location was used to match the missing variants with the list 
generated manually. The VEP was also able to identify several low impact variants (assumed to be mostly harmless and/or unlikely to influence protein behavior) spanning a total of 24 genes (also identified by manual curation, see Table IV.5). Thus VEP was able to identify one more gene $(10+24=34)$ than the list of genes identified manually (33). Impact assessment was not possible in the manual method.

Functions and biological significances (previously reported associations with clinical syndromes) of the 33 genes that contain the 82 exonic variants (and matches the sample genotype parameters) are reported in Table IV.7. Of the 10 genes with variants having moderate impact (as identified by VEP), one gene could possibly have an association with LS in Labrador retrievers - Transthyretin (TTR). A missense mutation (preserved protein length but with a different amino acid) was detected in TTR gene. Recent studies have reported that TTR-derived amyloidosis might have an association with Senile Systemic Amyloidosis (SSA) in humans ${ }^{239}$, a condition where amyloid protein deposits can be found on musculoskeletal connective tissues, usually also accompanied by LSS (lumbar spinal stenosis) and cardiomyopathy. Among the 24 genes identified by VEP as having variants with low impact, two genes could also have some association with LS in Labrador retrievers: Folate Receptor 2 (FOLR2), and Ubiquitin Specific Peptidase 9 X-linked (USP9X). Folate Receptor 2 or beta has been known to be associated with osteoarthritis $(O A){ }^{240}$, and association between $O A$ and LSS in humans is well documented. USP9X is an X-linked gene that escapes Xinactivation in mammalian females ${ }^{241}$, so females contain twice the dose of this gene product as males. The sex-specific trend of LS in dogs (males are affected almost twice as females, according to some reports) could mean that LS is an X-linked condition, and USP9X gene product doses being different between males and females could be playing a role in LS disease pathology. The positions of the candidate genes (from human LSS studies) in the canine genome (Broad CanFam3.1/canFam3 Assembly, September 2011) are represented in Table IV.8. No exonic variants were detected in any of the human LSS candidate genes. 


\section{IV.4: Discussion/Conclusion}

To the best of our knowledge, this is the only study that has investigated the genetics of lumbosacral stenosis (LS) in Labrador retrievers. Lumbosacral stenosis is the most common lumbosacral spinal disease affecting large breed dogs like German shepherds and Labrador retrievers. Even though German shepherds is the breed in which LS has been reported the most, most of these studies have also reported the Labrador retrievers as another affected breed (often as a close second according to recorded frequencies). There are several studies that have focused on LS in German shepherds, but as far as we know no other group is actively studying LS in Labrador retrievers another high-risk breed for LS. And with respect to genetic association studies of LS in dogs, none have been reported in any breed (as of the time of this manuscript preparation). Since LS is a naturally occurring disease in both Labrador retrievers and German shepherds, either of the 2 breeds could be a viable model for canine LS, but the growing popularity and vast numbers of Labrador retrievers found in the United States, not only as household pets but also as working dogs (especially detection military working dogs or MWDs), makes Labrador retrievers a popular choice for LS studies.

To make the most of the whole exome sequencing (WES) study, the first strategy is to select the optimum study subjects - usually ones representing the extremes of the phenotype being investigated ${ }^{242}$. With this approach, even a low number of study subjects can yield usable data. Military working dogs are selected and trained to be high-performance athletes. There exists a theory in human medicine that a physically strenuous and active life (like that led by athletes) can result in premature degeneration of the musculoskeletal system, which in turn can lead to early appearance of degenerative diseases - like LS. However there is little scientific evidence to back this statement. A similar theory also exists in canine medicine - and again there is a lack of scientific evidence to support it. Future studies investigating the effects of strenuous exercise on phenotypic expression of degenerative LS are needed in both human and 
canine athletes. Military working dogs would be a desirable study population for this research. In the current study, advantages of using MWD Labrador retrievers from a single military base (Lackland AFB, TX) as the study subjects were: (i) all dogs in the study were present at the same physical location making the logistics of data collection simple; (iii) all the dogs had a highly uniform lifestyle - same diet, same exercise regimen, same healthcare opportunities (Holland Military Working Dog Hospital present inside the military base premises), same living conditions, and all dogs are maintained at a high level of physical fitness ensuring - thereby ruling out several possible sources of external environmental variation that might have influenced the genetic association results; and (iii) the availability of the in-house CT scanner made the acquiring of CT scans for the phenotyping part of the study a much more feasible process. Disadvantages of using this sample population were that results might not be generalizable for other breeds and other types of work. Another limitation of this population is the absence of pedigree records for majority of the dogs due to procurement from a variety of vendors. This particular method of acquiring MWDs is common. In future studies more pro-active methods of selection of MWDs would be desirable.

However, the presence of the study subjects inside a secure military base also led to the logistical problem - DNA could not be isolated on-site, samples had to be collected on site and then safely transported with viable DNA for genetic analysis at a later date. Even though fresh blood in EDTA gives the best DNA yield, transportation would have posed a problem, and the samples would have to be processed as soon as possible (blood in EDTA does not have a long shelf life with or without refrigeration). Therein came the advantage of using Whatman ${ }^{\text {TM }}$ FTA $^{\text {TM }}$ (Flinders Technology Associate) cards - a relatively inexpensive medium for collecting biological samples (saliva, cell cultures, plant extracts, blood etc.), that can be stored for extended periods of time (sometimes up to decades), while preserving the genetic material for future genetic analyses (protected from external factors like environment and microbial contamination). The amount of blood required for analysis is also small compared to other comparable 
methods (blood in EDTA tubes). FTA ${ }^{\mathrm{TM}}$ cards are common practice in collecting genetic material in agricultural settings, including plants and animals like cows (Hu, $2010 \# 680)$, horses ${ }^{243}$, and dogs ${ }^{244}$ - especially in situations where in field laboratory setup is unavailable, or there is need for transportation and storage of samples without refrigeration. This feature of FTA $^{\mathrm{TM}}$ cards allowed us to extract viable DNA (sufficient quality and quantity for sequencing study) 2 years after data collection - samples were collected in 2013 , and DNA was extracted in 2015). So FTA ${ }^{\mathrm{TM}}$ cards can be a viable method for collection of genetic material from MWDs, especially because of the unpredictability of their location at any given point of time. In fact, FTA ${ }^{\mathrm{TM}}$ cards have already been in use in the US military for collecting DNA from human soldiers (for identification purposes). FTA ${ }^{\mathrm{TM}}$ cards can easily transition to benefit the health and welfare of the canine soldiers by collecting their genetic material not only for identification purposes but also for medical testing. We do acknowledge the fact that the amount of DNA extractable from these cards is not as high as one might get from fresh blood in EDTA tubes or buccal swabs (standard practices in canine genetic research), but situations in which transport and storage of the genetic material are of concern, FTA ${ }^{\mathrm{TM}}$ cards could be the solution. FTA $^{\mathrm{TM}}$ cards could also provide a unique opportunity to perform longitudinal studies.

The Yao lab at WVU already uses the Promega Wizard SV Genomic DNA recovery kit for DNA extractions needed for their ongoing projects in aquaculture and reproductive physiology. The ready availability of this kit inspired the attempt of extracting DNA from FTA $^{\text {TM }}$ cards using this method. The DNA yield was decent (average yield of 25 nanogram per microliter in 50 microliters suspension), but the blood contamination was also quite high (often visible as a reddish hue in solution). We attempted to purify the DNA with ethanol purification and DNA purification kits, but that resulted in loss of usable DNA volume. So we propose that the Promega kit can be used to extract DNA for basic PCR reactions but if the end-goal is sensitive sequencing reactions, then Promega Wizard SV Genomic DNA Recovery kit is probably not the best approach for DNA isolation from blood spots on FTA $^{\mathrm{TM}}$ cards, without running an additional 
purification step to remove blood contaminants. GenTegra GenSolve kit gave us better yield of DNA from blood on FTA ${ }^{\mathrm{TM}}$ cards. However, a major limitation of this study was the loss of DNA from the best 8 candidate dogs during initial DNA isolation phase. It would be beneficial to do a follow-up study in a larger population of true LS negative and LS positive Labrador retrievers to test the validity of FTA cards as a workable medium for collection of canine genetic material and GenTegra GenSolve kit's ability to extract the canine genetic material out of the FTA cards.

The 40 dogs in the study comprised of equal number of males and females, and the LS positive group was made up of 17 males and 16 females. Selection of dogs for exome sequencing to represent the extremes of the phenotype (LS positive or LS negative) was blinded. The dogs selected comprised of 4 affected males (LS positive) and 4 unaffected females (LS negative). This all male and all female selection was coincidental. Previous human LSS and canine LS studies have reported a higher incidence in males than in females. Possible reasons suggested include faster growth rate of males, larger body weight and more popular choice as working dogs 123189245 ${ }^{122}$. It is important to note that 3 of the LS negative dogs were related to each other and this could be a possible source of bias in the results. Complete pedigree information for all 40 dogs in the study was not available, so pedigree analysis was not possible. A future study investigating the pedigree structure of these dogs could yield valuable insight into prevalence of LS within the MWD population.

Low back pain (recorded as part of the physical examination during data collection) and LS status (recorded based on veterinary radiologist diagnosis) of the dogs included in this study did not agree consistently. This was in agreement with previous reports in MWDs ${ }^{18716}$. Only 1 of the 7 LS negative dogs (14.3\%) was LBP negative, the other 6 $(85.7 \%)$ showed signs of pain despite being negative for stenosis (according to CT findings). Of the 33 dogs that were designated LS positive (in at least one vertebral location), 18 dogs (54.5\%) were LBP positive, however there were 15 dogs (45.5\%) that showed no signs of LBP despite being positive for LS. One possible explanation for this 
discrepancy could be the fact that these dogs are selected and bred for stoicism and high working drive. Therefore some dogs with LS could have been masking their clinical signs. Another possible reason for the discrepancy could be that LBP might have been caused by other clinical problems besides LS like degenerative sacroiliac joint disease (DSJD) ${ }^{132}$, foraminal stenosis ${ }^{133}$ and Schmorl's nodes ${ }^{134}$. This high-drive personality makes this breed an excellent candidate for working dogs, but can also be disadvantageous in early detection of LS based on signs of LBP alone since the same trait that makes them good working dogs, also makes them good maskers of pain.

Age is usually considered to be a factor in degenerative LS, however in this study as a whole constituted of only young dogs, both groups (LS negative and LS positive) had representation from all ages (1 to 5). The appearance of LS at such relatively young ages could signal a different etiology of LS in this population of dogs i.e. MWDs. Since these dogs are too young to acquire degenerative changes in their bodies (despite the nature of their lifestyle), the type of LS affecting these MWDs could be idiopathic.

The FAR values in all LS negative dogs were consistently higher than the FAR values in LS positive dogs. The minimum FAR values for the LS negative group for 5 of the 8 locations were higher than the maximum FAR values in the LS positive group (L5 cranial and caudal; L6 cranial; L7 cranial and caudal). This further supports the results from previous study (chapter III) - that fat area ratio (FAR) is a viable tool to quantitatively phenotype LS in Labrador retrievers. Studies need to be conducted to test the validity of FAR as a measure of LS not only in a larger sample of Labrador retrievers, but also in other breeds of dogs and maybe in humans as well.

Even though WES usually involves small sample size, our sample size of eight individuals was too small to allow robust statistical analyses. Future studies with larger sample sizes are needed that would increase the power of statistical analyses. Also at the time this study was planned and conducted, there was no dedicated canine exome capture platform available in the market. However, since then an exome capture kit 
specific to the canine genome has been developed (Roche NimbleGen, Madison, WI). Future analyses using this species-specific kit would be desirable to improve the sensitivity of future canine WES studies in identifying genetic variants underlying LS.

Out of all the variants identified between the control and affected groups from the exome sequencing data, only 252 variants met the criteria that accounted for either asymptomatic or carriers. The study was unable to find any variants where the relationship between variants and phenotype was more straightforward without the need for making allowance for carriers/asymptomatic samples. Variant Effect Predictor was unable to find any variants with high impact and it could not annotate all the variants to specific predicted genes. VEP was able to identify variants with moderate impact (10 genes) and low impact ( 24 genes). Manual curating of the VCF file using Golden Helix SVS software was able to assign 82 of the 252 variants to exons of 33 protein-coding genes (NCBI and Ensembl). Of the 33 genes, 3 genes could have possible associations with LS in Labrador retrievers - Transthyretin (TTR), Folate Receptor 2 (FOLR2) and Ubiquitin Specific Peptidase 9, X-linked (USP9X).

First, TTR - recent studies have reported that TTR-derived amyloidosis might have an association with SSA (senile systemic amyloidosis) - a group of disorders involving the localized deposition of amyloid proteins in a variety of tissues ${ }^{246}$. A 2011 study found an association between senile systemic amyloidosis and lumbar spinal stenosis in the Japanese population ${ }^{247}$. This study examined ligamentum flavum specimens from 36 individuals with confirmed cases of LSS. Nineteen of the 36 samples tested positive for amyloid protein deposits. There are at least 30 different types of amyloid proteins that can be deposited in the human body ${ }^{248}$. Transthyretin-derived amyloidosis (ATTR) is one such condition and 16 of those 19 specimens with SSA that tested positive for amyloid deposits, had ATTR. Another recent study has also found an association between transthyretin-derived amyloidosis in SSA and LSS within the Swedish population ${ }^{239}$. This study comprised of resected material (bone fragments, pieces of ligament and other connective tissues) from 26 patients undergoing surgery for lumbar 
spinal stenosis (the only inclusion criterion). Amyloid deposits were detected in 25 of the 26 samples. Deposits of amyloid protein in the brain have been well investigated for several years because of the role it plays in Alzheimer's disease and Down's syndrome 249. Amyloid deposits are also commonly found in connective tissues like ligaments, tendons and cartilages especially in the joints (knee, hip, vertebrae) of elderly individuals 250251252 ; but the biological significance of this type of amyloidosis is unknown ${ }^{239}$. Similar to the amyloidosis seen in Alzheimer's disease (brain tissue), ATTR deposits (connective tissue/skeletal tissue/neural tissue) are also believed to be aging-related and are usually observed in individuals older than 60 years of age. Transthyretin-derived amyloidosis has a higher rate of incidence in males when compared to females; and is usually accompanied by cardiomyopathy and carpal tunnel syndrome as clinical complications. All these factors imply that LSS could be a consequence of SSA, making the transthyretin (TTR) gene a good candidate gene for future studies of LSS in humans, and maybe TTR could also be associated with LS in Labrador retrievers. Second, FOLR2 has been found in macrophages present in the synovial fluid of patients suffering from osteoarthritis (OA) ${ }^{240}$. And lastly, USP9X is an $X$-linked gene that escapes $X$-inactivation in mammalian females ${ }^{241}$, so females have twice the dose of this gene product as males. The sex-specific trend of LS in dogs (males are affected almost twice as females, according to some reports) could mean that LS is an X-linked condition, and USP9X gene product could be playing a protective role in LS disease pathology, and is the cause for the difference in incidence rate observed between males and females Despite these findings, it is important to note that these are just conjectures at this point, future studies investigating these "new candidate genes", especially TTR, are needed to delineate the true relationship between these 3 genes and LS in Labrador retrievers.

Another important aspect of the results in this study was the absence of any exonic variants within human LSS candidate genes. The sample size of this study was too low to rule out the involvement of these human LSS candidate genes altogether, so further analyses are needed in a larger sample size of Labrador retrievers to investigate the 
true relationship between canine LS and human LSS candidate genes. Also the genetic findings in this study could be specific for idiopathic LS and not degenerative LS. The candidate genes from human LSS studies (mostly degenerative kind) could be shared by degenerative type of canine LS. 
Figure IV.1.

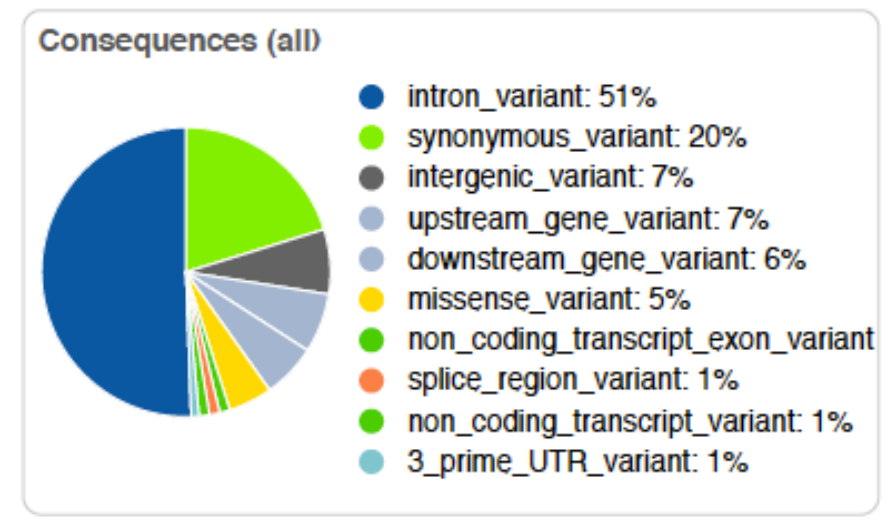

Figure IV.1. Consequences of 229 variants analyzed by Ensembl's Variant Effect Predictor 
Figure IV.2.

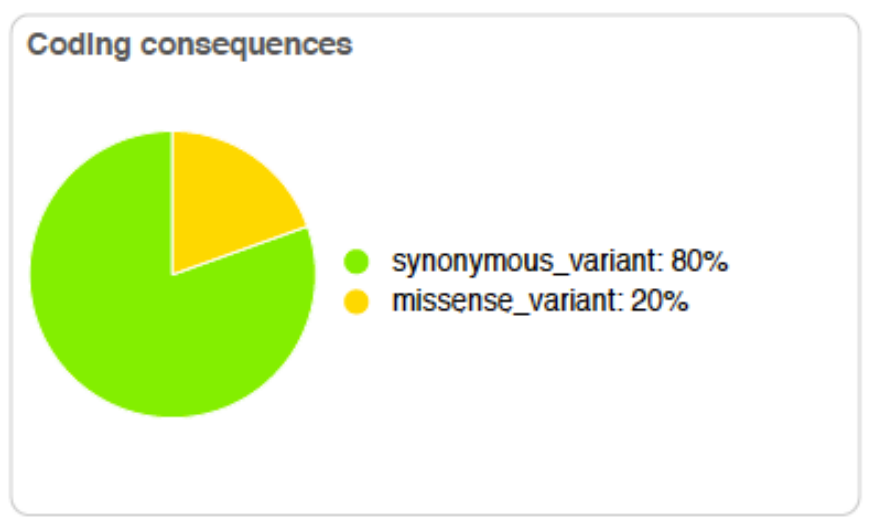

Figure IV.2. Percentage breakdown of variants with coding regions based on type of mutation 
Table IV.1. Clinical data demography of the study samples

\begin{tabular}{|l|l|l|}
\hline Group & CT LS negative & CT LS positive \\
\hline Number & 7 & 33 \\
\hline Average Age & $2.57( \pm 0.45)$ & $2.88( \pm 0.22)$ \\
\hline Sex & $3 \mathrm{M}, 4 \mathrm{~F}$ & $17 \mathrm{M}, 16 \mathrm{~F}$ \\
\hline Average Weight & $25.80( \pm 1.35)$ & $29.05( \pm 0.72)$ \\
\hline Weight Range & $22.50-32.66$ & $22.00-38.56$ \\
\hline Low back pain (LBP) status & 6 positive, 1 negative & 18 positive, 15 negative \\
\hline
\end{tabular}

Legend:

\begin{tabular}{|l|l|}
\hline CT - computed tomography & LS - lumbosacral stenosis \\
\hline M - male & F - female \\
\hline W - working & NW - non-working \\
\hline
\end{tabular}


Table IV.2.A. Maximum and minimum fat area ratio values for 8 vertebral locations among the 8 dogs selected to represent the extremes of the phenotype $-1^{\text {st }}$ round of selection (samples lost)

\begin{tabular}{|l|l|l|l|l|}
\hline \multirow{2}{*}{ Vertebral location } & \multicolumn{2}{|l|}{ LS negative } & \multicolumn{2}{l|}{ LS positive } \\
\cline { 2 - 5 } & Max & Min & Max & Min \\
\hline L4Cd & 0.174 & 0.113 & 0.115 & 0.029 \\
\hline $\mathrm{L5Cr}^{\wedge}$ & 0.183 & 0.075 & 0.061 & 0.028 \\
\hline $\mathrm{L} 5 \mathrm{Cd}^{\wedge}$ & 0.307 & 0.218 & 0.155 & 0.088 \\
\hline $\mathrm{L6Cr}^{\wedge}$ & 0.169 & 0.148 & 0.120 & 0.058 \\
\hline $\mathrm{L6Cd}^{\wedge}$ & 0.373 & 0.297 & 0.202 & 0.140 \\
\hline $\mathrm{L7Cr}^{\wedge}$ & 0.205 & 0.128 & 0.109 & 0.065 \\
\hline $\mathrm{L7Cd}^{\wedge}$ & 0.379 & 0.294 & 0.230 & 0.199 \\
\hline $\mathrm{S1Cr}^{\wedge}$ & 0.195 & 0.144 & 0.091 & 0.044 \\
\hline
\end{tabular}

Table IV.2.A. Maximum and minimum Fat Area Ratio (FAR) values for all of the 8 vertebral locations within the 2 groups of 4 dogs each (LS negative and LS positive). ^ Denotes vertebral locations where the lowest FAR value in LS negative (control) dog group was greater than the highest FAR value in LS positive (affected) dog group. 
Table IV.2.B. Maximum and minimum fat area ratio values for 8 vertebral locations among the 8 dogs selected to represent extremes of the phenotype $-2^{\text {nd }}$ round of selection (whole exome sequenced samples)

\begin{tabular}{|l|l|l|l|l|}
\hline \multirow{2}{*}{ Vertebral location } & \multicolumn{2}{|l|}{ LS negative } & \multicolumn{2}{l|}{ LS positive } \\
\cline { 2 - 5 } & Max & Min & Max & Min \\
\hline L4Cd & 0.115 & 0.074 & 0.099 & 0.038 \\
\hline $\mathrm{L5Cr}^{\wedge}$ & 0.140 & 0.088 & 0.056 & 0.029 \\
\hline${\mathrm{L} 5 \mathrm{Cd}^{\wedge}}^{\wedge}$ & 0.268 & 0.215 & 0.162 & 0.099 \\
\hline $\mathrm{L6Cr}^{\wedge}$ & 0.162 & 0.143 & 0.089 & 0.067 \\
\hline $\mathrm{LCCd}^{\wedge}$ & 0.294 & 0.233 & 0.251 & 0.189 \\
\hline $\mathrm{L7Cr}^{\wedge}$ & 0.162 & 0.142 & 0.091 & 0.052 \\
\hline $\mathrm{L7Cd} \wedge$ & 0.338 & 0.264 & 0.262 & 0.207 \\
\hline $\mathrm{S} 1 \mathrm{Cr}$ & 0.173 & 0.136 & 0.166 & 0.077 \\
\hline
\end{tabular}

Table IV.2.B. Maximum and minimum Fat Area Ratio (FAR) values for all of the 8 vertebral locations within the 2 groups of 4 dogs each (LS negative and LS positive).

$\wedge$ Denotes vertebral locations where the lowest FAR value in LS negative (control) dog group was greater than the highest FAR value in LS positive (affected) dog group. 
Table IV.3. Demographic data of the 8 dogs selected for exome sequencing

\begin{tabular}{|l|l|l|}
\hline Characteristic & LS negative & LS positive \\
\hline Age & $1,1,2,3$ & $3,4,4,5$ \\
\hline Sex & $4 \mathrm{~F}$ & $4 \mathrm{M}$ \\
\hline Mean weight & 24.05 & 31.75 \\
\hline LBP status & $3 \mathrm{Y}, 1 \mathrm{~N}$ & $2 \mathrm{Y}, 2 \mathrm{~N}$ \\
\hline Coat color & $3 \mathrm{BL}, 1 \mathrm{YL}$ & $3 \mathrm{BL}, 1 \mathrm{YL}$ \\
\hline Work status & $2 \mathrm{BR}, 2 \mathrm{IT}^{\star}$ & $2 \mathrm{IT}, 1 \mathrm{TA}, 1 \mathrm{HH}^{\wedge}$ \\
\hline
\end{tabular}

* - Former breeders (BR) that were spayed and placed in training (IT)

$\wedge$ - Detection dog but put in hospital hold for T. cruzi infection

Legend:

\begin{tabular}{|l|l|l|l|}
\hline Breeder & BR & Female & F \\
\hline In-training & IT & Male & M \\
\hline Training aide & TA & Yes & Y \\
\hline Hospital hold & HH & No & N \\
\hline Black & BL & Yellow & YL \\
\hline
\end{tabular}


Table IV.4. List of single nucleotide variants present within the canine exome and the genes that the exons correspond to as detected by manual curating

\begin{tabular}{|c|c|c|c|c|c|}
\hline \multicolumn{4}{|c|}{ Single nucleotide variants within exons } & \multirow[b]{2}{*}{$\begin{array}{l}\text { Control } \\
\text { sequence }\end{array}$} & \multirow[b]{2}{*}{$\begin{array}{l}\text { Affected } \\
\text { sequence }\end{array}$} \\
\hline Number & $\begin{array}{l}\text { Chromosome } \\
\text { number }\end{array}$ & Position & $\begin{array}{l}\text { Gene } \\
\text { symbol }\end{array}$ & & \\
\hline 1 & 1 & 89360055 & DOCK8 & $\mathrm{T}$ & $\mathrm{C}$ \\
\hline 2 & 1 & 118921713 & SLC7A10 & $\mathrm{C}$ & $T$ \\
\hline 3 & 1 & 119322126 & RGS9BP & $\mathrm{C}(\mathrm{G})$ & $\mathrm{T}(\mathrm{A})$ \\
\hline 4 & 1 & 120453353 & TSHZ3 & C & $T$ \\
\hline 5 & 4 & 20145950 & KIF1BP & $\mathrm{G}$ & $A$ \\
\hline 6 & 6 & 9069346 & TFR2 & $\mathrm{C}$ & $T$ \\
\hline 7 & 7 & 2203010 & KIF21B & $\mathrm{C}$ & $T$ \\
\hline 8 & 7 & 10364384 & $\overline{D T L}$ & G & $\mathrm{A}$ \\
\hline 9 & 7 & 56104696 & ASXL3 & $\mathrm{T}(\mathrm{A})$ & $\mathrm{C}(\mathrm{G})$ \\
\hline 10 & 7 & 56104802 & ASXL3 & $\mathrm{G}(\mathrm{C})$ & $T(A)$ \\
\hline 11 & 7 & 56106097 & ASXL3 & $\mathrm{C}(\mathrm{G})$ & $T(A)$ \\
\hline 12 & 7 & 57689546 & TRAPPC8 & $\mathrm{C}$ & $T$ \\
\hline 13 & 7 & 57946958 & TTR & $\mathrm{T}(\mathrm{A})$ & $\mathrm{C}(\mathrm{G})$ \\
\hline 14 & 8 & 4065167 & LRRC16B & $G$ & $A$ \\
\hline 15 & 8 & 50655038 & ADCK1 & C & $T$ \\
\hline 16 & 10 & 69081780 & ADD2 & $\mathrm{C}(\mathrm{G})$ & $T(A)$ \\
\hline 17 & 11 & 24735565 & SPOCK1 & $G(C)$ & $\mathrm{A}(\mathrm{T})$ \\
\hline 18 & 13 & 22573204 & RNF139 & $A$ & $\mathrm{G}$ \\
\hline 19 & 13 & 22573204 & TATDN1 & $A(T)$ & $G(C)$ \\
\hline 20 & 14 & 26883347 & EEF1A1 & $\mathrm{G}$ & $A$ \\
\hline 21 & 14 & 26883912 & EEF1A1 & $\mathrm{G}$ & $A$ \\
\hline 22 & 14 & 31311638 & AGR2 & $G(C)$ & $\mathrm{A}(\mathrm{T})$ \\
\hline 23 & 14 & 36176692 & DNAJA1 & $\mathrm{A}(\mathrm{T})$ & $\mathrm{G}(\mathrm{C})$ \\
\hline 24 & 14 & 36176713 & DNAJA1 & $A(T)$ & $\mathrm{G}(\mathrm{C})$ \\
\hline 25 & 14 & 52320547 & TMEM168 & $G(C)$ & $\mathrm{A}(\mathrm{T})$ \\
\hline 26 & 15 & 61421904 & CPE & $\mathrm{T}$ & $G$ \\
\hline 27 & 17 & 8320429 & GREB1 & $A$ & $\mathrm{G}$ \\
\hline 28 & 20 & 39606726 & BSN & $\mathrm{C}(\mathrm{G})$ & $T(A)$ \\
\hline
\end{tabular}




\begin{tabular}{|c|c|c|c|c|c|}
\hline 29 & 20 & 39607968 & BSN & $G(C)$ & $A(T)$ \\
\hline 30 & 20 & 45454325 & ABHD8 & $T$ & C \\
\hline 31 & 21 & 25954898 & FOLR2 & $T(A)$ & $C(G)$ \\
\hline 32 & 25 & 19512970 & PALLD & $\mathrm{T}$ & C \\
\hline 33 & 25 & 19513039 & PALLD & C & $T$ \\
\hline 34 & 27 & 25335426 & ABCC9 & $C$ & $T$ \\
\hline 35 & 27 & 31190558 & PTPRO & $T(A)$ & $C(G)$ \\
\hline 36 & 32 & 17161549 & SMARCAD1 & $T$ & A \\
\hline 37 & 34 & 32184660 & ZBBX & $A(T)$ & $T(A)$ \\
\hline 38 & 34 & 32184727 & ZBBX & $T(A)$ & $C(G)$ \\
\hline 39 & $x$ & 19788051 & ZFX & A & C \\
\hline 40 & $x$ & 19788059 & ZFX & C & A \\
\hline 41 & $X$ & 19788111 & ZFX & $C$ & $T$ \\
\hline 42 & $x$ & 19788144 & ZFX & G & $A$ \\
\hline 43 & $\mathrm{X}$ & 19789071 & ZFX & G & A \\
\hline 44 & $X$ & 19789132 & ZFX & A & $T$ \\
\hline 45 & $x$ & 19789173 & ZFX & C & A \\
\hline 46 & $X$ & 19789176 & ZFX & C & $T$ \\
\hline 47 & $\mathrm{X}$ & 19789317 & ZFX & A & G \\
\hline 48 & $x$ & 19789321 & ZFX & G & A \\
\hline 49 & $x$ & 19789401 & ZFX & C & $T$ \\
\hline 50 & $x$ & 19789437 & ZFX & $C$ & $\mathrm{~T}$ \\
\hline 51 & $X$ & 19789440 & ZFX & $C$ & $T$ \\
\hline 52 & $x$ & 19789458 & ZFX & A & G \\
\hline 53 & $x$ & 19789494 & ZFX & G & $C$ \\
\hline 54 & $\mathrm{X}$ & 19789503 & ZFX & G & A \\
\hline 55 & $x$ & 19789515 & ZFX & $\mathrm{G}$ & A \\
\hline 56 & $x$ & 19789551 & ZFX & $\mathrm{G}$ & $A$ \\
\hline 57 & $x$ & 19789563 & ZFX & $A$ & G \\
\hline 58 & $X$ & 19789569 & ZFX & $T$ & C \\
\hline 59 & $x$ & 19789651 & ZFX & $C$ & G \\
\hline 60 & $X$ & 19789653 & ZFX & $T$ & C \\
\hline 61 & $x$ & 19789689 & ZFX & C & $T$ \\
\hline 62 & $x$ & 19789692 & ZFX & $C$ & $T$ \\
\hline 63 & $x$ & 19789716 & ZFX & $T$ & $C$ \\
\hline
\end{tabular}




\begin{tabular}{|c|c|c|c|c|c|}
\hline 64 & $X$ & 19789740 & ZFX & $\mathrm{G}$ & A \\
\hline 65 & $X$ & 19789749 & ZFX & G & A \\
\hline 66 & $x$ & 19789803 & ZFX & $T$ & $C$ \\
\hline 67 & $x$ & 19789818 & ZFX & C & $\mathrm{T}$ \\
\hline 68 & $\mathrm{X}$ & 19789839 & ZFX & $A$ & G \\
\hline 69 & $x$ & 19789906 & ZFX & $\mathrm{C}$ & $T$ \\
\hline 70 & $x$ & 19789908 & ZFX & C & $G$ \\
\hline 71 & $\mathrm{X}$ & 19789914 & ZFX & C & $T$ \\
\hline 72 & $x$ & 19790001 & ZFX & $\mathrm{C}$ & $T$ \\
\hline 73 & $x$ & 19790028 & ZFX & $G$ & $A$ \\
\hline 74 & $X$ & 19790031 & ZFX & C & $T$ \\
\hline 75 & $x$ & 19790040 & ZFX & $T$ & $\mathrm{C}$ \\
\hline 76 & $x$ & 19790091 & ZFX & $A$ & $\mathrm{G}$ \\
\hline 77 & $\bar{X}$ & 19790106 & ZFX & $\mathrm{C}$ & $T$ \\
\hline 78 & $x$ & 19790136 & ZFX & $T$ & $\mathrm{G}$ \\
\hline 79 & $x$ & 19790197 & ZFX & $\mathrm{C}$ & $T$ \\
\hline 80 & $x$ & 19790207 & ZFX & $A$ & $G$ \\
\hline 81 & $x$ & 35651733 & USP9X & $G(C)$ & $A(T)$ \\
\hline 82 & $\mathrm{X}$ & 35659594 & USP9X & $G(C)$ & $A(T)$ \\
\hline
\end{tabular}

Table IV.4. List of 82 exonic variants matching sample genotype parameters (as detected by manual curation)

Also listed are the positions of the variants in the canine genome, the gene symbols they correspond to, and the sequence variation. Instances where the gene is read in the reverse, parentheses were used to denote the sequence of the sense strand and the sequence outside of the parentheses the sequence of the reverse strand. The 82 exonic variants encompass a total of 33 genes. 
Table IV.5. List of canine genes with exonic single nucleotide variants and their percentage homology with human and mouse orthologues

\begin{tabular}{|c|c|c|c|c|c|c|c|c|}
\hline \multirow[b]{2}{*}{ No. } & \multicolumn{2}{|c|}{ Dog (Canis familiaris) } & \multicolumn{3}{|c|}{ Human (Homo sapiens) } & \multicolumn{3}{|c|}{ Mouse (Mus musculus) } \\
\hline & $\begin{array}{l}\text { Chr. } \\
\text { No. }\end{array}$ & $\begin{array}{l}\text { Ensembl predicted gene } \\
\text { name }\end{array}$ & $\begin{array}{l}\text { Chr. } \\
\text { No. }\end{array}$ & $\begin{array}{l}\text { Sequence } \\
\text { identity (\%) }\end{array}$ & E-value & $\begin{array}{l}\text { Chr. } \\
\text { No. }\end{array}$ & $\begin{array}{l}\text { Sequence } \\
\text { identity (\%) }\end{array}$ & E-value \\
\hline 1 & 1 & DOCK8 & 9 & 93 & $2 e^{\wedge}-90$ & 19 & 88 & $2 e^{\wedge}-70$ \\
\hline 2 & 1 & SLC7A10 & 19 & 93 & $1 \mathrm{e}^{\wedge}-74$ & 7 & 91 & $1 e^{\wedge}-69$ \\
\hline 3 & 1 & RGS9BP* $^{*}$ & 19 & 81 & $1 \mathrm{e}^{\wedge}-167$ & 7 & 76 & $4 e^{\wedge}-98$ \\
\hline 4 & 1 & TSHZ3 & 19 & 91 & 0 & 7 & 87 & 0 \\
\hline 5 & 4 & KIAA1279 a.k.a. KIF1BP & 10 & 88 & 0 & 10 & 81 & 0 \\
\hline 6 & 6 & TFR2 & 7 & 88 & $5 e^{\wedge}-52$ & 5 & 87 & $4 e^{\wedge}-37$ \\
\hline 7 & 7 & KIF21B & 1 & 76 & $2 e^{\wedge}-173$ & 1 & 91 & $7 e^{\wedge}-79$ \\
\hline 8 & 7 & DTL & 1 & 92 & 0 & 1 & 85 & 0 \\
\hline 9 & 7 & ASXL3* & 18 & 87 & 0 & 18 & 81 & 0 \\
\hline 10 & 7 & TRAPPC8 & 18 & 90 & 0 & 18 & 81 & 0 \\
\hline 11 & 7 & TTR* $^{*}$ & 18 & 94 & $4 e^{\wedge}-24$ & 18 & NA & NA \\
\hline 12 & 8 & LRRC16B* $^{*}$ & 14 & 90 & $3 e^{\wedge}-109$ & 14 & 89 & $8 e^{\wedge}-109$ \\
\hline 13 & 8 & ADCK1 & 14 & 93 & $1 \mathrm{e}^{\wedge}-75$ & 12 & 92 & $2 e^{\wedge}-74$ \\
\hline 14 & 10 & ADD2 a.k.a. ADDB & 2 & 84 & $3 e^{\wedge}-133$ & 6 & 93 & $6 e^{\wedge}-55$ \\
\hline 15 & 11 & SPOCK1 & 5 & 91 & $2 e^{\wedge}-139$ & 13 & 90 & $3 e^{\wedge}-72$ \\
\hline 16 & 13 & RNF139 & 8 & 92 & 0 & 15 & 91 & 0 \\
\hline 17 & 13 & TATDN1 & 8 & 86 & $1 e^{\wedge}-48$ & 15 & 88 & 0 \\
\hline 18 & 14 & EEF1A1** & 6 & 88 & 0 & 9 & 86 & 0 \\
\hline 19 & 14 & AGR2 & 7 & 85 & $2 e^{\wedge}-32$ & 12 & 92 & $3 e^{\wedge}-19$ \\
\hline 20 & 14 & DNAJA1** & 9 & 89 & 0 & 4 & 89 & 0 \\
\hline 21 & 14 & TMEM168 & 7 & 81 & 0 & 6 & 88 & 0 \\
\hline 22 & 15 & CPE & 4 & 82 & 0 & 9 & 88 & $3 e^{\wedge}-6$ \\
\hline 23 & 17 & GREB1 or KIAA0575 & 2 & 86 & 0 & 12 & 79 & $3 e^{\wedge}-109$ \\
\hline 24 & 20 & BSN or ZNF231 & 3 & 88 & 0 & 9 & 84 & 0 \\
\hline 25 & 20 & ABHD8 & 19 & 87 & 0 & 8 & 90 & $2 e^{\wedge}-53$ \\
\hline 26 & 21 & FOLR2 or FBP & 11 & 94 & $1 e^{\wedge}-73$ & 7 & 81 & $2 e^{\wedge}-26$ \\
\hline 27 & 25 & PALLD & 4 & 84 & 0 & 8 & 80 & $3 e^{\wedge}-86$ \\
\hline 28 & 27 & $\mathrm{ABCC} 9$ & 12 & 95 & $5 e^{\wedge}-100$ & 6 & 86 & $2 e^{\wedge}-64$ \\
\hline
\end{tabular}




\begin{tabular}{|c|c|c|c|c|c|c|c|c|}
\hline 29 & 27 & PTPRO* & 12 & 78 & 0 & 6 & 91 & $2 e^{\wedge}-41$ \\
\hline 30 & 32 & SMARCAD1 & 4 & 92 & 0 & 6 & 82 & 0 \\
\hline 31 & 34 & ZBBX* & 3 & 84 & $2 e^{\wedge}-78$ & 3 & 80 & $2 e^{\wedge}-42$ \\
\hline 32 & $\bar{X}$ & $\mathrm{ZFX}^{* *}$ & $\bar{X}$ & 91 & 0 & $\mathrm{X}$ & 85 & 0 \\
\hline 33 & $\mathrm{X}$ & USP9X & $\mathrm{X}$ & 93 & 0 & $\mathrm{X}$ & 86 & 0 \\
\hline
\end{tabular}

Table IV.5. List of 33 genes with exonic variants between LS negative (control) and LS positive (affected) Labrador retrievers

Also listed are the percentage homology between the predicted genes (according to Ensembl database) and the human and mouse orthologues

* - Genes annotated by VEP as carrying moderate impact variants

** - Genes identified by VEP as carrying moderate impact variants but not annotated due to the uncharacterized nature of the canine gene product 
Table IV.6. Variants with moderate impact as detected by Ensembl's Variant Effect

Predictor (VEP)

\begin{tabular}{|l|l|l|l|l|l|l|l|}
\hline Location & $\begin{array}{l}\text { Variant } \\
\text { allele }\end{array}$ & Symbol & Gene & Exon & $\begin{array}{l}\text { Amino } \\
\text { acid }\end{array}$ & Codons & Strand \\
\hline $1: 117510670$ & T & SCN1B & ENSCAFG00000007129 & $1 / 5$ & A/T & Gca/Aca & -1 \\
\hline $1: 119322126$ & T & RGS9BP & ENSCAFG00000007509 & $1 / 1$ & R/H & cGc/cAc & -1 \\
\hline $7: 56104802$ & T & ASXL3 & ENSCAFG00000017980 & $10 / 11$ & T/N & aCt/aAt & -1 \\
\hline $7: 56104802$ & T & ASXL3 & ENSCAFG00000017980 & $4 / 5$ & T/N & aCt/aAt & -1 \\
\hline $7: 57946958$ & C & TTR & ENSCAFG00000018046 & $1 / 4$ & S/G & Agc/Ggc & -1 \\
\hline $8: 4065167$ & A & LRRC16B & ENSCAFG00000011712 & $16 / 40$ & A/T & Gcc/Acc & 1 \\
\hline $14: 26883912$ & A & - & ENSCAFG00000009915 & $4 / 8$ & A/T & Gcc/Acc & 1 \\
\hline $14: 36176692$ & C & - & ENSCAFG00000009635 & $4 / 6$ & W/R & Tgg/Cgg & 1 \\
\hline $14: 36176713$ & C & - & ENSCAFG00000009635 & $5 / 6$ & C/R & Tgt/Cgt & 1 \\
\hline $27: 31190558$ & C & PTPRO & ENSCAFG00000012789 & $2 / 27$ & N/S & aAc/aGc & -1 \\
\hline $34: 32184727$ & C & ZBBX & ENSCAFG00000014517 & $18 / 20$ & K/R & aAa/aGa & -1 \\
\hline $34: 32184727$ & C & ZBBX & ENSCAFG00000014517 & $16 / 17$ & K/R & aAa/aGa & -1 \\
\hline $\mathrm{X}: 19788059$ & A & - & ENSCAFG00000013408 & $6 / 7$ & T/N & aCc/aAc & 1 \\
\hline $\mathrm{X}: 19789132$ & T & - & ENSCAFG00000013408 & $7 / 7$ & T/S & Acc/Tcc & 1 \\
\hline $\mathrm{X}: 19789321$ & A & - & ENSCAFG00000013408 & $7 / 7$ & A/T & Gcc/Acc & 1 \\
\hline $\mathrm{X}: 19789651$ & G & - & ENSCAFG00000013408 & $7 / 7$ & L/V & Ctt/Gtt & 1 \\
\hline $\mathrm{X}: 19789906$ & T & - & ENSCAFG00000013408 & $7 / 7$ & L/F & Ctc/Ttc & 1 \\
\hline
\end{tabular}

Table IV.6. List of moderate impact variants detected by VEP (i.e. non-disruptive capable of changing protein effectiveness)

Also listed are the chromosome number, position, variant allele, name and annotation of the gene that the exon is part of and the amino acid change that takes place due to the variant. Variants without gene symbol represent canine genes that have yet to be characterized. 
Table IV.7. Biological significance and function of the 33 genes with detected exonic variants

\begin{tabular}{|c|c|c|c|c|c|c|}
\hline \# & $\begin{array}{l}\text { Chr } \\
\#\end{array}$ & $\begin{array}{l}\text { Predicted } \\
\text { gene }\end{array}$ & $\begin{array}{l}\text { Conserved } \\
\text { species }\end{array}$ & Description & Function & $\begin{array}{l}\text { Biological } \\
\text { significance }\end{array}$ \\
\hline 1 & 1 & DOCK8 & $\begin{array}{l}\text { Chimps, } \\
\text { Rhesus } \\
\text { Monkey, Cow, } \\
\text { Chicken, Frog, } \\
\text { Rat, Zebrafish }\end{array}$ & $\begin{array}{l}\text { Dedicator of } \\
\text { cytokinesis } 8\end{array}$ & $\begin{array}{l}\text { Encodes a member of DOCK180 } \\
\text { family guanine nucleotide } \\
\text { exchange factors that interact } \\
\text { with Rho GTPases \& take part in } \\
\text { intracellular signalling networks. }\end{array}$ & $\begin{array}{l}\text { Autosomal } \\
\text { recessive } \\
\text { form of } \\
\text { hyper-IgE } \\
\text { syndrome }\end{array}$ \\
\hline 2 & 1 & SLC7A10 & $\begin{array}{l}\text { Chimps, Frog } \\
\text { Chicken, Rat, } \\
\text { Zebrafish }\end{array}$ & $\begin{array}{l}\text { Solute } \\
\text { family } \\
\text { member } 10\end{array}$ & $\begin{array}{l}\text { Asc-type amino acid transporter - } \\
\text { Mediates high-affinity transport of } \\
\text { D-seine and several other neutral } \\
\text { amino acids }\end{array}$ & $\begin{array}{l}\text { Visceral fat in } \\
\text { women }\end{array}$ \\
\hline 3 & 1 & RGS9BP & $\begin{array}{l}\text { Chimps, } \\
\text { Rhesus } \\
\text { Monkey, Cow, } \\
\text { Frog Chicken, } \\
\text { Rat, Zebrafish, }\end{array}$ & $\begin{array}{l}\text { Regulator of } \\
\text { G protein } \\
\text { signaling } 9 \\
\text { binding } \\
\text { protein }\end{array}$ & $\begin{array}{l}\text { Encodes protein that regulates } G \\
\text { protein-coupled receptor } \\
\text { signaling in photo-transduction. } \\
\text { Bovine and mouse studies show } \\
\text { the protein to be expressed only } \\
\text { in the retina (rod outer segment } \\
\text { membranes) }\end{array}$ & $\begin{array}{l}\text { Bradyopsia } \\
\text { (prolonged } \\
\text { electro-retinal } \\
\text { response } \\
\text { suppression } \\
\text { or PERRS) }\end{array}$ \\
\hline 4 & 1 & TSHZ3 & $\begin{array}{l}\text { Chimps, } \\
\text { Rhesus } \\
\text { Monkey, Cow, } \\
\text { Rat, Chicken, } \\
\text { Zebrafish, } \\
\text { Frog }\end{array}$ & $\begin{array}{l}\text { Teashirt zinc } \\
\text { finger } \\
\text { homeobox } 3\end{array}$ & $\begin{array}{l}\text { Methylation of TSHZ3 promoter is } \\
\text { present in breast/prostrate } \\
\text { cancer. Regulation of myogenic } \\
\text { differentiation in the ureter in } \\
\text { conjunction with SOX9 and } \\
\text { MYOCD }\end{array}$ & $\begin{array}{l}\text { Breast \& } \\
\text { Prostrate } \\
\text { cancer, Pelvi- } \\
\text { ureteric } \\
\text { junction } \\
\text { obstruction }\end{array}$ \\
\hline 5 & 4 & $\begin{array}{l}\text { KIAA1279 } \\
\text { a.k.a. } \\
\text { KIF1BP }\end{array}$ & $\begin{array}{l}\text { Chimps, } \\
\text { Rhesus } \\
\text { Monkey, Cow, } \\
\text { Rat, Chicken, } \\
\text { Zebrafish, } \\
\text { Frog, Fruit fly, } \\
\text { Mosquito }\end{array}$ & $\begin{array}{l}\text { KIF1 (kinesin } \\
\text { family } \\
\text { member 1) } \\
\text { binding } \\
\text { protein }\end{array}$ & $\begin{array}{l}\text { Encodes protein that localizes to } \\
\text { the mitochondria and maybe } \\
\text { involved in regulating } \\
\text { mitochondrial transport }\end{array}$ & $\begin{array}{l}\text { Goldberg- } \\
\text { Shprintzen } \\
\text { megacolon } \\
\text { syndrome }\end{array}$ \\
\hline
\end{tabular}




\begin{tabular}{|c|c|c|c|c|c|c|}
\hline 6 & 6 & TFR2 & $\begin{array}{l}\text { Chimps, } \\
\text { Rhesus } \\
\text { Monkey, Cow, } \\
\text { Rat, Zebrafish }\end{array}$ & $\begin{array}{l}\text { Transferrin } \\
\text { receptor } 2\end{array}$ & $\begin{array}{l}\text { Single-pass type II membrane } \\
\text { protein (member of transferrin } \\
\text { receptor-like family) that mediates } \\
\text { cellular uptake of transferrin- } \\
\text { bound iron } \\
\text { metabolism/hepatocyte } \\
\text { function/erythrocyte } \\
\text { differentiation) }\end{array}$ & $\begin{array}{l}\text { Hereditary } \\
\text { hemochromat } \\
\text { osis type III }\end{array}$ \\
\hline 7 & 7 & KIF21B & $\begin{array}{l}\text { Chimps, Rat, } \\
\text { Frog Chicken, } \\
\text { Zebrafish }\end{array}$ & $\begin{array}{l}\text { Kinesin family } \\
\text { member 21B }\end{array}$ & $\begin{array}{l}\text { Encodes member of kinesin } \\
\text { superfamily (ATP-dependent } \\
\text { microtubule-based motor proteins } \\
\text { involved in intracellular transport } \\
\text { of membranous organelles) }\end{array}$ & $\begin{array}{l}\text { Inflammatory } \\
\text { bowel } \\
\text { disease } \\
\text { Multiple } \\
\text { sclerosis }\end{array}$ \\
\hline 8 & 7 & DTL & $\begin{array}{l}\text { Chimps, } \\
\text { Rhesus } \\
\text { Monkey, Cow, } \\
\text { Rat, Chicken, } \\
\text { Zebrafish, } \\
\text { Frog }\end{array}$ & $\begin{array}{l}\text { Denticleless } \\
\text { E3 ubiquitin } \\
\text { protein ligase } \\
\text { homolog }\end{array}$ & $\begin{array}{l}\text { Involved in stress-related DNA } \\
\text { damage repair and ubiquitin- } \\
\text { protein }\end{array}$ & $\begin{array}{l}\text { Cancers } \\
\text { ovarian, } \\
\text { colon, } \\
\text { gastric, } \\
\text { breast, liver, } \\
\text { throat, } \\
\text { osteosarcom } \\
\text { a, Ewing } \\
\text { sarcoma }\end{array}$ \\
\hline 9 & 7 & ASXL3 & $\begin{array}{l}\text { Chimps, } \\
\text { Rhesus } \\
\text { Monkey, Cow, } \\
\text { Chicken, Frog }\end{array}$ & $\begin{array}{l}\text { Additional sex } \\
\text { combs like } \\
\text { transcriptional } \\
\text { regulator } 3\end{array}$ & $\begin{array}{l}\text { Belongs to family of epigenetic } \\
\text { scaffold proteins }\end{array}$ & $\begin{array}{l}\text { Both } \\
\text { cancerous } \\
\text { and non- } \\
\text { cancerous } \\
\text { diseases }\end{array}$ \\
\hline 10 & 7 & TRAPPC8 & $\begin{array}{l}\text { Chimps, } \\
\text { Rhesus } \\
\text { Monkey, Cow, } \\
\text { Rat, Chicken, } \\
\text { Zebrafish, } \\
\text { Frog, Rice A. } \\
\text { thaliana, Fruit } \\
\text { fly, Mosquito }\end{array}$ & $\begin{array}{l}\text { Trafficking } \\
\text { protein } \\
\text { particle } \\
\text { complex } 8\end{array}$ & $\begin{array}{l}\text { Involved in various stages of } \\
\text { vesicle transport }\end{array}$ & NA \\
\hline
\end{tabular}




\begin{tabular}{|c|c|c|c|c|c|c|}
\hline 11 & 7 & TTR & $\begin{array}{l}\text { Chimps, } \\
\text { Rhesus } \\
\text { Monkey, Cow, } \\
\text { Rat, Chicken, } \\
\text { Zebrafish, } \\
\text { Frog }\end{array}$ & Transthyretin & $\begin{array}{l}\text { lo } 3 \text { prealbumin carrier } \\
\text { One of the } \\
\text { proteins that transport thyroid } \\
\text { hormones in the plasma and } \\
\text { CSF, also retinol in plasma. Also } \\
\text { found on cartilage surfaces } \\
\text { (extracellular } \\
\text { organization). More than } 80 \\
\text { mutations reported - mostly } \\
\text { related to amyloid deposition } \\
\text { disorders affecting peripheral } \\
\text { nerves and/or heart.Associated } \\
\text { with aging (loss over time) leads } \\
\text { to Alzheimers. Neuropeptide } Y\end{array}$ & $\begin{array}{l}\text { Amyloidotic } \\
\text { polyneuropat } \\
\text { hy, euthyroid } \\
\text { hyperthyroxin } \\
\text { aemia, } \\
\text { amyloidotic } \\
\text { vitreous } \\
\text { opacities, } \\
\text { cardiomyopat } \\
\text { hy, } \\
\text { oculoleptome } \\
\text { ningeal } \\
\text { amyloidosis, } \\
\text { meningocere } \\
\text { brovascular } \\
\text { amyloidosis, } \\
\text { carpal tunnel } \\
\text { syndrome, } \\
\text { Leiden } \\
\text { muscular } \\
\text { dystrophy, } \\
\text { osteoarthritis } \\
\text { and spinal } \\
\text { stenosis }\end{array}$ \\
\hline 12 & 8 & LRRC16B & $\begin{array}{l}\text { Chimps, } \\
\text { Rhesus } \\
\text { Monkey, Cow, } \\
\text { Rat, Chicken, } \\
\text { Zebrafish, } \\
\text { Frog }\end{array}$ & $\begin{array}{l}\text { Leucine rich } \\
\text { repeat } \\
\text { containing } \\
16 \mathrm{~B}\end{array}$ & $\begin{array}{l}\text { Candidate onco-fetal gene } \\
\text { (expressed in embryos/fetuses } \\
\text { that should get down-regulated/ } \\
\text { undetectable in adult tissue, but } \\
\text { are found in tumors). Also in } \\
\text { mammalian neurogenesis. }\end{array}$ & Cancer \\
\hline
\end{tabular}




\begin{tabular}{|c|c|c|c|c|c|c|}
\hline 13 & 8 & ADCK1 & $\begin{array}{l}\text { Chimps, } \\
\text { Rhesus } \\
\text { Monkey, Cow, } \\
\text { Rat, Chicken, } \\
\text { Zebrafish, } \\
\text { Frog, Fruit fly, } \\
\text { Mosquito, A. } \\
\text { thaliana, C. } \\
\text { elegans, S. } \\
\text { cerevisiae, S. } \\
\text { pombe, M. } \\
\text { oryzae, } \mathrm{N} . \\
\text { crassa, Rice }\end{array}$ & $\begin{array}{l}\text { aarF domain } \\
\text { containing } \\
\text { kinase } 1\end{array}$ & Function unknown. & NA \\
\hline 14 & 10 & $\begin{array}{l}\text { ADD2 a.k.a. } \\
\text { ADDB }\end{array}$ & $\begin{array}{l}\text { Chimps, } \\
\text { Rhesus } \\
\text { Monkey, Cow, } \\
\text { Rat, Chicken, } \\
\text { Zebrafish, } \\
\text { Frog }\end{array}$ & Adducin 2 & $\begin{array}{l}\text { Encodes for beta subunit of the } \\
\text { adducin family that cross-links } \\
\text { actin filaments with spectrin at } \\
\text { cytoskeletal membrane. Primarily } \\
\text { found in brain and hematopoietic } \\
\text { cells. }\end{array}$ & $\begin{array}{l}\text { Hypertension } \\
\text {, Hemolytic } \\
\text { anemia, } \\
\text { Impaired } \\
\text { synaptic } \\
\text { plasticity, IgA } \\
\text { nephropathy }\end{array}$ \\
\hline 15 & 11 & SPOCK1 & $\begin{array}{l}\text { Chimps, } \\
\text { Rhesus } \\
\text { Monkey, Cow, } \\
\text { Rat, Chicken, } \\
\text { Zebrafish }\end{array}$ & $\begin{array}{l}\text { Sparc/osteon } \\
\text { ectin, cwcv } \\
\text { and kazal-like } \\
\text { domains } \\
\text { proteoglycan } \\
\text { (testican) } 1\end{array}$ & $\begin{array}{l}\text { Encodes the protein core of } \\
\text { plasma proteoglycan containing } \\
\text { chondroitin and heparan-sulfate } \\
\text { chains. Function unknown. } \\
\text { Suspected to be similar to } \\
\text { thyropin-type cysteine protease- } \\
\text { inhibitors (protease inhibition). }\end{array}$ & $\begin{array}{l}\text { Lung cancer, } \\
\text { pancreatic } \\
\text { cancer, } \\
\text { variation of } \\
\text { age at } \\
\text { menarche. }\end{array}$ \\
\hline 16 & 13 & RNF139 & $\begin{array}{l}\text { Chimps, } \\
\text { Rhesus } \\
\text { Monkey, Cow, } \\
\text { Rat, Chicken, } \\
\text { Zebrafish, } \\
\text { Frog, Fruit fly, } \\
\text { Mosquito }\end{array}$ & $\begin{array}{l}\text { Ring finger } \\
\text { protein } 139\end{array}$ & $\begin{array}{l}\text { Encodes multi-membrane } \\
\text { spanning protein that contains a } \\
\text { RING-H2 finger. Located in the } \\
\text { endoplasmic reticulum. Has } \\
\text { ubiquitin ligase activity. Possibly } \\
\text { responsible for degradation of } \\
\text { tumor suppressor gene. }\end{array}$ & $\begin{array}{l}\text { Hereditary } \\
\text { renal and } \\
\text { non- } \\
\text { medullary } \\
\text { thyroid } \\
\text { cancer }\end{array}$ \\
\hline
\end{tabular}




\begin{tabular}{|c|c|c|c|c|c|c|}
\hline 17 & 13 & TATDN1 & 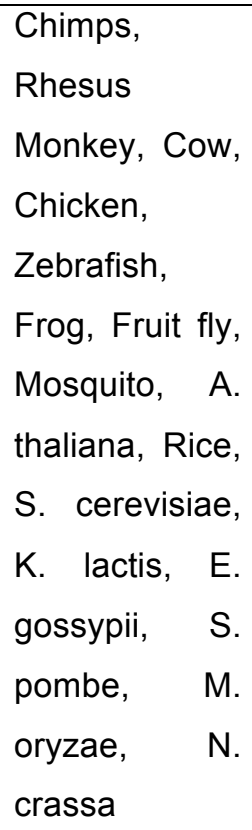 & $\begin{array}{l}\text { TatD Dnase } \\
\text { domain } \\
\text { containing } 1\end{array}$ & Function unknown. & NA \\
\hline 18 & 14 & EEF1A1 & $\begin{array}{l}\text { Chimps, } \\
\text { Rhesus } \\
\text { Monkey, Cow, } \\
\text { Rat, Chicken, } \\
\text { Zebrafish, } \\
\text { Frog, A. } \\
\text { thaliana, Fruit } \\
\text { fly and } \\
\text { Mosquito }\end{array}$ & $\begin{array}{l}\text { Eukaryotic } \\
\text { translation } \\
\text { elongation } \\
\text { factor } 1 \text { alpha } \\
1\end{array}$ & $\begin{array}{l}\text { Encodes an isoform of the alpha } \\
\text { subunit of the elongation factor-1 } \\
\text { complex that enzymatically } \\
\text { delivers amino-acyl tRNAs to the } \\
\text { ribosome during translation. } \\
\text { Expressed in the brain, placenta, } \\
\text { lung, liver, kidney, and pancreas }\end{array}$ & $\begin{array}{l}\text { Precancerou } \\
\mathrm{s} \text { hepatic } \\
\text { lesions in } \\
\text { hepatitis B } \\
\text { related liver } \\
\text { carcinogenes } \\
\text { is. Also other } \\
\text { diseases } \\
\text { associated } \\
\text { with telomere } \\
\text { dysfunction, } \\
\text { and/or DNA } \\
\text { damage. }\end{array}$ \\
\hline 19 & 14 & AGR2 & $\begin{array}{l}\text { Chimps, } \\
\text { Rhesus } \\
\text { Monkey, Cow, } \\
\text { Rat, Chicken, } \\
\text { Zebrafish, } \\
\text { Frog }\end{array}$ & $\begin{array}{l}\text { Anterior } \\
\text { gradient } 2\end{array}$ & $\begin{array}{l}\text { Part of the pro-oncogenic protein } \\
\text { disulfide isomerase (PDI) family - } \\
\text { it maintains homeostasis in the } \\
\text { endoplasmic reticulum }\end{array}$ & $\begin{array}{l}\text { Cancers } \\
\text { breast, liver, } \\
\text { throat, colon, } \\
\text { pancreatic, } \\
\text { ovarian, } \\
\text { thyroid, } \\
\text { gastric, } \\
\text { prostrate, } \\
\text { adenoma etc. }\end{array}$ \\
\hline
\end{tabular}




\begin{tabular}{|c|c|c|c|c|c|c|}
\hline 20 & 14 & DNAJA1 & $\begin{array}{l}\text { Chimps, } \\
\text { Rhesus } \\
\text { Monkey, Cow, } \\
\text { Rat, Chicken, } \\
\text { Zebrafish, } \\
\text { Frog }\end{array}$ & $\begin{array}{l}\text { DnaJ } \\
\text { homolog } \\
\text { superfamily } \\
\text { A } \\
\text { member } 1 \\
\text { isoform }\end{array}$ & DnaJ heat shock superfamily & $\begin{array}{l}\text { Pancreatic } \\
\text { cancer }\end{array}$ \\
\hline 21 & 14 & TMEM168 & $\begin{array}{l}\text { Chimps, } \\
\text { Rhesus } \\
\text { Monkey, Cow, } \\
\text { Rat, Chicken, } \\
\text { Zebrafish, } \\
\text { Frog }\end{array}$ & $\begin{array}{l}\text { Transmembra } \\
\text { ne protein } \\
168\end{array}$ & $\begin{array}{l}\text { Proposed: membrane-associated } \\
\text { HD superfamily } \\
\text { phosphohydrolase }\end{array}$ & NA \\
\hline 22 & 15 & CPE & $\begin{array}{l}\text { Chimps, } \\
\text { Rhesus } \\
\text { Monkey, Cow, } \\
\text { Rat, Chicken, } \\
\text { Zebrafish, } \\
\text { Frog, C. } \\
\text { elegans. }\end{array}$ & $\begin{array}{l}\text { Carboxy- } \\
\text { peptidase E }\end{array}$ & $\begin{array}{l}\text { Encodes member of M14 family } \\
\text { of Metallo-carboxypeptidases. } \\
\text { Peripheral membrane protein } \\
\text { cleaves C-terminal amino acid } \\
\text { residues \& is involved in } \\
\text { biosynthesis of peptide hormones } \\
\& \text { neurotransmitters like insulin. } \\
\text { Functions as a neurotrophic } \\
\text { factor promoting neuronal } \\
\text { survival and/or sorting receptor } \\
\text { that binds to regulated secretory } \\
\text { pathway proteins. }\end{array}$ & $\begin{array}{l}\text { Type } \\
\text { diabetes } \\
\text { Pancreatic } \\
\text { cancer } \\
\text { Colorectal } \\
\text { cancer } \\
\text { Alzheimer's, } \\
\text { Coronary } \\
\text { atheroscleros } \\
\text { is Obesity }\end{array}$ \\
\hline 23 & 17 & $\begin{array}{l}\text { GREB1 or } \\
\text { KIAA0575 }\end{array}$ & $\begin{array}{l}\text { Chimps, } \\
\text { Rhesus } \\
\text { Monkey, Cow, } \\
\text { Rat, Chicken, } \\
\text { Zebrafish, } \\
\text { Frog }\end{array}$ & $\begin{array}{l}\text { Growth } \\
\text { regulation by } \\
\text { estrogen in } \\
\text { breast cancer } \\
1\end{array}$ & $\begin{array}{l}\text { An early response estrogen- } \\
\text { responsive gene in the estrogen } \\
\text { receptor-regulated pathway. } \\
\text { Believed to play an important role } \\
\text { in hormone-responsive tissues } \\
\text { and cancer. }\end{array}$ & $\begin{array}{l}\text { Breast } \\
\text { cancer, } \\
\text { Ovarian } \\
\text { cancer, } \\
\text { Endometriosi } \\
\text { s, Prostrate } \\
\text { cancer, } \\
\text { Polycystic } \\
\text { ovarian } \\
\text { syndrome }\end{array}$ \\
\hline
\end{tabular}




\begin{tabular}{|c|c|c|c|c|c|c|}
\hline 24 & 20 & $\begin{array}{l}\text { BSN } \\
\text { ZNF231 }\end{array}$ & $\begin{array}{l}\text { Chimps, } \\
\text { Rhesus } \\
\text { Monkey, Cow, } \\
\text { Rat, Chicken, } \\
\text { Zebrafish, } \\
\text { Frog }\end{array}$ & $\begin{array}{l}\text { Bassoon } \\
\text { presynaptic } \\
\text { cytomatrix } \\
\text { protein }\end{array}$ & $\begin{array}{l}\text { Expressed primarily in the brain, } \\
\text { this gene is believed to encode a } \\
\text { scaffolding protein that is involved } \\
\text { in organizing the presynaptic } \\
\text { cytoskeleton (metal ion binding). }\end{array}$ & $\begin{array}{l}\text { Crohn's } \\
\text { disease, } \\
\text { Schizophreni } \\
\text { a, } \\
\text { neurodegene } \\
\text { rative } \\
\text { disorders like } \\
\text { multiple } \\
\text { system } \\
\text { atrophy. }\end{array}$ \\
\hline 25 & 20 & ABHD8 & $\begin{array}{l}\text { Chimps, } \\
\text { Rhesus } \\
\text { Monkey, Cow, } \\
\text { Rat, Chicken, } \\
\text { Zebrafish, } \\
\text { Frog }\end{array}$ & $\begin{array}{l}\text { Abhydrolase } \\
\text { domain- } \\
\text { containing } \\
\text { protein } 8\end{array}$ & $\begin{array}{l}\text { In humans, this gene is upstream } \\
\text { of, and in head-to-head } \\
\text { orientation with the gene for } \\
\text { mitochondrial ribosomal protein } \\
\text { L34. Predicted protein has } \\
\text { alpha/beta hydrolase fold and } \\
\text { secretory lipase domains. }\end{array}$ & $\begin{array}{l}\text { Breast } \\
\text { cancer }\end{array}$ \\
\hline 26 & 21 & $\begin{array}{l}\text { FOLR2 } \\
\text { FBP }\end{array}$ & $\begin{array}{l}\text { Chimps, } \\
\text { Rhesus } \\
\text { Monkey, Cow, } \\
\text { Rat }\end{array}$ & $\begin{array}{l}\text { Folate } \\
\text { receptor } \\
\text { (fetal) }\end{array}$ & $\begin{array}{l}\text { Encodes a member of the folate } \\
\text { receptor family. Proteins of this } \\
\text { family have high sequence } \\
\text { homology with each other, and } \\
\text { have a high affinity for folic acid } \\
\text { and its derivatives, mediating the } \\
\text { delivery of } \\
\text { methyltetrahydrofolate to the } \\
\text { interior of cells. }\end{array}$ & $\begin{array}{l}\text { Rheumatoid } \\
\text { arthritis, } \\
\text { atheroscleros } \\
\text { is, } \\
\text { osteoarthritis, } \\
\text { pancreatic } \\
\text { cancer, } \\
\text { arsenic } \\
\text { susceptibility } \\
\text { in mice. }\end{array}$ \\
\hline 27 & 25 & PALLD & $\begin{array}{l}\text { Chimps, } \\
\text { Rhesus } \\
\text { Monkey, Cow, } \\
\text { Rat, Chicken, } \\
\text { Zebrafish, } \\
\text { Frog }\end{array}$ & Palladin & $\begin{array}{l}\text { Encodes a cytoskeletal protein } \\
\text { that is required for organizing the } \\
\text { actin cytoskeleton - a component } \\
\text { of actin containing microfilaments } \\
\text { that is involved in the control of } \\
\text { cell shape, adhesion and } \\
\text { contraction. }\end{array}$ & $\begin{array}{l}\text { Pancreatic } \\
\text { cancer, } \\
\text { breast } \\
\text { cancer, colon } \\
\text { cancer, } \\
\text { atheroscleros } \\
\text { is, myocardial } \\
\text { infarction. }\end{array}$ \\
\hline
\end{tabular}




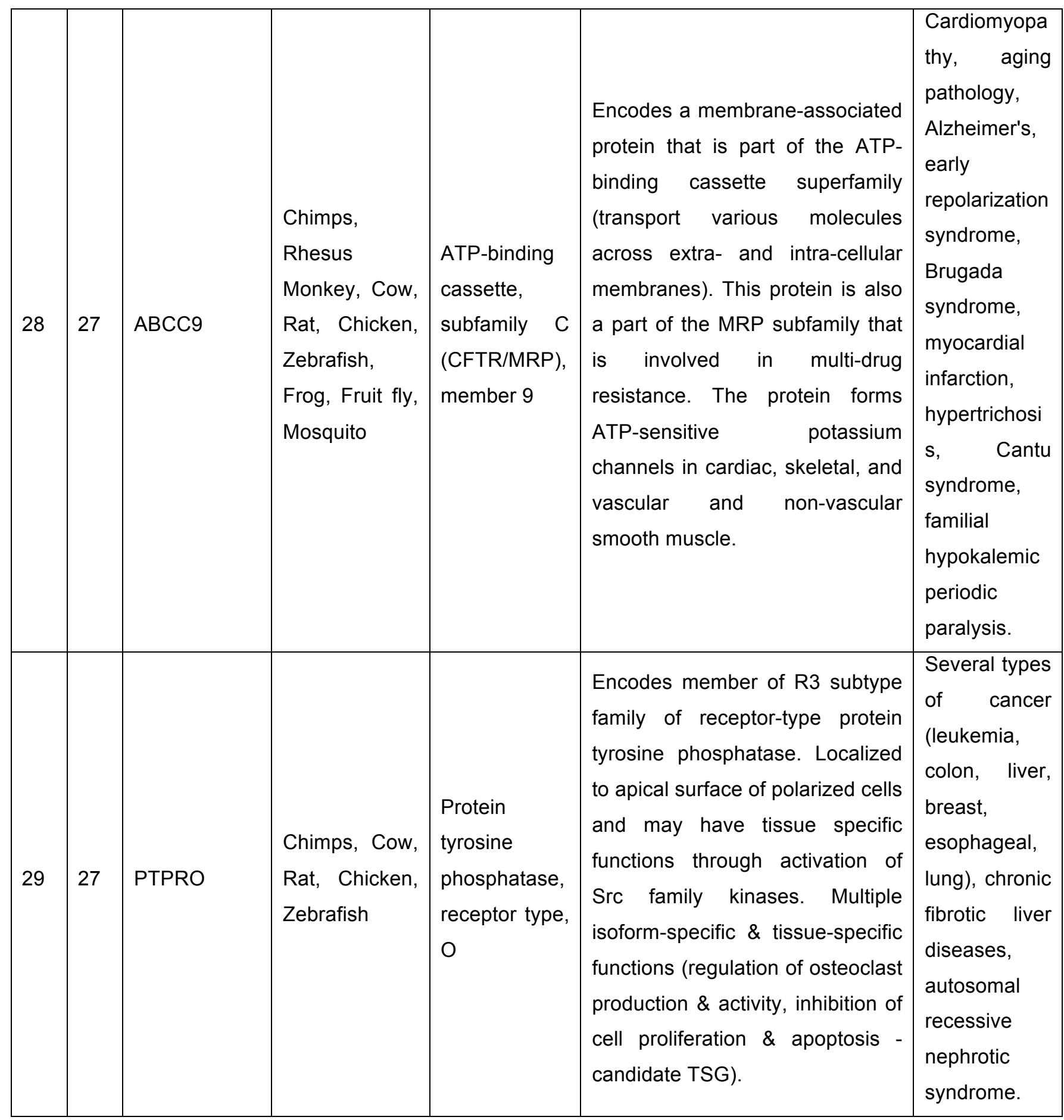




\begin{tabular}{|c|c|c|c|c|c|c|}
\hline 30 & 32 & SMARCAD1 & $\begin{array}{l}\text { Chimps, } \\
\text { Rhesus } \\
\text { Monkey, Cow, } \\
\text { Rat, Chicken, } \\
\text { Zebrafish, } \\
\text { Frog, Fruit fly, } \\
\text { Mosquito }\end{array}$ & $\begin{array}{l}\text { SWI/SNF- } \\
\text { related, } \\
\text { matrix- } \\
\text { associated } \\
\text { actin- } \\
\text { dependent } \\
\text { regulator of } \\
\text { chromatin, } \\
\text { subfamily a, } \\
\text { containing } \\
\text { DEAD/H box } \\
1\end{array}$ & $\begin{array}{l}\text { Encodes a member of the SNF } \\
\text { subfamily of helicase proteins } \\
\text { that plays a critical role in } \\
\text { restoration of heterochromatin } \\
\text { organization and propagation of } \\
\text { epigenetic patterns after DNA } \\
\text { replication by mediating histone } \\
\mathrm{H} 3 / \mathrm{H} 4 \text { de-acetylation. }\end{array}$ & $\begin{array}{l}\text { Adermato- } \\
\text { glyphia }\end{array}$ \\
\hline 31 & 34 & ZBBX & $\begin{array}{l}\text { Chimps, } \\
\text { Rhesus } \\
\text { Monkey, Cow, } \\
\text { Rat, Frog }\end{array}$ & $\begin{array}{l}\text { Zinc finger, B- } \\
\text { box domain } \\
\text { containing }\end{array}$ & Function unknown. & NA \\
\hline 32 & $x$ & ZFX & $\begin{array}{l}\text { Chimps, Cow, } \\
\text { Rat, Chicken, } \\
\text { Zebrafish, } \\
\text { Frog }\end{array}$ & $\begin{array}{l}\text { Zinc finger } \\
\text { protein, } X- \\
\text { linked }\end{array}$ & $\begin{array}{l}\text { Structurally similar to a related } \\
\text { gene on } \mathrm{Y} \text { chromosome. } \\
\text { Encodes a member of the } \\
\text { krueppel C2H2-type zinc-finger } \\
\text { protein family. Full-length protein } \\
\text { product contains an acidic } \\
\text { transcriptional activation domain, } \\
\text { a nuclear localization sequence \& } \\
\text { DNA binding domain (13 } \mathrm{C} 2 \mathrm{H} 2- \\
\text { type zinc fingers). Mice studies } \\
\text { suggest role in stem cell self- } \\
\text { renewal, not growth \& } \\
\text { differentiation of stem cell } \\
\text { progeny. }\end{array}$ & $\begin{array}{l}\text { Several types } \\
\text { of cancer - } \\
\text { squamous } \\
\text { cell, } \\
\text { colorectal, } \\
\text { liver, } \\
\text { leukemia, } \\
\text { gastric, } \\
\text { glioma), } \\
\text { acute } \\
\text { myeloid } \\
\text { leukemia } \\
\text { (mice). }\end{array}$ \\
\hline 33 & $x$ & USP9X & $\begin{array}{l}\text { Chimps, Cow, } \\
\text { Rat, Chicken, } \\
\text { Zebrafish, } \\
\text { Frog }\end{array}$ & $\begin{array}{l}\text { Ubiquitin } \\
\text { specific } \\
\text { peptidase 9, } \\
\text { X-linked }\end{array}$ & $\begin{array}{l}\text { Encodes a member of the } \\
\text { peptidase C19 family that is } \\
\text { similar to ubiquitin-specific } \\
\text { proteases. Escapes X- } \\
\text { inactivation. }\end{array}$ & $\begin{array}{l}\text { Cancers, } \\
\text { Turner's } \\
\text { syndrome }\end{array}$ \\
\hline
\end{tabular}


Table IV.8. Human LSS candidate genes and their location in the canine genome

\begin{tabular}{|l|l|l|l|}
\hline $\begin{array}{l}\text { Candidate } \\
\text { Genes }\end{array}$ & $\begin{array}{l}\text { Homo sapiens } \\
\text { Chromosome } \\
\text { Number }\end{array}$ & $\begin{array}{l}\text { Canis familiaris } \\
\text { Chromosome } \\
\text { Number }\end{array}$ & $\begin{array}{l}\text { Musculo-skeletal } \\
\text { diseases associated }\end{array}$ \\
\hline COL1A1 & 17 & CF 9 & LSS \\
\hline COL1A2 & 7 & CF 14 & LSS, OI, EDS \\
\hline COL2A1 & 12 & CF 27 & OA, LSS \\
\hline COL9A1 & 6 & CF 12 & OA, LSS \\
\hline COL9A2 & 1 & CF 15 & OA, LSS, DDD \\
\hline COL9A3 & 20 & CF 24 & OA, LSS, DDD \\
\hline COL11A1 & 1 & CF 6 & OA, LSS \\
\hline COL11A2* & 6 & CF 12 & OA, LSS, DDD, OPLL \\
\hline VDR & 12 & CF 5 & DDD, LSS \\
\hline MMP-3 & 11 & CF 27 & DDD, LSS \\
\hline
\end{tabular}

* Strong association found in human lumbar spinal stenosis studies.

Legend

\begin{tabular}{|l|l|}
\hline COL (x) A (y): Collagen Type (x), Alpha (y) & $\begin{array}{l}\text { CF: Canis familiaris chromosome } \\
\text { number }\end{array}$ \\
\hline VDR: Vitamin D Receptor & MMP-3: Matrix Metallopeptidase 3 \\
\hline OA: Osteoarthritis & DDD: Degenerative Disc Disease \\
\hline EDS: Ehlers-Danlos syndrome & Ol: Osteogenesis imperfecta \\
\hline $\begin{array}{l}\text { OPLL: Ossification of Posterior Longitudinal } \\
\text { Ligament }\end{array}$ & LSS: Lumbar Spinal Stenosis \\
\hline
\end{tabular}




\section{CHAPTER V. OVERALL SUMMARY AND CONCLUSIONS}

Lumbosacral stenosis (LS) in large breed dogs is a major debilitating condition that can often lead to compression, irritation and stretching injury of nerves and their blood vessels that can then lead to clinical conditions. The most common outward signs of LS on physical examination in dogs include a painful reaction to palpation of the lower back region or elevation of the tail, abnormal tail carriage, reluctance to sit, reluctance to jump up into a car or truck, refusal to climb stairs or other obstacles, and reluctance to assume positions that require hyperextension of the lower back such as standing upright on the hind limbs or jumping over obstacles ${ }^{16}$. Working dogs differ from most companion dogs in that they are bred and trained to be stoic and are highly motivated to do their job. They often mask clinical signs of pain in the early stages. Thus, LS in working dogs, especially in high-drive breeds like Labrador retrievers, often does not become apparent until the dog develops an irreversible functional deficit. By the time this happens, the likelihood of return to full active duty is significantly decreased. Early detection of the likelihood of this disease occurring and implementation of necessary rehabilitative treatments is critical for minimizing loss of man-hours, financial investment, and mission readiness for teams that depend on working dogs. The current standard for detection of LS usually involves expensive radiological imaging investigations like computed tomography (CT) and magnetic resonance imaging (MRI). These methods are expensive and lengthy, not really feasible at the time of procurement of dogs for training intention. Basic radiographs are used instead that can rule out musculoskeletal diseases like canine hip dysplasia and canine elbow dysplasia, but cannot detect lumbosacral joint abnormalities like LS. This warrants the development of a possible genetic biomarker for the disease that can potentially inexpensively help identify the predisposition of LS well before symptoms become too severe. The goal is to identify the structural risk factor before the dog starts showing irreversible clinical signs and is forced to retire - so early intervention would allow for implementations of modified training protocols or re-designed working tasks aiming for minimizing loss of muscle mass and developing of compensatory gait abnormalities by affected dogs. An improved understanding of genetic risk factors would 
also assist international working dog breeder associations in their efforts to produce higher quality dogs.

At the time of inception for this project and on its completion, no published information could be found describing the genetic risk factors for LS in the Labrador retrievers. Studies have stated that Labrador retrievers are at high-risk for LS, but the exact reasons are mostly unknown lacking scientific evidence. The purpose of this project was to phenotype and genotype LS in Labrador retrievers. In this project, we focused on young working Labrador retrievers to detect genetic predisposition without the interferance of aging as a co-factor. We also selected MWD housed at the same base to rule out other environmental variables.

The most significant finding from the first study of this project was the development of the novel CT measurement of fat area ratio (FAR) to phenotypically quantify LS allowing robust statistical analyses to strengthen research findings (Chapter III). This FAR measurement displayed a strong association with the qualitative assessment of LS (as made by a veterinary radiologist, the current standard). The other measurement i.e. canal area ratio or CAR was not so successful in agreement with CT qualitative diagnosis of LS. Possible reason for this observation could be due to the fact that just a subjectively "narrow" canal (as estimated by the ratio of the canal area over vertebral body area) would not be assigned by the radiologist as LS positive without the presence of other characteristic signs of LS - loss of epidural fat being one such trait. Since FAR is a measure of this loss of epidural fat in the vertebral canal, this could be the reason behind FAR having good agreement with qualitative assessment of LS as made by a licensed veterinary radiologist. Because the genotyping study (Chapter IV) was a prospective study, the study design allowed for CT scans to include images of 8 vertebral locations that included both part of the lumbar spinal canal (L4) as well as the "standard" lumbosacral spine (L5 - S1) recorded in the clinical setting. The two additional location FAR values were also included in the selection process for dogs whose exomes were to 
be sequenced, even though the measurements at these two locations could not be validated in study 1 (chapter III).

Another significant finding from this project came from the second study. We were able to identify 3 new possible "candidate genes" - TTR, FOLR2 and USP9X. Even though there are no genetic studies that can explain whether these 3 genes are true candidate genes, few non-genetic studies have hinted at possible associations. Transthyretin (TTR) has been associated with Senile Systemic Amyloidosis or SSA - a condition often appearing simultaneously with LSS in humans. Folate receptor 2 or FOLR2 has also been found in macrophages in the synovial lining of individuals affected by osteoarthritis - a condition also found to be present in individuals already affected by LSS. And lastly, Ubiquitin Specific Peptidase 9 X-linked or USP9X has differential expression between males and females, and the difference in incidence rate of LS in males and females could have a connection with the expression patterns of this gene. The connection of LS with these genes is spurious at best at the present time; so more rigorous investigations are necessary where robust statistical analyses can be done before any claims of association can be made. The other 30 genes also identified as carrying exonic variants differing between LS positive and LS negative groups could also have significance, even though none could be found in the present date (limited by the annotations of genes uploaded by different research groups working on different subjects). The study also looked at human LSS candidate genes, however no significant variants were detected. However, it is too early to rule out these candidate genes, further investigations are needed to either confirm their validity as canine LS candidate genes before any claims can be made that canine LS and human LSS do not share the same disease pathology i.e. same candidate genes.

This was an exploratory study of LS in a pre-disposed and high-risk breed ${ }^{130}$. However most studies of LS in dogs lean heavily towards German shepherds (the most commonly affected breed according to studies reported), more studies are required investigating LS in Labrador retrievers. Further investigations of these genes and the role they might play 
in LS in other breeds (not just Labrador retrievers) need to be undertaken - that could tell us if they are breed specific factors or more universal. These findings could also very well be translated into the human lumbar spinal stenosis problem that closely resembles canine LS. 


\section{CHAPTER VI. RECOMMENDATIONS}

A genetic test for detecting risk factors of LS in working dogs could help reduce the risk of early retirement in these valued animals. Lumbosacral stenosis is not detectable with routine screening methods currently used at the time of military working dog procurement. A genetic test that could be successfully used at the time of procurement could potentially save the military millions of dollars. In addition, this genetic test could help owners, breeders, and trainers of other at-risk working dogs detect the problem earlier and implement preventative measures. Our study identified promising candidate genes that warrant further study. In particular, transthyretin (TTR) may be a marker for premature degeneration of connective and ligamentous tissues. Future studies of blood and tissue samples from clinically affected dogs would be needed to explore the true nature of the relationship between TTR and LS. Small sample sizes are not ideal for genome wide association studies (GWAS), but GWAS can be useful in future association studies if the sample size could be larger. So a GWAS for LS in a larger sample of Labrador retrievers could yield interesting results.

Improved methods for quantitative deep phenotyping of LS in dogs could be helpful for supporting development of these genetic tests. In the current study, fat area ratio (FAR) was introduced as a novel CT measurement that can quantitatively characterize lumbosacral stenosis (LS) in Labrador retrievers for research purposes and possibly also in other breeds of dogs. In order to develop more definitive threshold values, further studies are needed in a larger sample of Labrador retrievers as well as other atrisk breeds. Further analysis is also needed to compare the ratio measurements with the absolute measurements in this study. Canal area ratio or CAR did not have a significant association with qualitative LS in our sample population of dogs, however further studies testing the relationship between CAR and FAR may be helpful. These two measures detect different structural phenotypic traits and may also be complementary. Canal area ratio primarily quantifies bony canal narrowing and FAR detects narrowing due to a combination of bony and soft tissue encroachment (i.e. the combination of characteristics most often used by radiologists for diagnosing the 
condition). Consistent with previous studies, low back pain status (LBP) was not significantly associated with an overall qualitative diagnosis of LS. However, when multi-level stenosis (i.e. stenosis at 2 or more vertebral levels) was examined as a separate factor, subjective evidence of a possible association between multi-level stenosis and LBP was observed. Statistically significant associations were not detected due to small sample size. Future studies should explore the interactions among risk of early retirement due to LS and all possible co-variates such as LBP status, number of levels of stenosis, age, gender, working status, and body weight.

Improved methods for collecting, storing and analyzing genetic material are also needed to support development of genetic screening tests for LS in dogs. Multiple studies have reported several different protocols for extraction of DNA from biological samples (including blood) on FTA $^{\mathrm{TM}}$ cards. After several trials using different commercially available protocols, the GenTegra platform (combination of GenTegra's GenSolve kit and QIAGEN's blood purification kit) had the best yield of DNA for dogs in our sample both quality and quantity of the extracted DNA was sufficient for downstream sequencing reactions. Thus, use of FTA cards was found to be a feasible method for collection and storage of blood samples, and extraction of DNA for genetic testing in military working dogs. This technique could therefore be used in future studies of military working dogs deployed in locations far away from medical facilities and/or sources of refrigeration.

An improved understanding of the progression of LS in dogs is also needed. There are two distinct etiologies of LS in dogs - congenital and acquired. Degenerative LS falls into the acquired category, while idiopathic LS is a rare but congenital type of LS. The primary aim would be to understand the difference between idiopathic and degenerative LS - whether different genetic mechanisms are responsible for the different types of LS or whether they share the same/similar pathophysiological mechanisms. One possible future study could be to follow the outcomes of the same 40 dogs in this study over the years to see if any of the previously LS negative dogs develop clinical signs or become 
LS positive over time and/or whether the LS positive dogs develop worsening of their condition and/or experience early retirement. A longitudinal study starting with a large number of young Labrador retrievers and tracking their growth, as well as the occurrence and/or progression of LS in them over the years could also be informative for our attempt at understanding the mechanisms underlying LS in dogs. This study design will also allow for identifying and understanding the distinction between idiopathic LS and degenerative LS. This type of study design would also allow for studying the relationship between working tasks performed by the dogs and the effect they might have on the lumbosacral spine of the dogs.

More studies also need to be done to develop more sensitive tests for early detection and more accurate localization of lower back pain in working dogs. Current standard clinical tests such as palpation of low back region of the spine and recording the dog's reaction to the stimuli are too insensitive for early detection of LS in stoic, high-drive working dogs. Breed specific phenotypic traits involving the lumbosacral and the sacroiliac joints also warrant further investigations as possible sources of LBP and early retirement in working dogs, i.e. the dog could be displaying signs of pain due to these other conditions and not LS. 


\section{BIBLIOGRAPHY}

1. Olson PN. The modern working dog - a call for interdisciplinary collaboration. Journal Of The American Veterinary Medical Association 2002;221:352355.

2. Evans RI, Herbold JR, Bradshaw BS, et al. Causes for discharge of military working dogs from service: 268 cases (2000-2004). Javma-Journal Of The American Veterinary Medical Association 2007;231:1215-1220.

3. Sinn DL, Gosling SD, Hillard S. Personality and performance in military working dogs: Reliability and predictive validity of behavioral tests. Applied Animal Behaviour Science 2010;127:51-65.

4. Palmer R, Chambers J. Canine lumbosacral diseases. 1. Anatomy, pathophysiology, and clinical presentation. The Compendium on continuing education for the practicing veterinarian 1991.

5. Watt PR. Degenerative lumbosacral stenosis in 18 dogs. Journal of Small Animal Practice 1991;32:125-134.

6. Ness MG. Degenerative lumbosacral stenosis in the dog: a review of 30 cases. Journal of Small Animal Practice 1994;35:185-190.

7. Tarvin G, Prata RG. Lumbosacral stenosis in dogs. Journal of the American Veterinary Medical Association 1980;177:154-159.

8. Indrieri RJ. Lumbosacral stenosis and injury of the cauda equina. The Veterinary clinics of North America Small animal practice 1988;18:697-710.

9. Damur-Djuric N, Steffen F, Hassig M, et al. Lumbosacral transitional vertebrae in dogs: classification, prevalence, and association with sacroiliac morphology. Vet Radiol Ultrasound 2006;47:32-38.

10. FlÜCkiger MA, Damur - Djuric N, HÄSsig M, et al. A Lumbosacral Transitional Vertebra In The Dog Predisposes To Cauda Equina Syndrome. Veterinary Radiology \& Ultrasound 2006;47:39-44.

11. Ondreka N, Amort KH, Stock KF, et al. Skeletal morphology and morphometry of the lumbosacral junction in German shepherd dogs and an evaluation of the possible genetic basis for radiographic findings. Vet $J$ 2013;196:64-70. 
12. Morgan JP. Congenital Anomalies of the Vertebral Column of the Dog: A Study of the Incidence and Significance Based on a Radiographic and Morphologic Study1. Veterinary Radiology 1968;9:21-29.

13. Morgan JP. Transitional lumbosacral vertebral anomaly in the dog: a radiographic study. J Small Anim Pract 1999;40:167-172.

14. Rooney NJ, Gaines SA, Bradshaw JWS, et al. Validation of a method for assessing the ability of trainee specialist search dogs. Applied Animal Behaviour Science 2007;103:90-104.

15. Smith S. Most popular dog breeds in America: American Kennel Club, 2015.

16. Linn LL, Bartels KE, Rochat MC, et al. Lumbosacral stenosis in 29 military working dogs: epidemiologic findings and outcome after surgical intervention (19901999). Veterinary surgery : VS 2003;32:21-29.

17. Arnoldi CC, Brodsky AE, Cauchoix J, et al. Lumbar spinal stenosis and nerve root entrapment syndromes. Definition and classification. Clin Orthop Relat Res 1976:4-5.

18. Ciol MA, Deyo RA, Howell E, et al. An assessment of surgery for spinal stenosis: time trends, geographic variations, complications, and reoperations. J Am Geriatr Soc 1996;44:285-290.

19. Kalichman L, Cole R, Kim DH, et al. Spinal stenosis prevalence and association with symptoms: the Framingham Study. The Spine Journal 2009;9:545-550.

20. Noponen-Hietala N, Kyllonen E, Mannikko M, et al. Sequence variations in the collagen IX and XI genes are associated with degenerative lumbar spinal stenosis. Ann Rheum Dis 2003;62:1208-1214.

21. Hyun SJ, Park BG, Rhim SC, et al. A haplotype at the COL9A2 gene locus contributes to the genetic risk for lumbar spinal stenosis in the Korean population. Spine (Phila Pa 1976) 2011;36:1273-1278.

22. Costandi S, Chopko B, Mekhail M, et al. Lumbar spinal stenosis: therapeutic options review. Pain Pract 2015;15:68-81. 
23. Bae HW, Rajaee SS, Kanim LE. Nationwide trends in the surgical management of lumbar spinal stenosis. Spine (Phila Pa 1976) 2013;38:916-926.

24. De Decker S, Wawrzenski LA, Volk HA. Clinical signs and outcome of dogs treated medically for degenerative lumbosacral stenosis: 98 cases (2004-2012). Journal of the American Veterinary Medical Association 2014;245:408-413.

25. Fritz JM, Lurie JD, Zhao W, et al. Associations between physical therapy and long-term outcomes for individuals with lumbar spinal stenosis in the SPORT study. The Spine Journal 2014;14:1611-1621.

26. Eisenstein S. The morphometry and pathological anatomy of the lumbar spine in South African negroes and caucasoids with specific reference to spinal stenosis. J Bone Joint Surg Br 1977;59:173-180.

27. Eisenstein $S$. The trefoil configuration of the lumbar vertebral canal. A study of South African skeletal material. Journal of Bone \& Joint Surgery, British Volume 1980;62:73-77.

28. Larsen JL, Smith D. Size of the subarachnoid space in stenosis of the lumbar canal. Acta radiologica: diagnosis 1979;21:627-632.

29. Panjabi MM, Goel V, Oxland T, et al. Human Lumbar Vertebrae: Quantitative Three-Dimensional Anatomy. Spine 1992;17:299-306.

30. Lee H-M, Kim N-H, Kim H-J, et al. Morphometric study of the lumbar spinal canal in the Korean population. Spine 1995;20:1679-1684.

31. Epstein BS, Epstein JA, Lavine L. The Effect of Anatomic Variations in the Lumbar Vertebrae and Spinal Canal on Cauda Equina and Nerve Root Syndromes. Am J Roentgenol Radium Ther Nucl Med 1964;91:1055-1063.

32. Angevine JB, Jr. Chapter 7 . Clinically relevant embryology of the vertebral column and spinal cord. Clin Neurosurg 1973;20:95-113.

33. Roberson GH, Llewellyn HJ, Taveras JM. The narrow lumbar spinal canal syndrome. Radiology 1973;107:89-97.

34. Pennal GF, Schatzker J. Stenosis of the lumbar spinal canal. Clin Neurosurg 1971;18:86-105. 
35. Sarpyener MA. Congenital stricture of the spinal canal. The Journal of Bone \& Joint Surgery 1945;27:70-79.

36. Morgan DF, Young RF. Spinal neurological complications of achondroplasia. Results of surgical treatment. J Neurosurg 1980;52:463-472.

37. Hukuda S, Kojima Y. Sex discrepancy in the canal/body ratio of the cervical spine implicating the prevalence of cervical myelopathy in men. Spine 2002;27:250-253.

38. Yilmaz M, Kalemci O, Yilmaz H, et al. Lumbar spinal stenosis in a young individual as a result of ligamantum flavum ossification: A case report. International journal of surgery case reports 2013;4:645-647.

39. LaBan M. Poster 76 "Young" cervical spinal stenosis: a review of 118 patients less than 51 years of age. Archives of Physical Medicine and Rehabilitation 2003;84:E18.

40. Miller JAA, Schmatz C, Schultz AB. Lumbar disc degeneration: Correlation with age, sex, and spine level in 600 autopsy specimens. Spine 1988;13:173-178.

41. Grabias S. Current concepts review. The treatment of spinal stenosis. $J$ Bone Joint Surg Am 1980;62:308-313.

42. Hasue M, Kikuchi S, Inoue K, et al. Posttraumatic spinal stenosis of the lumbar spine: report of a case caused by hyperextension injury; review of literature. Spine (Phila Pa 1976) 1980;5:259-263.

43. Resnick D, Guerra J, Robinson CA, et al. Association of diffuse idiopathic skeletal hyperostosis (DISH) and calcification and ossification of the posterior longitudinal ligament. American Journal of Roentgenology 1978;131:1049-1053.

44. Weisz GM. Lumbar spinal canal stenosis in Paget's disease. Spine (Phila Pa 1976) 1983;8:192-198.

45. Weinstein PR, Karpman RR, Gall EP, et al. Spinal cord injury, spinal fracture, and spinal stenosis in ankylosing spondylitis. J Neurosurg 1982;57:609-616.

46. Luken MG, 3rd, Patel DV, Ellman MH. Symptomatic spinal stenosis associated with ankylosing spondylitis. Neurosurgery 1982;11:703-705. 
47. Magnaes B, Hauge T. Rheumatoid arthritis contributing to lumbar spinal stenosis. Neurogenic intermittent claudication. Scand J Rheumatol 1978;7:215-218.

48. Epstein N, Whelan M, Benjamin V. Acromegaly and spinal stenosis. Case report. J Neurosurg 1982;56:145-147.

49. Nancy E, Margaret W, Vallo B. Acromegaly and spinal stenosis. Journal of Neurosurgery 1982;56:145-147.

50. Hadjipavlou A, Shaffer N, Lander P, et al. Pagetic spinal stenosis with extradural pagetoid ossification: a case report. Spine 1988;13:128-130.

51. Okada K, Sakusabe N, Saitoh H, et al. Pseudohypoparathyroidismassociated spinal stenosis. Spine 1994;19:1186-1189.

52. Reíd IR, Hardy DC, Murphy WA, et al. X-linked hypophosphatemia: a clinical, biochemical, and histopathologic assessment of morbidity in adults. Medicine 1989;68:336-352.

53. Ciricillo SF, Weinstein PR. Lumbar spinal stenosis. Western journal of medicine 1993;158:171.

54. Nixon JE. Spinal stenosis: Arnold, 1991.

55. Portal A. Cours d'anatomie médicale, ou éléments de l'anatomie de I'homme: Baudoin, 1803.

56. Mixter WJ, Barr JS. Rupture of the Intervertebral Disc with Involvement of the Spinal Canal. New England Journal of Medicine 1934;211:210-215.

57. Verbiest $\mathrm{H}$. A radicular syndrome from developmental narrowing of the lumbar vertebral canal. J Bone Joint Surg Br 1954;36-B:230-237.

58. Joffe R, Appleby A, Arjona V. "Intermittent ischaemia" of the cauda equina due to stenosis of the lumbar canal. J Neurol Neurosurg Psychiatry 1966;29:315-318.

59. Paine KW. Clinical features of lumbar spinal stenosis. Clin Orthop Relat Res 1976:77-82.

60. Porter RW. Spinal stenosis and neurogenic claudication. Spine 1996;21:2046-2052.

61. Haig AJ. Diagnostic tests the NASS stenosis guidelines. Spine $J$ 2014;14:200-201. 
62. Porter RW, Ward D. Cauda equina dysfunction. The significance of twolevel pathology. Spine (Phila Pa 1976) 1992;17:9-15.

63. Zingg P, Boos N. Lumbar Spinal Stenosis In: Boos N,Aebi M, eds. Spinal Disorders: Springer Berlin Heidelberg, 2008;513-537.

64. Lavy C, James A, Wilson-MacDonald J, et al. Cauda Equina Syndrome. BMJ: British Medical Journal 2009;338:881-884.

65. Olmarker K, Rydevik B. Single-versus double-level nerve root compression: an experimental study on the porcine cauda equina with analyses of nerve impulse conduction properties. Clinical orthopaedics and related research 1992;279:35-39.

66. Jones RA, Thomson JL. The narrow lumbar canal. A clinical and radiological review. J Bone Joint Surg Br 1968;50:595-605.

67. Paine KWE. Clinical features of lumbar spinal stenosis. Clinical orthopaedics and related research 1976;115:77-82.

68. Singh K, Samartzis D, Vaccaro AR, et al. Congenital lumbar spinal stenosis: a prospective, control-matched, cohort radiographic analysis. The Spine Journal 2005;5:615-622.

69. Katz JN, Dalgas M, Stucki G, et al. Degenerative lumbar spinal stenosis Diagnostic value of the history and physical examination. Arthritis \& Rheumatism 1995;38:1236-1241.

70. Hall S, Bartleson JD, Onofrio BM, et al. Lumbar spinal stenosis: clinical features, diagnostic procedures, and results of surgical treatment in 68 patients. Annals of internal medicine 1985;103:271-275.

71. Kent DL, Haynor DR, Larson EB, et al. Diagnosis of lumbar spinal stenosis in adults: a metaanalysis of the accuracy of CT, MR, and myelography. American Journal of Roentgenology 1992;158:1135-1144.

72. Hounsfield GN. Computerized transverse axial scanning (tomography): Part 1. Description of system. The British journal of radiology 1973;46:1016-1022.

73. Hathcock JT, Stickle RL. Principles and concepts of computed tomography. Vet Clin North Am Small Anim Pract 1993;23:399-415. 
74. Glenn WV, Jr., Rhodes ML, Altschuler EM, et al. Multiplanar display computerized body tomography applications in the lumbar spine. Spine (Phila Pa 1976) 1979;4:282-352.

75. Ullrich CG, Binet EF, Sanecki MG, et al. Quantitative assessment of the lumbar spinal canal by computed tomography. Radiology 1980;134:137-143.

76. Lancourt JE, Glenn WV, Jr., Wiltse LL. Multiplanar computerized tomography in the normal spine and in the diagnosis of spinal stenosis. A gross anatomic-computerized tomographic correlation. Spine (Phila Pa 1976) 1979;4:379-390.

77. McAfee PC, Ullrich CG, Yuan HA, et al. Computed tomography in degenerative spinal stenosis. Clin Orthop Relat Res 1981:221-234.

78. Wilmink JT, Korte JH, Penning L. Dimensions of the spinal canal in individuals symptomatic and non-symptomatic for sciatica: a CT study. Neuroradiology 1988;30:547-550.

79. Eun SS, Lee HY, Lee SH, et al. MRI versus CT for the diagnosis of lumbar spinal stenosis. J Neuroradiol 2012;39:104-109.

80. Fortin JD, Wheeler MT. Imaging in lumbar spinal stenosis. Pain Physician 2004;7:133-139.

81. Maravilla KR, Lesh P, Weinreb JC, et al. Magnetic resonance imaging of the lumbar spine with CT correlation. AJNR Am J Neuroradiol 1985;6:237-245.

82. Dorwart RH, Vogler JB, 3rd, Helms CA. Spinal stenosis. Radiol Clin North Am 1983;21:301-325.

83. Schonstrom NS, Bolender NF, Spengler DM. The pathomorphology of spinal stenosis as seen on CT scans of the lumbar spine. Spine (Phila Pa 1976) 1985;10:806-811.

84. Teplick JG, Teplick SK, Goodman L, et al. Pitfalls and unusual findings in computed tomography of the lumbar spine. J Comput Assist Tomogr 1982;6:888-893.

85. McAfee PC, Yuan HA. Computed tomography in spondylolisthesis. Clin Orthop Relat Res 1982:62-71.

86. Eisenstein S. Lumbar vertebral canal morphometry for computerised tomography in spinal stenosis. Spine (Phila Pa 1976) 1983;8:187-191. 
87. Weisz GM, Lee P. Spinal canal stenosis. Concept of spinal reserve capacity: radiologic measurements and clinical applications. Clin Orthop Relat Res 1983:134-140.

88. Verbiest $\mathrm{H}$. Results of surgical treatment of idiopathic developmental stenosis of the lumbar vertebral canal. A review of twenty-seven years' experience. $J$ Bone Joint Surg Br 1977;59:181-188.

89. Verbiest $\mathrm{H}$. The significance and principles of computerized axial tomography in idiopathic developmental stenosis of the bony lumbar vertebral canal. Spine (Phila Pa 1976) 1979;4:369-378.

90. Zheng F, Farmer J, Sandhu H, et al. A Novel Method for the Quantitative Evaluation of Lumbar Spinal Stenosis. HSS Journal 2006;2:136-140.

91. Gouzien P, Cazalbou C, Boyer B, et al. Measurements of the normal lumbar spinal canal by computed tomography. Segmental study of L3-L4 and L4-L5 related to the height of the subject. Surg Radiol Anat 1990;12:143-148.

92. Kornberg M, Rechtine GR. Quantitative assessment of the fifth lumbar spinal canal by computed tomography in symptomatic L4-L5 disc disease. Spine (Phila Pa 1976) 1985;10:328-330.

93. Gomez Prat A, Garcia Olle L, Ginebreda Marti I, et al. [Lumbar canal stenosis in achondroplasia. Prevention and correction of lumbosacral lordosis]. An Esp Pediatr 2001;54:126-131.

94. Varughese G, Quartey GR. Familial lumbar spinal stenosis with acute disc herniations. Case reports of four brothers. J Neurosurg 1979;51:234-236.

95. Postacchini F, Massobrio M, Ferro L. Familial lumbar stenosis. Case report of three siblings. J Bone Joint Surg Am 1985;67:321-323.

96. Igarashi S, Koyama T, Shimosaka S, et al. [Familial narrow spinal canal (lumbar canal stenosis with narrow cervical canal): case reports of three brothers]. No Shinkei Geka 1982;10:961-966.

97. Maeda S, Koga H, Matsunaga S, et al. Gender-specific haplotype association of collagen alpha2 (XI) gene in ossification of the posterior longitudinal ligament of the spine. J Hum Genet 2001;46:1-4. 
98. Postacchini F, Gumina S, Cinotti G, et al. Ligamenta flava in lumbar disc herniation and spinal stenosis. Light and electron microscopic morphology. Spine (Phila Pa 1976) 1994;19:917-922.

99. Yoshida M, Shima K, Taniguchi Y, et al. Hypertrophied Ligamentum Flavum in Lumbar Spinal Canal Stenosis: Pathogenesis and Morphologic and Immunohistochemical Observation. Spine 1992;17:1353-1360.

100. Maeda $\mathrm{S}$, Ishidou $\mathrm{Y}, \mathrm{Koga} \mathrm{H}$, et al. Functional impact of human collagen alpha2(XI) gene polymorphism in pathogenesis of ossification of the posterior longitudinal ligament of the spine. J Bone Miner Res 2001;16:948-957.

101. Annunen S, Paassilta $P$, Lohiniva J, et al. An allele of COL9A2 associated with intervertebral disc disease. Science 1999;285:409-412.

102. Paassilta $\mathrm{P}$, Lohiniva J, Goring $\mathrm{HH}$, et al. Identification of a novel common genetic risk factor for lumbar disk disease. JAMA 2001;285:1843-1849.

103. Watanabe N, Ogura T, Kimori K, et al. Epidural hematoma of the lumbar spine, simulating extruded lumbar disk herniation: clinical, discographic, and enhanced magnetic resonance imaging features. A case report. Spine (Phila Pa 1976) 1997;22:105-109.

104. Kawaguchi Y, Osada R, Kanamori M, et al. Association between an aggrecan gene polymorphism and lumbar disc degeneration. Spine (Phila Pa 1976) 1999;24:2456-2460.

105. Videman T, Nurminen M, Troup JDG. Lumbar Spinal Pathology In Cadaveric Material In Relation To History Of Back Pain, Occupation, And Physical Loading. Spine 1990;15:728-740.

106. Jones $G$, White $C$, Sambrook $P$, et al. Allelic variation in the vitamin $D$ receptor, lifestyle factors and lumbar spinal degenerative disease. Ann Rheum Dis 1998;57:94-99.

107. Takahashi M, Haro H, Wakabayashi $\mathrm{Y}$, et al. The association of degeneration of the intervertebral disc with $5 \mathrm{a} / 6$ a polymorphism in the promoter of the human matrix metalloproteinase-3 gene. J Bone Joint Surg Br 2001;83:491-495. 
108. Amundsen $\mathrm{T}$, Weber $\mathrm{H}$, Nordal $\mathrm{HJ}$, et al. Lumbar spinal stenosis: conservative or surgical management?: A prospective 10-year study. Spine (Phila Pa 1976) 2000;25:1424-1435; discussion 1435-1426.

109. Atlas SJ, Keller RB, Wu YA, et al. Long-term outcomes of surgical and nonsurgical management of lumbar spinal stenosis: 8 to 10 year results from the maine lumbar spine study. Spine (Phila Pa 1976) 2005;30:936-943.

110. Turner JA, Ersek M, Herron L, et al. Patient outcomes after lumbar spinal fusions. JAMA 1992;268:907-911.

111. Feeney DA, Fletcher TF, Hardy RM. Atlas of correlative imaging anatomy of the normal dog. Ultrasound and computed tomography. Philiadelphia, PA: W.B. Saunders Co., 1991.

112. Jones JC, Wright JC, Bartels JE. Computed tomographic morphometry of the lumbosacral spine of dogs. American journal of veterinary research 1995;56:11251132.

113. Camiciottoli G, Bigazzi F, Paoletti M, et al. Pulmonary function and sputum characteristics predict computed tomography phenotype and severity of COPD. European Respiratory Journal 2013;42:626-635.

114. Bergknut N, Meij B. Degenerative lumbosacral stenosis part 1 Pathogenesis, clinical signs and diagnostics. European Journal of Companion Animal Practice 2012;22:23-33.

115. Chambers JN. Degenerative lumbosacral stenosis in dogs. Veterinary medicine report (USA) 1989.

116. Oliver JE, Jr., Selcer RR, Simpson S. Cauda equina compression from lumbosacral malarticulation and malformation in the dog. J Am Vet Med Assoc 1978;173:207-214.

117. Bailey CS, Morgan JP. Congenital spinal malformations. Veterinary Clinics of North America: Small Animal Practice 1992;22:985-1015.

118. Delamarter RB, Bohlman HH, Dodge LD, et al. Experimental lumbar spinal stenosis. Analysis of the cortical evoked potentials, microvasculature, and histopathology, 1990. 
119. Konno S, Yabuki S, Sato K, et al. A Model for Acute, Chronic, and Delayed Graded Compression of the Dog Cauda Equina: Presentation of the Gross, Microscopic, and Vascular Anatomy of the Dog Cauda Equina and Accuracy in Pressure Transmission of the Compression Model. Spine 1995;20:2758-2764.

120. Apazidis A, Ricart PA, Diefenbach CM, et al. The prevalence of transitional vertebrae in the lumbar spine. Spine $J$ 2011;11:858-862.

121. Steffen F, Berger M, Morgan JP. Asymmetrical, transitional, lumbosacral vertebral segments in six dogs: a characteristic spinal syndrome. J Am Anim Hosp Assoc 2004;40:338-344.

122. Fluckiger MA, Damur-Djuric N, Hassig M, et al. A lumbosacral transitional vertebra in the dog predisposes to cauda equina syndrome. Vet Radiol Ultrasound 2006;47:39-44.

123. Danielsson F, Sjostrom L. Surgical treatment of degenerative lumbosacral stenosis in dogs. Veterinary surgery: VS 1999;28:91-98.

124. De Risio L, Sharp NJ, Olby NJ, et al. Predictors of outcome after dorsal decompressive laminectomy for degenerative lumbosacral stenosis in dogs: 69 cases (1987-1997). Journal of the American Veterinary Medical Association 2001;219:624628.

125. Suwankong N, Meij BP, Voorhout G, et al. Review and retrospective analysis of degenerative lumbosacral stenosis in 156 dogs treated by dorsal laminectomy. Veterinary and comparative orthopaedics and traumatology : VCOT 2008;21:285-293.

126. Brandt KD. Transection of the anterior cruciate ligament in the dog: a model of osteoarthritis. Seminars in arthritis and rheumatism 1991;22-32.

127. Morgan JP. Canine hip dysplasia. Veterinary Radiology 1987;28:2-5.

128. Priester WA. Canine intervertebral disc disease-Occurrence by age, breed, and sex among 8,117 cases. Theriogenology 1976;6:293-303.

129. Meij BP, Bergknut N. Degenerative lumbosacral stenosis in dogs. The Veterinary clinics of North America Small animal practice 2010;40:983-1009. 
130. Bergknut N, Egenvall A, Hagman R, et al. Incidence and mortality of diseases related to intervertebral disc degeneration in a population of over 600,000 dogs. Journal of American Veterinary Medical Association 2012;240:1300-1309.

131. Bergknut N, Meij BP, Hagman R, et al. Intervertebral disc disease in dogs - part 1: a new histological grading scheme for classification of intervertebral disc degeneration in dogs. Vet $J$ 2013;195:156-163.

132. Edge-Hughes L. Hip and sacroiliac disease: Selected disorders and their management with physical therapy. Clinical Techniques in Small Animal Practice 2007;22:183-194.

133. Jones JC, Davies SE, Werre SR, et al. Effects of body position and clinical signs on L7-S1 intervertebral foraminal area and lumbosacral angle in dogs with lumbosacral disease as measured via computed tomography. American Journal of Veterinary Research 2008;69:1446-1454.

134. Gaschen L, Lang J, Haeni H. Intravertebral Disc Herniation (SchmorlsNode) In 5 Dogs. Veterinary Radiology \& Ultrasound 1995;36:509-516.

135. Haughton VM, Williams AL. Computed Tomography of the Spine. Journal of Computer Assisted Tomography 1982;6:1407.

136. Jones JC, Wilson ME, Bartels JE. A review of high resolution computed tomography and a proposed technique for regional examination of the canine lumbosacral spine. Veterinary Radiology \& Ultrasound 1994;35:339-346.

137. Fingeroth JM, Johnson GC, Burt JK, et al. Neuroradiographic diagnosis and surgical repair of tethered cord syndrome in an English bulldog with spina bifida and myeloschisis. J Am Vet Med Assoc 1989;194:1300-1302.

138. Burk RL. Problems in the radiographic interpretation of intervertebral disc disease in the dog. Probl Vet Med 1989;1:381-401.

139. Jones EC, Sorjonen DC, Simpson ST, et al. Comparison Between Computed Tomographic And Surgical Findings In Nine Large-Breed Dogs With Lumbosacral Stenosis. Veterinary Radiology \& Ultrasound 1996;37:247-256. 
140. Feeney DA, Evers P, Fletcher TF, et al. Computed tomography of the normal canine lumbosacral spine: a morphologic perspective. Veterinary Radiology \& Ultrasound 1996;37:399-411.

141. Clutton-Brock J. Origins of the dog: domestication and early history. The domestic dog: Its evolution, behaviour and interactions with people 1995:7-20.

142. Vila C, Savolainen P, Maldonado JE, et al. Multiple and ancient origins of the domestic dog. Science 1997;276:1687-1689.

143. Wayne RK, Geffen E, Girman DJ, et al. Molecular systematics of the Canidae. Syst Biol 1997;46:622-653.

144. Savolainen P, Zhang YP, Luo J, et al. Genetic evidence for an East Asian origin of domestic dogs. Science 2002;298:1610-1613.

145. Wang GD, Zhai W, Yang HC, et al. The genomics of selection in dogs and the parallel evolution between dogs and humans. Nat Commun 2013;4:1860.

146. Lindblad-Toh K, Wade C, Mikkelsen T, et al. Genome sequence, comparative analysis and haplotype structure of the domestic dog. Nature 2005;438:803 - 819 .

147. Quignon P, Herbin L, Cadieu E, et al. Canine population structure: assessment and impact of intra-breed stratification on SNP-based association studies. PLoS One 2007;2:e1324.

148. Leroy G, Verrier E, Meriaux JC, et al. Genetic diversity of dog breeds: between-breed diversity, breed assignation and conservation approaches. Anim Genet 2009;40:333-343.

149. Lindblad-Toh K, Wade CM, Mikkelsen TS, et al. Genome sequence, comparative analysis and haplotype structure of the domestic dog. Nature 2005;438:803-819.

150. Shearin AL, Ostrander EA. Leading the way: canine models of genomics and disease. Disease models \& mechanisms 2010;3:27-34.

151. Ostrander EA. Franklin H. Epstein Lecture. Both ends of the leash--the human links to good dogs with bad genes. N Engl J Med 2012;367:636-646. 
152. Vonholdt BM, Pollinger JP, Lohmueller KE, et al. Genome-wide SNP and haplotype analyses reveal a rich history underlying dog domestication. Nature 2010;464:898-902.

153. Parker HG. Genomic analyses of modern dog breeds. Mamm Genome 2012;23:19-27.

154. Ostrander EA, Galibert F, Patterson DF. Canine genetics comes of age. Trends Genet 2000;16:117-124.

155. Sargan DR. IDID: inherited diseases in dogs: web-based information for canine inherited disease genetics. Mamm Genome 2004;15:503-506.

156. Tsai KL, Clark LA, Murphy KE. Understanding hereditary diseases using the dog and human as companion model systems. Mamm Genome 2007;18:444-451.

157. Kirkness EF, Bafna V, Halpern AL, et al. The dog genome: survey sequencing and comparative analysis. Science 2003;301:1898-1903.

158. Haitina $T$, Fredriksson R, Foord S, et al. The G protein-coupled receptor subset of the dog genome is more similar to that in humans than rodents. $B M C$ Genomics 2009;10:24.

159. Goggin J, Li A-S, Franti C. Canine intervertebral disk disease: characterization by age, sex, breed, and anatomic site of involvement. American journal of veterinary research 1970;31:1687-1692.

160. Valentine B, Cummings J, Cooper B. Development of Duchenne-type cardiomyopathy. Morphologic studies in a canine model. The American journal of pathology 1989;135:671.

161. Pond M, Nuki G. Experimentally-induced osteoarthritis in the dog. Annals of the Rheumatic Diseases 1973;32:387.

162. Dong Y, Wang W, Cao J, et al. Quantitative evaluation of contrastenhanced ultrasonography in the diagnosis of chronic ischemic renal disease in a dog model. PLoS One 2013;8:e70337.

163. Han X, Liu H, Wang D, et al. Alveolar bone regeneration around immediate implants using an injectable $\mathrm{nHAC/CSH}$ loaded with autogenic blood- 
acquired mesenchymal progenitor cells: an experimental study in the dog mandible. Clin Implant Dent Relat Res 2013;15:390-401.

164. Li X, Wang X, Zhao T, et al. Guided bone regeneration using chitosancollagen membranes in dog dehiscence-type defect model. J Oral Maxillofac Surg 2014;72:304 e301-314.

165. Delamarter RB, Bohlman H, Dodge Lea, et al. Experimental lumbar spinal stenosis. Analysis of the cortical evoked potentials, microvasculature, and histopathology. J Bone Joint Surg Am 1990;72:110-120.

166. GÖDde T, Steffen F. Surgical Treatment of Lumbosacral Foraminal Stenosis Using a Lateral Approach in Twenty Dogs with Degenerative Lumbosacral Stenosis. Veterinary Surgery 2007;36:705-713.

167. Jeffery ND, Barker A, Harcourt-Brown T. What progress has been made in the understanding and treatment of degenerative lumbosacral stenosis in dogs during the past 30 years? The Veterinary Journal 2014;201:9-14.

168. Verbiest H. [Primary stenosis of the lumbar spinal canal in adults, a new syndrome]. Nederlands tijdschrift voor geneeskunde 1950;94:2415-2433.

169. Gradner G, Bockstahler B, Peham C, et al. Kinematic study of back movement in clinically sound malinois dogs with consideration of the effect of radiographic changes in the lumbosacral junction. Vet Surg 2007;36:472-481.

170. Kirkaldy-Willis WH, Paine KW, Cauchoix J, et al. Lumbar spinal stenosis. Clin Orthop Relat Res 1974:30-50.

171. Mclvor GW, Kirkaldy-Willis WH. Pathological and myelographic changes in the major types of lumbar spinal stenosis. Clin Orthop Relat Res 1976:72-76.

172. Katz JN, Harris MB. Clinical practice. Lumbar spinal stenosis. The New England journal of medicine 2008;358:818-825.

173. Fritz JM, Delitto A, Welch WC, et al. Lumbar spinal stenosis: a review of current concepts in evaluation, management, and outcome measurements. Arch Phys Med Rehabil 1998;79:700-708.

174. Genevay S, Atlas SJ. Lumbar spinal stenosis. Best Pract Res Clin Rheumatol 2010;24:253-265. 
175. Meij BP, Suwankong N, van den Brom WE, et al. Tibial nerve somatosensory evoked potentials in dogs with degenerative lumbosacral stenosis. Veterinary surgery : VS 2006;35:168-175.

176. Lazarowski L, Dorman DC. A comparison of pet and purpose-bred research dog (Canis familiaris) performance on human-guided object-choice tasks. Behav Processes 2014.

177. Sheldon JJ, Sersland T, Leborgne J. Computed tomography of the lower lumbar vertebral column. Normal anatomy and the stenotic canal. Radiology 1977;124:113-118.

178. Lee $\mathrm{CK}$, Hansen HT, Weiss AB. Developmental lumbar spinal stenosis. Pathology and surgical treatment. Spine (Phila Pa 1976) 1978;3:246-255.

179. Postacchini F, Pezzeri G, Montanaro A, et al. Computerised tomography in lumbar stenosis. A preliminary report. J Bone Joint Surg Br 1980;62-B:78-82.

180. Dorwart RH. Computed tomography of the lumbar spine: techniques, normal anatomy, pitfalls, and clinical applications. Crit Rev Diagn Imaging 1984;22:1-42.

181. Modic MT, Masaryk T, Boumphrey F, et al. Lumbar herniated disk disease and canal stenosis: prospective evaluation by surface coil MR, CT, and myelography. AJR Am J Roentgenol 1986;147:757-765.

182. Schnebel B, Kingston S, Watkins R, et al. Comparison of MRI to contrast CT in the diagnosis of spinal stenosis. Spine (Phila Pa 1976) 1989;14:332-337.

183. Sasaki K, Hasegawa K, Shimoda H, et al. Can recumbent magnetic resonance imaging replace myelography or computed tomography myelography for detecting lumbar spinal stenosis? Eur J Orthop Surg Traumatol 2013;23 Suppl 1:S7783.

184. Saifuddin A. The imaging of lumbar spinal stenosis. Clin Radiol 2000;55:581-594.

185. Saint-Louis LA. Lumbar spinal stenosis assessment with computed tomography, magnetic resonance imaging, and myelography. Clin Orthop Relat Res 2001:122-136. 
186. Ramirez O, Thrall DE. A Review Of Imaging Techniques For Canine Cauda Equina Syndrome. Veterinary Radiology \& Ultrasound 1998;39:283-296.

187. Jones JC, Banfield CM, Ward DL. Association between postoperative outcome and results of magnetic resonance imaging and computed tomography in working dogs with degenerative lumbosacral stenosis. J Am Vet Med Assoc 2000;216:1769-1774.

188. Jones JC, Shires PK, Inzana KD, et al. Evaluation of canine lumbosacral stenosis using intravenous contrast-enhanced computed tomography. Vet Radiol Ultrasound 1999;40:108-114.

189. De Risio L, Thomas WB, Sharp NJ. Degenerative lumbosacral stenosis. The Veterinary clinics of North America Small animal practice 2000;30:111-132, vi.

190. Suwankong N, Voorhout G, Hazewinkel HA, et al. Agreement between computed tomography, magnetic resonance imaging, and surgical findings in dogs with degenerative lumbosacral stenosis. Journal of the American Veterinary Medical Association 2006;229:1924-1929.

191. Jones JC, Inzana KD. Subclinical CT abnormalities in the lumbosacral spine of older large-breed dogs. Vet Radiol Ultrasound 2000;41:19-26.

192. van Schaik JJ, Verbiest H, van Schaik FD. Morphometry of lower lumbar vertebrae as seen on CT scans: newly recognized characteristics. AJR Am J Roentgenol 1985;145:327-335.

193. Haig AJ, Tomkins CC. Diagnosis and management of lumbar spinal stenosis. JAMA 2010;303:71-72.

194. Kanbara S, Yukawa Y, Ito K, et al. Dynamic changes in the dural sac of patients with lumbar canal stenosis evaluated by multidetector-row computed tomography after myelography. Eur Spine J 2014;23:74-79.

195. Senel A, Tanik A, Akan H. Quantitative assessment of the normal adult spinal canal at the fourth lumbar vertebra by computed tomography. Neuroradiology 1994;36:54-55.

196. Midia M, Miabi Z. Quantitative Size Assessment Of The Lumbar Spinal Canal By Computed Tomography. Acta Medica Iranica 2007;45:377-382. 
197. Williams AL, Haughton VM, Syvertsen A. Computed tomography in the diagnosis of herniated nucleus pulposus. Radiology 1980;135:95-99.

198. Clary RA, Pengilly A, Bailey M, et al. Analysis of voice outcomes in pediatric patients following surgical procedures for laryngotracheal stenosis. Arch Otolaryngol Head Neck Surg 1996;122:1189-1194.

199. Rushing H, Karl A, Wisnowski J. Design and Analysis of Experiments by Douglas Montgomery: A Supplement for Using JMP. Cary: SAS Institute, 2013.

200. Kaps M, Lamberson WR. Biostatistics for animal science. Cambridge, MA; Wallingford, Oxfordshire: CABI Pub, 2004.

201. Stokes ME, Davis CS, Koch GG. Categorical data analysis using the SAS system. Cary, NC; Hoboken, N.J.: SAS Institute, 2003.

202. Benjamini Y, Hochberg Y. Controlling the false discovery rate: a practical and powerful approach to multiple testing. Journal of the Royal Statistical Society Series B (Methodological) 1995:289-300.

203. Thanassoulis G, Campbell CY, Owens DS, et al. Genetic associations with valvular calcification and aortic stenosis. New England journal of medicine 2013;368:503-512.

204. Gould GA, MacNee W, McLean A, et al. CT Measurements of Lung Density in Life Can Quantitate Distal Airspace Enlargement-An Essential Defining Feature of Human Emphysema. American Review of Respiratory Disease 1988;137:380-392.

205. Lee Y, Oh Y-M, Lee J-H, et al. Quantitative Assessment of Emphysema, Air Trapping, and Airway Thickening on Computed Tomography. Lung 2008;186:157165.

206. Brookes DSK, Briody JN, Munns CF, et al. Cystic fibrosis-related bone disease in children: Examination of peripheral quantitative computed tomography (pQCT) data. Journal of Cystic Fibrosis 2015;14:668-677.

207. Schmidt C, Priemel M, Kohler T, et al. Precision and Accuracy of Peripheral Quantitative Computed Tomography ( $\mathrm{pQCT}$ ) in the Mouse Skeleton 
Compared With Histology and Microcomputed Tomography ( $\mu \mathrm{CT})$. Journal of Bone and Mineral Research 2003;18:1486-1496.

208. Bellus GA, Hefferon TW, de Luna RO, et al. Achondroplasia is defined by recurrent G380R mutations of FGFR3. American journal of human genetics 1995;56:368.

209. Antonarakis SE, Krawczak M, Cooper DN. The nature and mechanisms of human gene mutation. 2001.

210. Cooper DN. The nature and mechanisms of human gene mutation. The metabolic and molecular bases of inherited disease 1995:259-291.

211. Manolio TA, Collins FS, Cox NJ, et al. Finding the missing heritability of complex diseases. Nature 2009;461:747-753.

212. Visscher PM, Brown MA, McCarthy MI, et al. Five years of GWAS discovery. The American Journal of Human Genetics 2012;90:7-24.

213. Korte A, Farlow A. The advantages and limitations of trait analysis with GWAS: a review. Plant methods 2013;9:29.

214. Wray NR, Purcell SM, Visscher PM. Synthetic Associations Created by Rare Variants Do Not Explain Most GWAS Results. PLOS BIOLOGY 2011;9:e1000579.

215. Zeggini E, Scott LJ, Saxena R, et al. Meta-analysis of genome-wide association data and large-scale replication identifies additional susceptibility loci for type 2 diabetes. Nature genetics 2008;40:638-645.

216. Choi M, Scholl UI, Ji W, et al. Genetic diagnosis by whole exome capture and massively parallel DNA sequencing. Proceedings of the National Academy of Sciences 2009;106:19096-19101.

217. Cohen JC, Kiss RS, Pertsemlidis A, et al. Multiple rare alleles contribute to low plasma levels of HDL cholesterol. Science 2004;305:869-872.

218. Ji W, Foo JN, O'Roak BJ, et al. Rare independent mutations in renal salt handling genes contribute to blood pressure variation. Nature genetics 2008;40:592599.

219. Bamshad MJ, Ng SB, Bigham AW, et al. Exome sequencing as a tool for Mendelian disease gene discovery. Nature Reviews Genetics 2011;12:745-755. 
220. Do R, Kathiresan S, Abecasis GR. Exome sequencing and complex disease: practical aspects of rare variant association studies. Human molecular genetics 2012;21:R1-R9.

221. Parsons DW, Jones S, Zhang X, et al. An integrated genomic analysis of human glioblastoma multiforme. Science 2008;321:1807-1812.

222. Yu TW, Chahrour MH, Coulter ME, et al. Using whole-exome sequencing to identify inherited causes of autism. Neuron 2013;77.

223. O'Roak BJ, Deriziotis $\mathrm{P}$, Lee $\mathrm{C}$, et al. Exome sequencing in sporadic autism spectrum disorders identifies severe de novo mutations. Nat Genet 2011;43:585589.

224. Izumi R, Niihori T, Aoki Y, et al. Exome sequencing identifies a novel TTN mutation in a family with hereditary myopathy with early respiratory failure. $J$ Hum Genet 2013;58.

225. McInerney-Leo AM, Marshall MS, Gardiner B, et al. Whole exome sequencing is an efficient, sensitive and specific method of mutation detection in osteogenesis imperfecta and Marfan syndrome. BoneKEy Rep 2013;2.

226. Andrews S. FastQC: A quality control tool for high throughput sequence data. Reference Source 2010.

227. Bolger AM, Lohse M, Usadel B. Trimmomatic: a flexible trimmer for Illumina sequence data. Bioinformatics 2014:btu170.

228. Langmead B, Trapnell C, Pop M, et al. Ultrafast and memory-efficient alignment of short DNA sequences to the human genome. Genome Biology 2009;10:110.

229. Li H, Handsaker B, Wysoker A, et al. The sequence alignment/map format and SAMtools. Bioinformatics 2009;25:2078-2079.

230. Danecek $P$, Auton $A$, Abecasis $G$, et al. The variant call format and VCFtools. Bioinformatics 2011;27:2156-2158.

231. Cingolani $P$, Platts $A$, Wang LL, et al. A program for annotating and predicting the effects of single nucleotide polymorphisms, SnpEff: SNPs in the genome of Drosophila melanogaster strain w1118; iso-2; iso-3. Fly 2012;6:80-92. 
232. Hoeppner MP, Lundquist A, Pirun M, et al. An Improved Canine Genome and a Comprehensive Catalogue of Coding Genes and Non-Coding Transcripts. PLoS ONE 2014;9:e91172.

233. Karolchik D, Baertsch R, Diekhans M, et al. The UCSC genome browser database. Nucleic acids research 2003;31:51-54.

234. Rosenbloom KR, Armstrong J, Barber GP, et al. The UCSC genome browser database: 2015 update. Nucleic acids research 2015;43:D670-D681.

235. McLaren W, Pritchard B, Rios D, et al. Deriving the consequences of genomic variants with the Ensembl API and SNP Effect Predictor. Bioinformatics 2010;26:2069-2070.

236. Johnson M, Zaretskaya I, Raytselis Y, et al. NCBI BLAST: a better web interface. Nucleic acids research 2008;36:W5-W9.

237. Coordinators NR. Database resources of the national center for biotechnology information. Nucleic acids research 2015;43:D6.

238. Cunningham F, Amode MR, Barrell D, et al. Ensembl 2015. Nucleic acids research 2015;43:D662-D669.

239. Westermark P, Westermark GT, Suhr OB, et al. Transthyretin-derived amyloidosis: Probably a common cause of lumbar spinal stenosis. Upsala Journal of Medical Sciences 2014;119:223.

240. Tsuneyoshi Y, Tanaka M, Nagai T, et al. Functional folate receptor betaexpressing macrophages in osteoarthritis synovium and their M1/M2 expression profiles. Scand J Rheumatol 2012;41:132-140.

241. Jones $\mathrm{MH}$, Furlong RA, Burkin $\mathrm{H}$, et al. The Drosophila developmental gene fat facets has a human homologue in Xp11.4 which escapes $\mathrm{X}$-inactivation and has related sequences on Yq11.2. Hum Mol Genet 1996;5:1695-1701.

242. Li D, Lewinger JP, Gauderman WJ, et al. Using extreme phenotype sampling to identify the rare causal variants of quantitative traits in association studies. Genetic epidemiology 2011;35:790-799.

243. Alhassan A, Iseki H, Kim C, et al. Comparison of polymerase chain reaction methods for the detection of Theileria equi infection using whole blood 
compared with pre-extracted DNA samples as PCR templates. Tropical animal health and production 2007;39:369-374.

244. Chang H-S, Mizukami K, Yabuki A, et al. A novel rapid genotyping technique for Collie eye anomaly: SYBR Green-based real-time polymerase chain reaction method applicable to blood and saliva specimens on Flinders Technology Associates filter paper. Journal of veterinary diagnostic investigation 2010;22:708-715.

245. Scharf G, Steffen F, Grunenfelder F, et al. The lumbosacral junction in working german shepherd dogs -- neurological and radiological evaluation. J Vet Med A Physiol Pathol Clin Med 2004;51:27-32.

246. Pitkänen P, Westermark P, Cornwell GG. Senile systemic amyloidosis. The American Journal of Pathology 1984;117:391-399.

247. Sueyoshi T, Ueda M, Jono $\mathrm{H}$, et al. Wild-type transthyretin-derived amyloidosis in various ligaments and tendons. Human Pathology 2011;42:1259-1264.

248. Sipe JD, Benson MD, Buxbaum JN, et al. Amyloid fibril protein nomenclature: 2012 recommendations from the Nomenclature Committee of the International Society of Amyloidosis. Amyloid 2012;19:167-170.

249. Glenner GG, Wong CW. Alzheimer's disease and Down's syndrome: sharing of a unique cerebrovascular amyloid fibril protein. Biochemical and biophysical research communications 1984;122:1131-1135.

250. Ladefoged C, Christensen HE, Sorensen KH. Amyloid in osteoarthritic hip joints. Depositions in cartilage and capsule. Semiquantitative aspects. Acta Orthop Scand 1982;53:587-590.

251. Ladefoged C. Amyloid in osteoarthritic hip joints: deposits in relation to chondromatosis, pyrophosphate, and inflammatory cell infiltrate in the synovial membrane and fibrous capsule. Ann Rheum Dis 1983;42:659-664.

252. Ladefoged C, Fedders O, Petersen OF. Amyloid in intervertebral discs: a histopathological investigation of surgical material from 100 consecutive operations on herniated discs. Ann Rheum Dis 1986;45:239-243. 
Appendix I: Protocol used for DNA extraction from FTA cards

\section{GenTegra $^{\mathrm{TM}}$ GenSolve $^{\mathrm{TM}}$ DNA recovery Kit (GenTegra LLC., Pleasanton, CA)}

\section{Kit Contents}

1. Recovery Solution $\mathrm{A} ; 0.2 \mathrm{ml}, 4$ each

2. $1 \%$ LiDS Solution; $66 \mathrm{ml}, 1$ bottle

3. Protease solution; $2.5 \mathrm{ml}, 1$ vial

4. Recovery Solution B; $2.5 \mathrm{ml}, 1$ vial

5. User Guide

\section{Storage}

Protease should be stored at $2-8^{\circ} \mathrm{C}$. All other components can be stored at either room temperature or $2-8{ }^{\circ} \mathrm{C}$. After re-suspension and addition of Protease, Recovery Solution A should be used within 2-3 hours for maximum DNA yield.

\section{Additional Equipment and Materials required}

- Incubator/Shaker

- GenTegra Spin Basket/Tube Assembly (GenTegra \#GVSPIN250)

○ Ethanol, $100 \%$

- QIAGEN QIAamp DNA Blood Mini Kit (50 preps, QIAGEN \#51104)

- QIAGEN $2.0 \mathrm{ml}$ collection tubes (QIAGEN \#19201)

- Millipore Microcon MRCF0R100 (optional)

- Microfuge Tubes, $1.7 \mathrm{ml}$ and $2.0 \mathrm{ml}$

- P200 and P1000 pipettes, pipette tips

$\circ$ Microcentrifuge 


\section{Kit Protocol}

\section{Stage 1: DNA recovery}

1. Pre-heat Incubator/Shaker to $65^{\circ} \mathrm{C}$.

2. To the bottle of Solution A, add 1\% LiDS according to the volumes in Table 1 .

Table 1. Volume of $1 \%$ LiDS and Protease used to add to Solution A

\begin{tabular}{|l|l|}
\hline Volume of 1\% LiDS & Volume of Protease \\
\hline $16 \mathrm{ml}$ & $535 \mu \mathrm{L}$ \\
\hline
\end{tabular}

3. Vortex briefly to mix Solution A bottle and LiDS solution.

4. Add Protease into the vial of Solution A from Step 2 according to the volumes described in Table 1 and vortex briefly.

5. Punch element(s) into one $2 \mathrm{ml}$ microtube for each unique sample.

6. Add $620 \mu \mathrm{L}$ of Recovery Solution A/Protease mix.

7. Place the tube in the Incubator/Shaker pre-heated to $65^{\circ} \mathrm{C}$. Vortex $\sim 1$ minute at $1,400 \mathrm{rpm}$ and inspect to make sure that each element is completely submerged in the solution; repeat until all elements are submerged. Continue vortexing for one hour. It is important to vortex at $1,400 \mathrm{rpm}$ for maximum DNA recovery. If speed $<1,400 \mathrm{rpm}$, vortex for 2 hours, speed $<700 \mathrm{rpm}$ is not recommended.

8. Centrifuge at $16,300 \times \mathrm{g}$ for 0.5 minutes to collect liquid off cap.

9. Add $20 \mu \mathrm{L}$ of Recovery Solution B to a new microcentrifuge tube and insert a spin basket. Transfer the solution from step 7 into the Spin Basket making sure to transfer along the element(s) by scooping it with pipette tip.

10. Centrifuge at $16,300 \times \mathrm{g}$ for two minutes.

11. Discard Spin Basket and element.

12. Pulse vortex each microtube.

13. Proceed directly to DNA purification. 


\section{Stage 2: DNA Purification}

1. Add $600 \mu \mathrm{L}$ of $100 \%$ Ethanol to each microtube containing recovered DNA.

2. Pulse-vortex each sample. Centrifuge briefly.

3. Load $600 \mu \mathrm{L}$ of the sample onto a spin column/collection tube. Close the cap and centrifuge at $6,000 \times \mathrm{g}$ for 1 minute. Place the spin column in a new $2 \mathrm{ml}$ collection tube and discard the tube containing the filtrate.

4. Repeat step 3 until the entire sample has been applied into the spin column.

5. Add $500 \mu \mathrm{L}$ of AW1 Buffer onto the spin column and centrifuge at $6,000 \times \mathrm{g}$ for 1 minute. Discard the collection tube containing the filtrate and place the spin column in a new $2 \mathrm{ml}$ collection tube.

6. Add $500 \mu \mathrm{L}$ of AW2 Buffer onto the spin column and centrifuge at $16,300 \times \mathrm{g}$ for 4 minutes. Discard the collection tube containing the filtrate and place the spin column in a new $2 \mathrm{ml}$ collection tube.

7. Centrifuge at $16,300 \times \mathrm{g}$ for 1.5 minutes.

8. Place the spin column in a new $1.7 \mathrm{ml}$ tube.

9. Elute the DNA sample by adding $200 \mu \mathrm{L}$ of AE Buffer to spin column. Incubate the sample at room temperature for 5 minutes and centrifuge at $6000 \times \mathrm{g}$ for 1 minute.

10. Elute is ready for quantitation and downstream analysis. 


\section{Appendix II: Description of an unexpected qualitative phenotypic trait observed}

in this sample of Labrador retrievers, i.e. "a reverse trapezoid vertebral canal". Previous studies have reported that the shape of the lumbosacral canal becomes progressively semi-circular or crescent shaped as it transitions from the cranial to the caudal end of the canal ${ }^{112}$, with the cross-sectional area of the canal is at its greatest at mid-lumbar level and gets progressively narrower both cranially and caudally to that. Conventional belief is that the canal begins wider at the lumbar level and then progressively narrows as the canal transitions to the sacrum.

However, during the construction of bar-graphs to represent mean canal area ratio (CAR) and mean fat area ratio (FAR) values of LS negative and LS positive dogs at each of the 6 vertebral locations ( $\mathrm{L} 5 \mathrm{Cd}-\mathrm{S} 1 \mathrm{Cr}$ ) in chapter III, an interesting observation was made with regards to the shape and size of the vertebral canal as it transitions from the cranial end to the caudal end of the body. At each vertebral level, the cranial end was narrower than the caudal end. This "reverse trapezoid" pattern of the vertebral canal was not found to be reported in any previously published literature.

This structural characteristic of the lumbosacral spine was observed in all dogs in both the studies ( 1 and 2 ) of this project for both the ratio measurements: mean canal area ratio or CAR (Figure A.1 and A.2); and mean fat area ratio or FAR (Figure A.3 and A.4). Since vertebral body measurements were used to construct the ratios, the analyses were also repeated with the absolute values to test whether the vertebral body dimensions could be a source of variation. However, this trend was observed in both sets of absolute values - mean canal area or CA (Figure A.5 and A.6); and mean fat area or FA (Figure A.7 and A.8).

This trait appears to be more prominent from L5 cranial to $\mathrm{S} 1$ cranial locations. It is important to note that all dogs in our project were of a single breed i.e. Labrador retrievers. So this trait could be specific to this breed alone, or it could be a canine morphological trait in general. The number of dogs in both studies was too small to 
assign this trait to this specific breed. Further studies are needed in larger sample of Labrador retrievers (to validate this observation) as well as other breeds of dogs to characterize this phenotype as either breed specific or non-breed specific. 
Figure A.1.

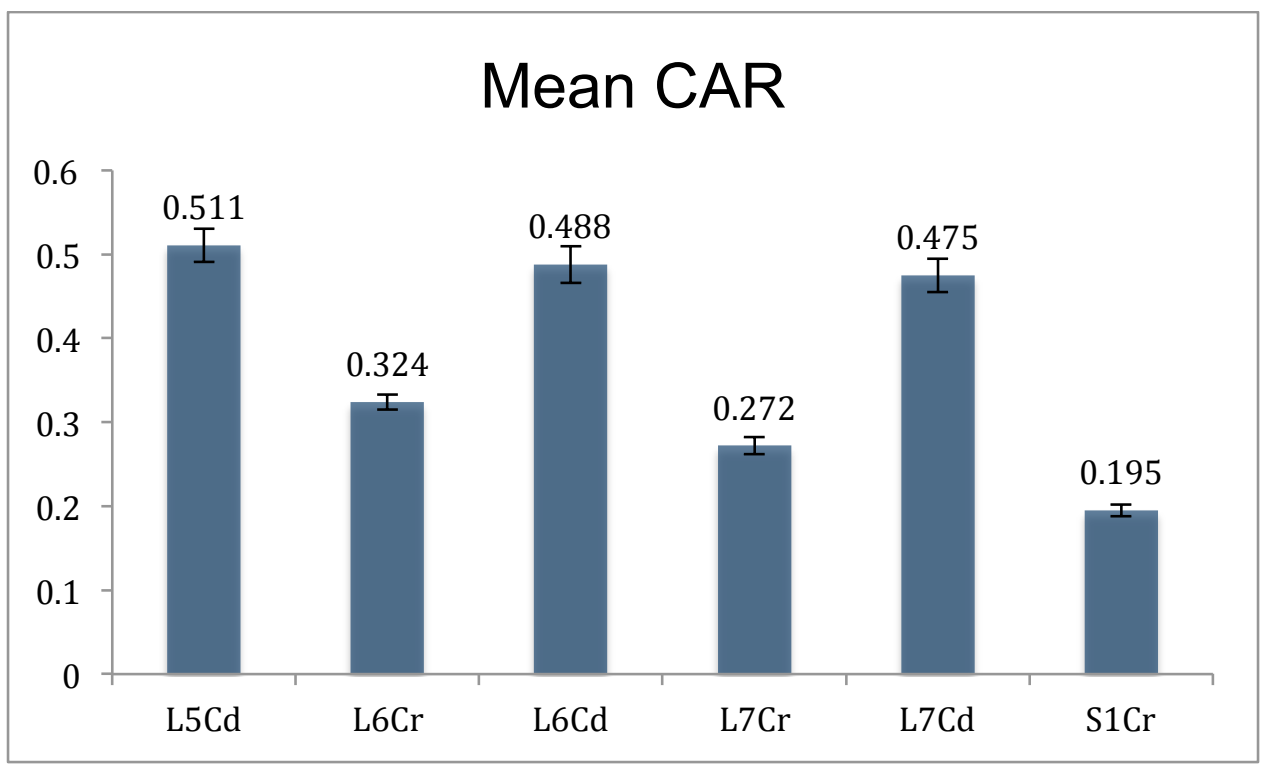

Figure A.1. Mean canal area ratios (CARs) in study 1 $(\mathrm{N}=24$ at L5Cd $-\mathrm{L} 6 \mathrm{Cr} ; \mathrm{N}=25$ at L6Cd $-\mathrm{S} 1 \mathrm{Cr})$ 
Figure A.2.

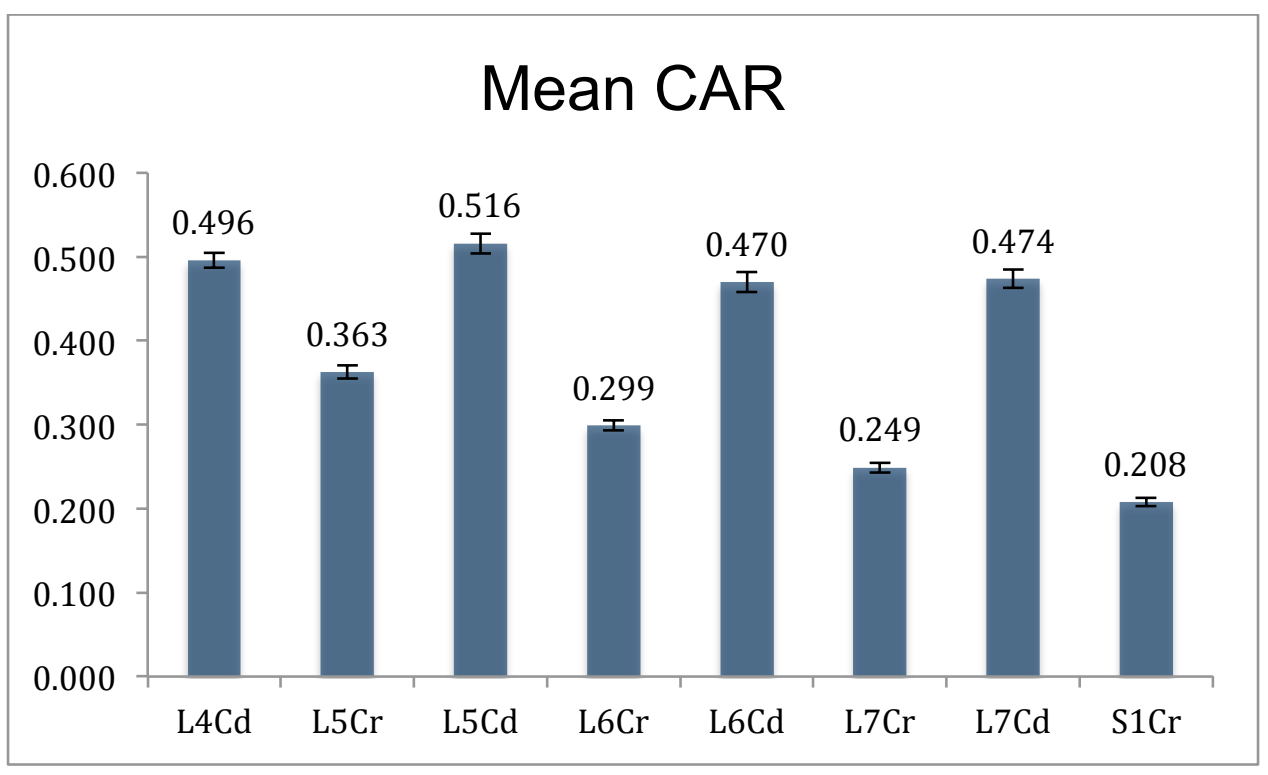

Figure A.2. Mean canal area ratios (CARs) in study 2 $(\mathrm{N}=40$ at $\mathrm{L} 4 \mathrm{Cd}-\mathrm{S} 1 \mathrm{Cr})$ 
Figure A.3.

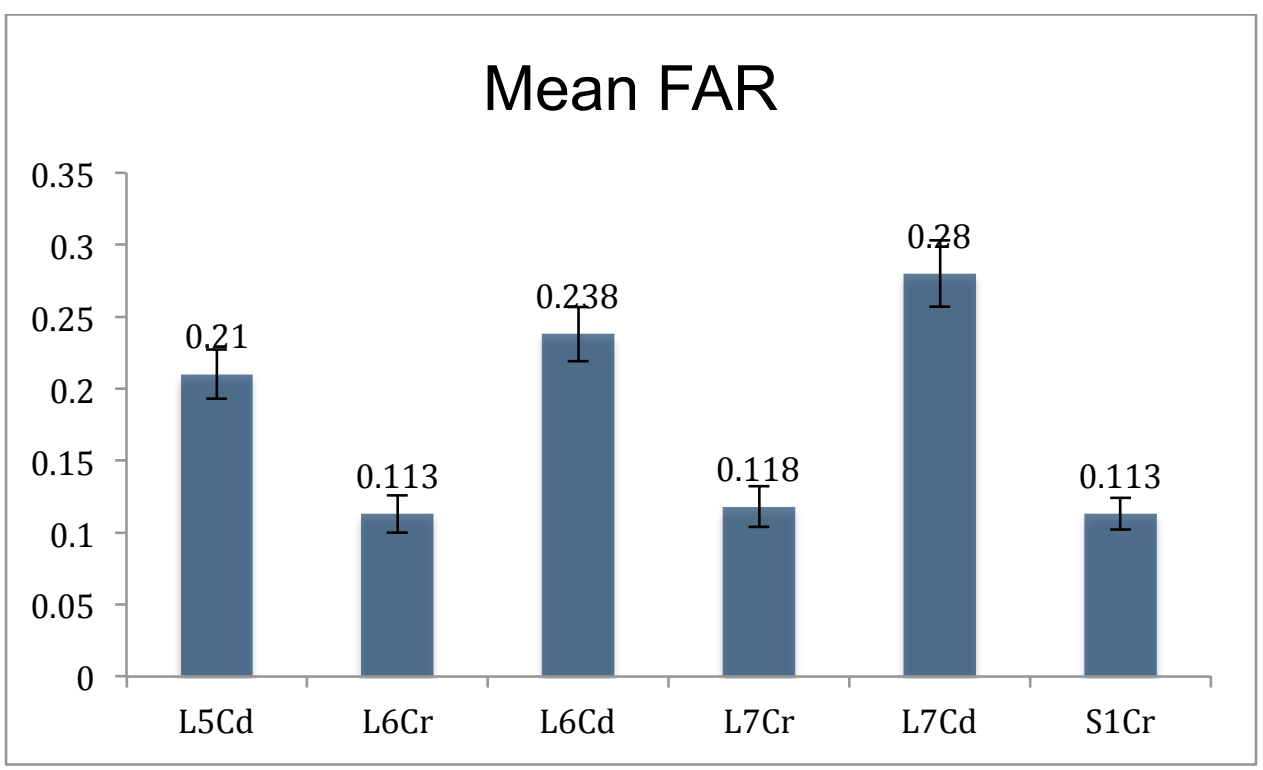

Figure A.3. Mean fat area ratios (FARs) in study 1 $(\mathrm{N}=24$ at $\mathrm{L} 5 \mathrm{Cd}-\mathrm{L} 6 \mathrm{Cr} ; \mathrm{N}=25$ at L6Cd $-\mathrm{S} 1 \mathrm{Cr})$ 
Figure A.4.

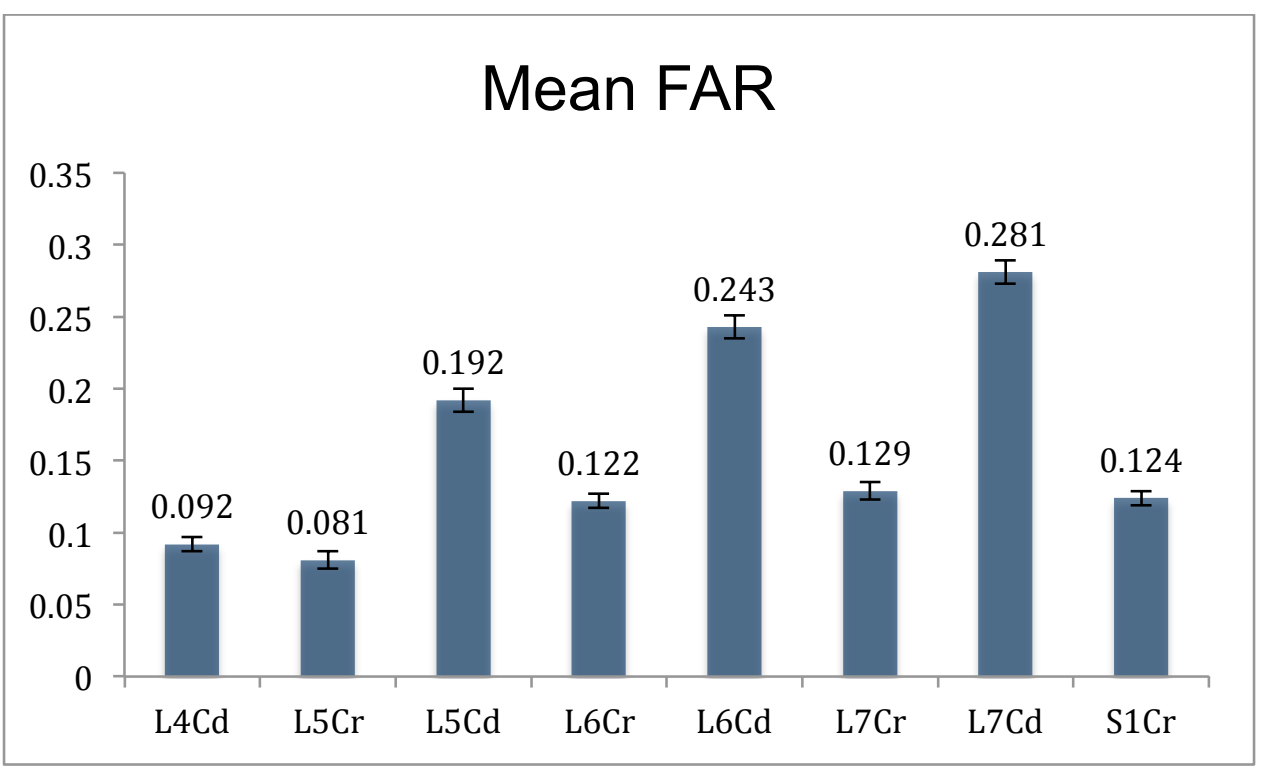

Figure A.4. Mean fat area ratios (FARs) in study 2

$(\mathrm{N}=40$ at $\mathrm{L} 4 \mathrm{Cd}-\mathrm{S} 1 \mathrm{Cr})$ 
Figure A.5.

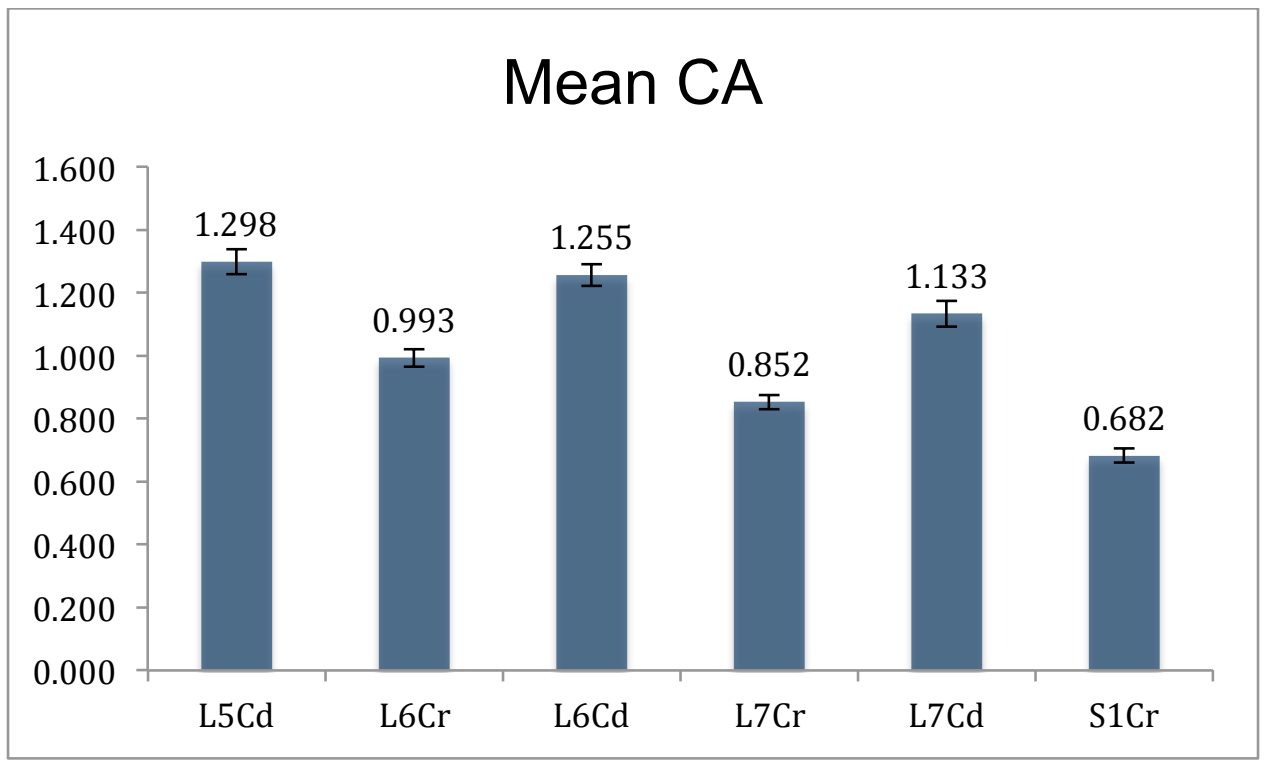

Figure A.5. Mean canal areas (CAs) in study 1 $(\mathrm{N}=24$ at L5Cd - L6Cr; $\mathrm{N}=25$ at L6Cd $-\mathrm{S} 1 \mathrm{Cr})$ 
Figure A.6.

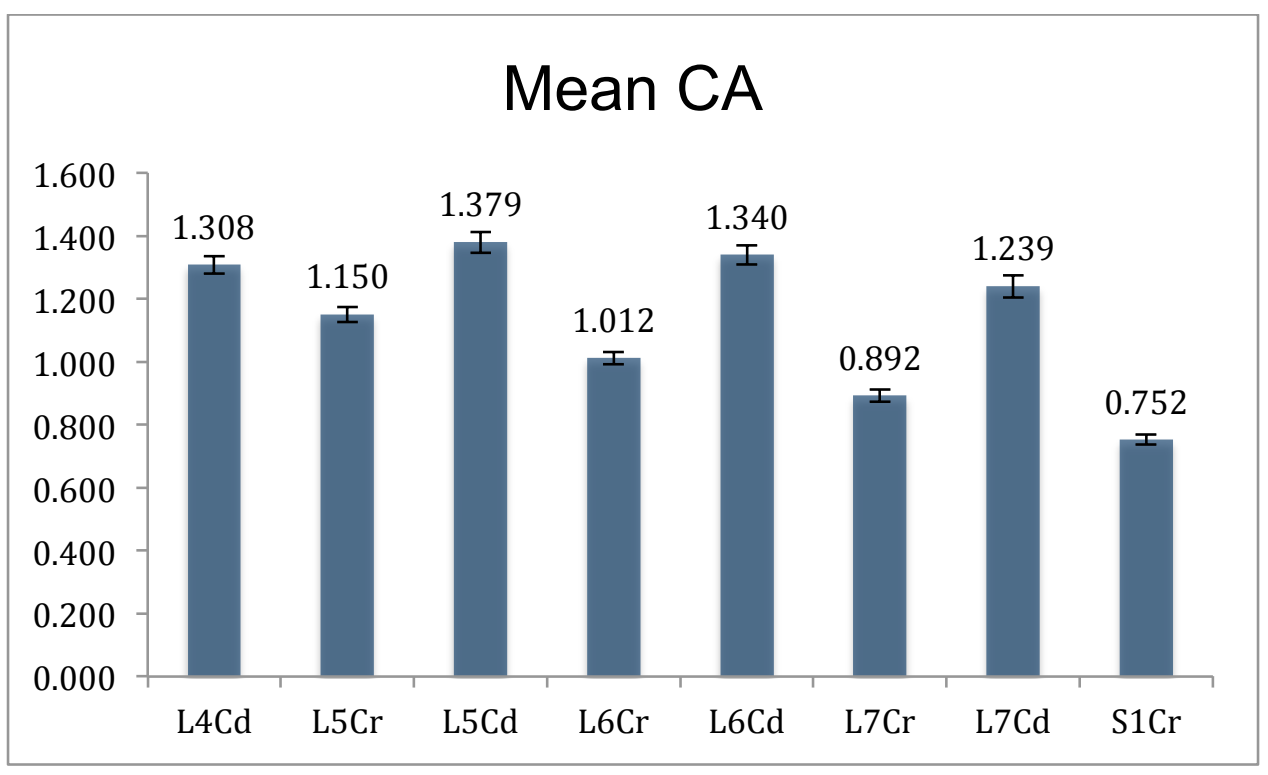

Figure A.6. Mean canal areas (CAs) in study 2 $(\mathrm{N}=40$ at $\mathrm{L} 4 \mathrm{Cd}-\mathrm{S} 1 \mathrm{Cr})$ 
Figure A.7.

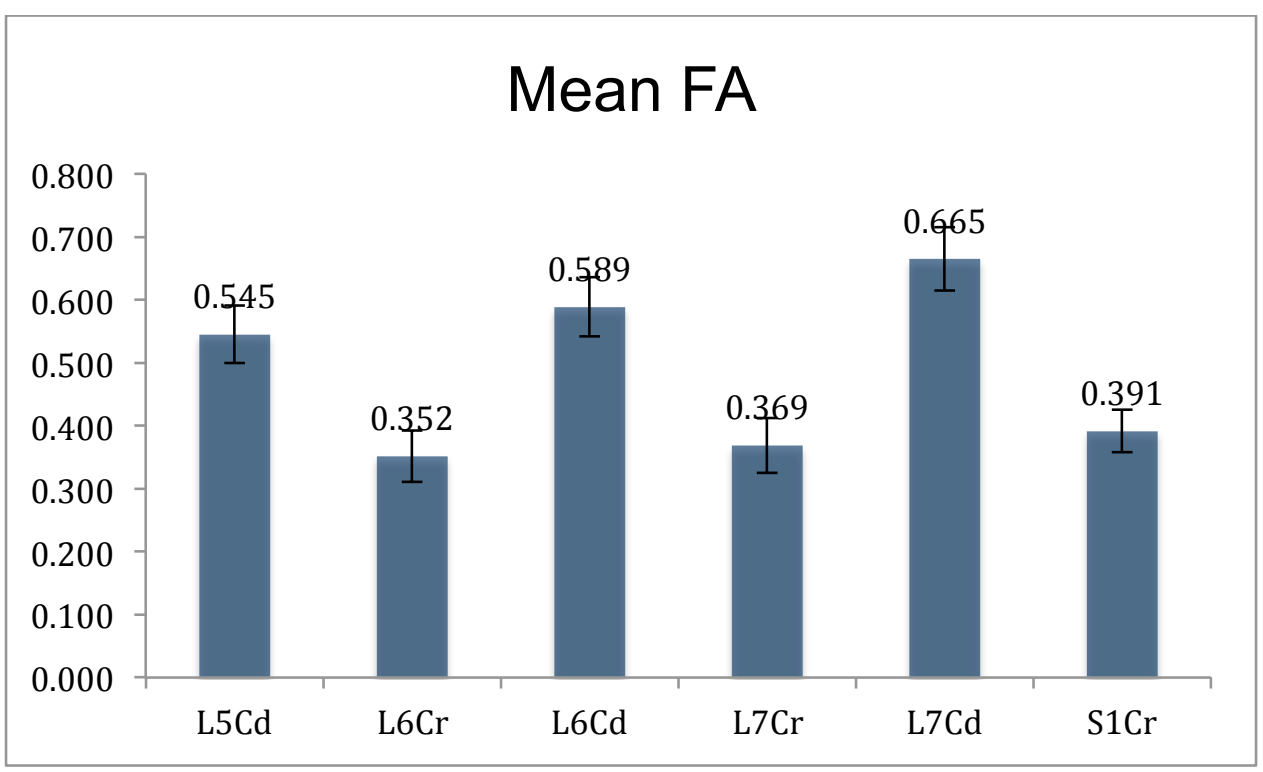

Figure A.7. Mean fat areas (FAs) in study 1 $(\mathrm{N}=24$ at $\mathrm{L} 5 \mathrm{Cd}-\mathrm{L} 6 \mathrm{Cr} ; \mathrm{N}=25$ at L6Cd $-\mathrm{S} 1 \mathrm{Cr})$ 
Figure A.8.

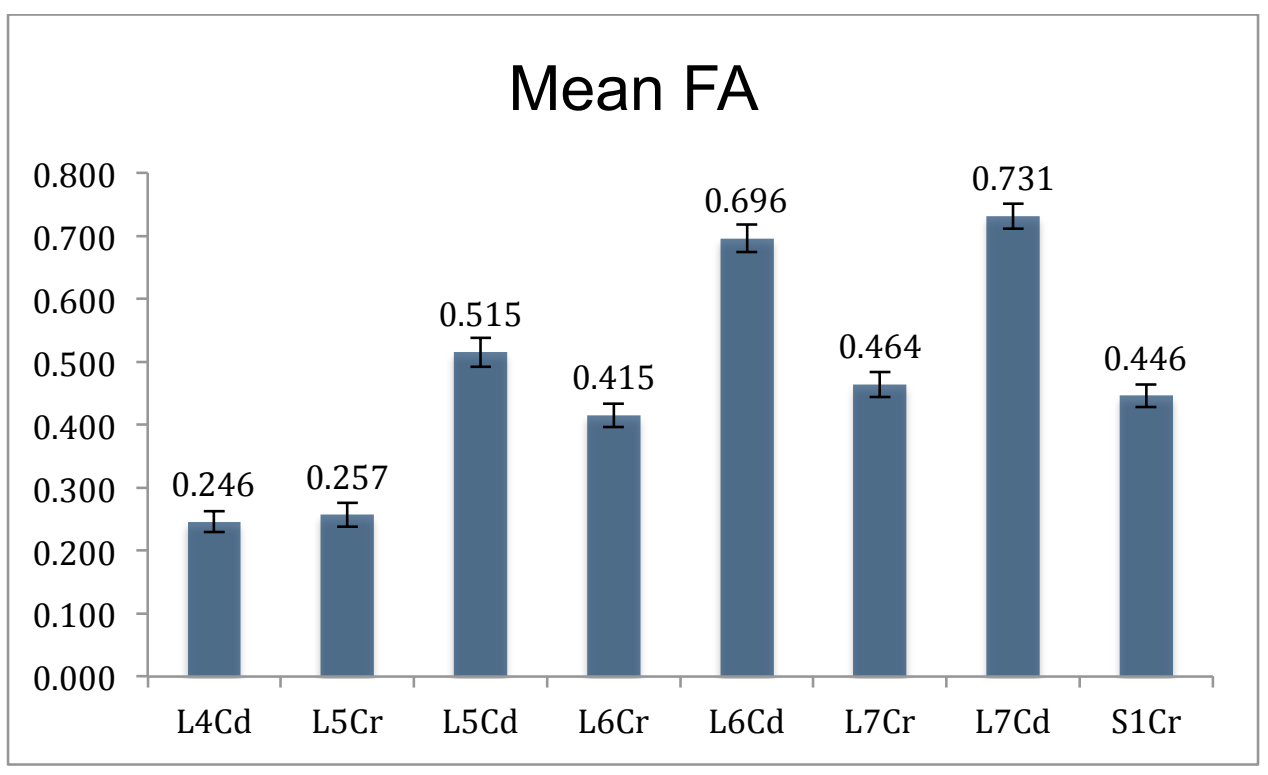

Figure A.8. Mean fat areas (FAs) in study 2

$(\mathrm{N}=40$ at $\mathrm{L} 4 \mathrm{Cd}-\mathrm{S} 1 \mathrm{Cr})$ 
Appendix III: Logistic regression analysis of the association between FAR and qualitative LS status in the $\mathbf{4 0}$ dogs recruited for the second study (chapter IV)

Logistic regression analysis from study 1 was repeated in 40 dogs of the second study (see chapter III). The association between fat area ratio (FAR) values and the qualitative assessment of LS was statistically significant $(p<0.0001)$ at only one vertebral location - L6 cranial (Figure A.9). We were able to identify that age is a covariant in this model, i.e. FAR values have better correspondence with qualitative LS status with increasing age (Figure A.10). Study 1 was able to identify that older dogs have a higher incidence of qualitative LS. However it is important to note that older dogs are at a higher risk of acquiring degenerative LS, a disease process that could be separate from idiopathic LS (type of LS probably observed in study 2 sample of young Labrador retrievers). This warrants further analysis where distinction between idiopathic LS and degenerative LS is possible. 
Figure A.9.

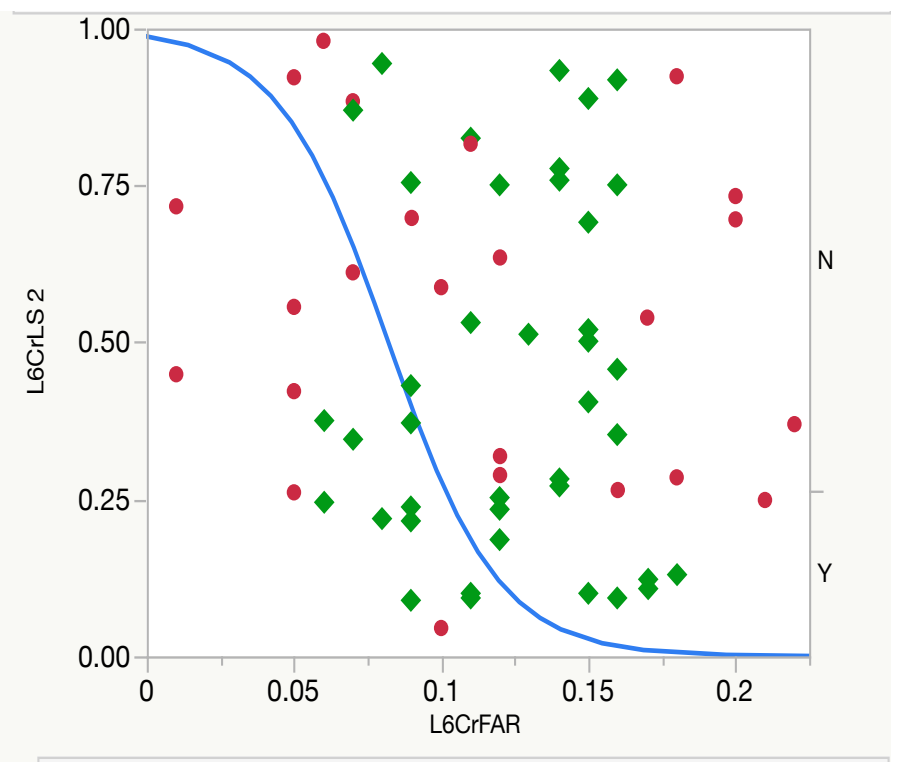

Figure A.9. Logistic regression of $F A R \vee$ qualitative $L S$ at $\mathrm{L} 6 \mathrm{Cr}$ 
Figure A.10.

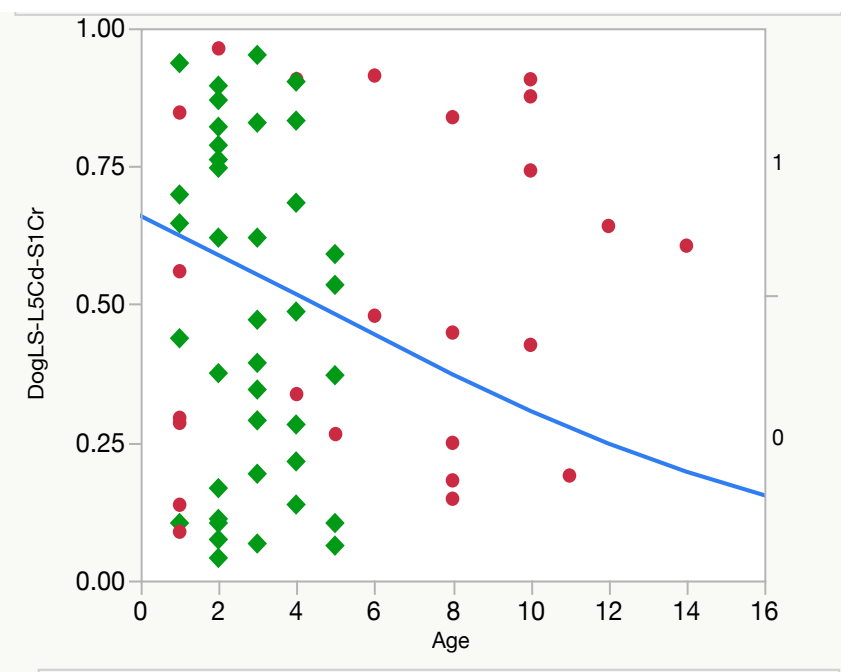

Figure A.10. Logistic regression of age $v$ qualitative $\mathrm{LS}$ at $\mathrm{L} 6 \mathrm{Cr}$ 


\section{Appendix IV: Proposed explanations for clinical low back pain observed in dogs}

\section{from both studies.}

In study 1, there were 14 LS positive dogs. Eight of these 14 dogs were low back pain (LBP) negative. The remaining 6 dogs were positive for both LS and LBP. Five out of these 6 dogs (83.33\%) were stenotic at more than one vertebral level, while the remaining 1 dog was LS positive at only one vertebral location. There were 3 (out of 11) dogs that were LBP positive despite being LS negative. This contradiction can be explained by the presence of one or more of the following conditions that can cause LBP in the lumbosacral junction (besides LS) in all 3 dogs: sacroiliac joint disease ${ }^{132}$, foraminal stenosis ${ }^{133}$, and Schmorl's nodes ${ }^{134}$.

In study 2 there were 33 LS positive dogs. Fifteen out of these 33 were LBP negative (possible causes explained in previous chapters). The remaining 18 were positive for both LS and LBP. Fourteen of these 18 dogs (77.78\%) were stenotic at more than one vertebral level, while the remaining 4 were LS positive at only a single location. There were 6 (out of 7 ) dogs that were LBP positive despite being LS negative. Again the reason for this discrepancy could be due to other clinical conditions that can affect the lumbosacral spine of large breed dogs.

Out of the 8 dogs selected for exome sequencing, the LS positive group comprised of 2 LBP positive dogs and 2 LBP negative dogs. It is interesting to note that the 2 LBP negative LS positive dogs had stenosis at only 1 vertebral level, while each of the 2 LBP positive LS positive dogs were stenotic at more than 2 levels ( 3 and 4 levels). On the other hand the LS negative group had only 1 dog that was negative for both LS and LBP. The other 3 dogs showed signs of pain, though only one of them had stenosis at a single level. The pain displayed by these relatively asymptomatic dogs could be due to other reasons (previously described) besides LS.

So in both studies, majority ( $83 \%$ in study 1 , and $78 \%$ in study 2 ) of the LS positive dogs that were also LBP positive, were stenotic at more than one vertebral level. This 
observation could be explained by the theory that compression of the cauda equina nerves at 2 or more locations causes increased disruption of electrical signals and arterial blood supply ${ }^{6562}$. Future studies are necessary to understand the true nature of the relationship between LS and LBP, especially the significance of LS at multiple vertebral levels on presence or absence of LBP. 
Appendix V: Analysis of covariance and multivariate logistic regression tests for effects of covariates on comparisons between FAR and LS status in dogs from both studies.

Analyses of covariance (ANCOVA) were done using PROC GLM procedure of statistical software SAS on combined datasets of studies 1 and $2(N=65)$. The ANCOVA tested whether regression of the quantitative measurement FAR on age (covariate) differed between the two groups (LS positive and LS negative) at the 6 common vertebral locations: L5Cd, L6Cr, L6Cd, L7Cr, L7Cd and S1Cr. The terms in the model are: main effect of group, main effect of age and the interaction of the group and age. The significant interaction of age and group in the ANCOVA would be an indicator of the different slopes between the two groups (LS positive and LS negative). The $p$-values for ANCOVA analyses on the combined dataset were significant for the main effect of group (qualitative diagnosis of LS) at all locations except L5Cd: L6Cr ( $p<0.0001)$, L6Cd $(p=0.0097), \operatorname{L7Cr}(p=0.0010), \operatorname{LCCd}(p<0.0001)$ and $\mathrm{S} 1 \mathrm{Cr}(p<0.0001)$. This also serves as a verification of earlier results of study 1 and $L 6 C r$ results in study 2 . The $p$-value was also significant for the main effect of age at $\mathrm{LTCr}(p=0.0058)$. However, the interaction term (age and qualitative LS) was not significant at any of the 6 locations.

In addition the multivariate logistic regression was done on this combined dataset, where variables such as age, weight, and sex were added besides the LS diagnosis to see if any of them or their interactions can predict FAR. The $p$-values were significant for the main effect of LS at 4 of the 6 vertebral locations: $L 5 C d(p=0.0189), L 6 \mathrm{Cr}$ $(p<0.0001), \operatorname{L7Cr}(p=0.0018)$ and $\mathrm{S} 1 \mathrm{Cr}(\mathrm{p}=0.0033)$. Interaction of age with LS status and age was not significant at any of the 6 locations. in agreement with previous findings) 


\section{CURRICULUM VITAE}

\section{Meenakshi Mukherjee}

Address: 1108 Tiger Boulevard Apt \#121• Clemson, SC 29631

Phone: (304) 7773640 • E-Mail: meenakshi.mukherjee9@gmail.com

\section{Education}

Ph.D. candidate in Genetics

Department of Genetics and Developmental Biology

Davis College of Agriculture, Natural Resources and Design

West Virginia University

Morgantown, WV

2011 - Present [Expected graduation May 13 ${ }^{\text {th }}, 2016$ ]

Master of Science in Biomedical Genetics (Thesis option)

Vellore Institute of Technology University

Vellore, India

$2008-2010$

Bachelor of Science in Genetics

Bangalore University

Bangalore, India

$2005-2008$ 


\section{Employment experience}

Graduate Research Assistant

Department of Animal and Nutritional Sciences

Davis College of Agriculture, Natural Resources and Design

West Virginia University

Morgantown, WV (2011 - 2015)

Research Specialist

Department of Animal and Veterinary Sciences

College of Agriculture, Forestry and Life Sciences

Clemson University

Clemson, SC (2015 - Present [Expected end date July 2016])

\section{Lecturer}

Department of Animal and Veterinary Sciences

College of Agriculture, Forestry and Life Sciences

Clemson University

Clemson, SC (Fall 2015)

\section{Teaching Experience}

1. Graduate Teaching Assistant

Current Literature - Animal Science course (A\&VS 451)

Department of Animal and Nutritional Sciences, West Virginia University (2012 - 2014)

Course description: advanced level scientific writing course intended for senior undergraduate students in varying majors (pre-veterinary, animal science, nutrition, premed, wildlife, biology)

Responsibilities: assisting students in performing literature search, critiquing scientific articles with respect to research question and writing literature reviews; evaluating and grading student literature reviews and seminar presentations 


\section{Graduate Teaching Assistant}

Intro to Animal Physiology course (ANPH 301)

Department of Animal and Nutritional Sciences, West Virginia University (2013 - 2014)

Course description: introductory level animal physiology course intended for $3^{\text {rd }}$ year undergraduate students in varying majors (pre-veterinary, animal science, nutrition, premed, wildlife, biology)

Responsibilities: grading homework assignments and extra-credit assignments; monitoring examinations; tutoring; giving two lectures and creating questions for examination covering the reproductive physiology portion of the course

\section{Primary Instructor}

Animal Genetics course (AVS 4700/6700)

Department of Animal and Veterinary Sciences, Clemson University (Fall 2015)

Course description: animal genetics course intended for $3^{\text {rd }} / 4^{\text {th }}$ year undergraduate and graduate students of the College of Agriculture, Forestry and Life Sciences (predominantly pre-veterinary, animal agribusiness, and wildlife and fisheries majors)

Responsibilities: completely redesigned course, introducing a new textbook; creating lecture slides and presentations; creating and grading new homework assignments, examinations and scientific writing assignments; evaluating graduate student presentations; maintaining course materials on blackboard (online repository), holding regular office hours

Goal: ensuring that the material taught (genetic principles and their applications underlying modern day animal science practices) was approachable to students with diverse backgrounds with respect to experience with genetics. 
4. Research Assistant

Jones Research Lab

Department of Animal and Veterinary Sciences, Clemson University (Fall 2015 present)

Responsibilities: assisting Dr. Jones with research data collection, analysis, and preparation/submission of publications; assisting undergraduate research students and MS students in lab with their research projects; advising/mentoring student members of the lab; participation in journal club meetings; assistance with statistical analyses; assistance with writing; assistance with strategies for meeting their GTA responsibilities

\section{Undergraduate and Graduate Students Mentored in Research}

Ben Stewart - 2011 - 2014 (currently Masters student at Colorado State University) Bethany Cain - 2013 - 2014 (currently Veterinary Medicine student at Virginia Tech) Michael Carnevale - 2013 - 2016 (currently a Masters student at Clemson University) Catherine Jula - $2014-2015$ (currently a veterinary student at OSU)

Tiana Dodd - $2014-2015$ (currently pre-vet student at WVU)

\section{Research Experience}

Doctoral Research

Phenotypic and genotypic characterization of lumbosacral stenosis in Labrador Retrievers

Co-major advisors: Dr. Jeryl Jones and Dr. Jianbo Yao

Advisory committee members: Dr. Amy Welsh, Dr. Barbara Meade and Dr. Raymond Raylman

Field of study: Canine Genetics (and CT image analysis)

Department of Animal and Nutritional Sciences

West Virginia University

Morgantown, WV

Aug 2011 - Present [Expected graduation date: $13^{\text {th }}$ May 2016] 


\section{Masters Research}

The effect of neem leaf glycoprotein on growth and control of metastasis of B16 melanoma cell line in murine model C57BL/6

Field of study: Cancer Immunology

Supervisor: Dr. Rathindranath Baral

Department of Immunoregulation and Immunodiagnostics (IRID)

Chittaranjan National Cancer Institute ( $\mathrm{CNCl})$

Kolkata, India

Jan 2010 - Jun 2010

\section{Research Interests}

The primary focus area of my current research is canine genetics. The emphasis of my doctoral research project has been the investigation of the role of genetics in the canine disease of lumbosacral stenosis. Prevalent in large sized dog breeds (especially in Labrador retrievers), lumbosacral stenosis is the leading cause of low back pain and retirement in working dogs. I am interested in continuing research in this area with my long-term research goal being the identification of genetic markers for lumbosacral stenosis in dogs that could then possibly lead to designing of a simple and inexpensive diagnostic test.

\section{Grants}

1. Co-Pl's Jones J, Yao J.

Genetic risk factors for lumbosacral stenosis in Labrador Retrievers

US Army Research Office

$\$ 29,999$ (2013 - 2015)

Provided detailed methodology content for the following grant as graduate research assistant in Dr. Jones' lab 


\section{PI: Mukherjee, $M$.}

Genetic Risk Factors for Lower Back Disease in Labrador Retrievers

Stitzel Graduate Student Support Fund (Davis College of Agriculture, Natural

Resources and Design Graduate Enrichment Fund Awards 2014-2015

$\$ 1000$ (2014 - 2015)

Presented poster in the annual Plant and Animal Genome (PAG XXIII) conference in San Diego, CA (January 2015)

\section{Scientific Presentations with Published Abstracts}

Mukherjee M, Yao J, Welsh A, Jones J, Holaskova I. Genetic factors associated with lumbosacral stenosis in Labrador Retrievers. In: Abstracts for Plant and Animal Genome XXIII Conference: San Diego, California, January 10-14, 2015

Mukherjee M, Jones J, Childs K, Pierce B, Grimm P. CT phenotypic characteristics of the lumbar spinal canal in Labrador Retriever dogs. In: Abstracts for the 2013 ACVR Scientific Conference: Savannah, Georgia. Vet Radiol Ultras 2013: 54(6); 680-698

Cain B, Jones J, Childs K, Mukherjee M. CT morphometry of paraspinal muscles in working Belgian Malinois with versus without lumbosacral pain. In: Abstracts for the 2013 ACVR Scientific Conference: Savannah, Georgia. Vet Radiol Ultras 2013: 54(6); 694

Francis B, Jones J, Pierce B, Childs K, Grimm P, Mukherjee M. CT morphometry of paraspinal muscles in Labrador Retrievers with versus without lumbosacral pain. In: Abstracts for the 2012 Scientific Conference: Las Vegas, Nevada, October 18-21, 2012. Vet Radiol Ultras 2012: 53:6; 690 


\section{Scientific Presentations with Unpublished Abstracts}

Title: CT landmarks as phenotypic markers of lumbosacral stenosis in Labrador Retrievers

Authors: M. Mukherjee, J. Jones, K. Childs, B. Pierce, and P. Grimm

Davis College of Agriculture, Natural Resources and Design Research Day

Seventeenth Annual Student Paper \& Poster Competition

West Virginia University, Morgantown, WV (April $\left.9^{\text {th }}, 2013\right)$

\section{Scientific Meetings Attended without Presentation}

Silver Jubilee International Conference on Biotechnological Solutions for Environmental Sustainability

Vellore Institute of Technology, Vellore, India $\left(21^{\text {st }}-23^{\text {rd }}\right.$ October 2009)

Davis College of Agriculture, Natural Resources and Design Research Day

Annual Student Paper \& Poster Competition

West Virginia University, Morgantown, WV (2014 - 2015)

\section{Publications}

Mukherjee M., Jones J., Holásková I., Meade J., Raylman R.

Novel Technique for Quantitative Phenotyping Of Lumbosacral Stenosis In Labrador Retrievers by Computed Tomography

(Research in Veterinary Science, in preparation) 


\section{Technical Experience}

Molecular: DNA and RNA extraction from blood and other tissue samples, agarose gel electrophoresis, polymerase chain reaction, reading and analyzing sequencing data, FTA card processing.

Software: Microsoft Office suite (Word, Excel, PowerPoint), JMP (statistics), Osirix (computed tomography digital image analysis).

Bioinformatics: BLAST, CD Search, ORF Finder and other basic NCBI database tools required in molecular biology; GoldenHelix SVS Suite; VEP in Ensembl.

\section{Volunteer Work}

Marion County Humane Society, Fairmont WV (2013)

Petco Pet Adoption Drive, Morgantown WV (2013 - 2015)

International Dinner - South East Asia night, organized by International Student Organization (ISO) of West Virginia University (2012)

TARANG - celebration of Indian festival of lights Diwali, organized by Indian Students Association (ISA) of West Virginia University $(2011$ - 2014)

Public relations officer of the Indian Students Association (ISA) of WVU (2012 - 2013) Pet-sitting for friends and acquaintances

Tutoring undergraduate students and graduate peer 